Utah State University

DigitalCommons@USU

\title{
Backcountry Visitor Experience and Social Science Indicators for Glacier Bay National Park
}

\author{
Gabriella R. Furr \\ Utah State University, gabriella.furr@usu.edu \\ Chase C. Lamborn \\ Utah State University, chase.lamborn@usu.edu \\ Abigail Sisneros-Kidd \\ University of Wyoming \\ Christopher Monz \\ Utah State University, chris.monz@usu.edu \\ Shannon T. Wesstrom \\ Utah State University, shannon.wesstrom@usu.edu
}

Follow this and additional works at: https://digitalcommons.usu.edu/envs_stures

Part of the Environmental Studies Commons

\section{Recommended Citation}

Furr, G., C. Lamborn, A. Sisneros-Kidd, C. Monz, and S. Wesstrom. 2021. Backcountry visitor experience and social science indicators for Glacier Bay National Park. Natural Resource Report NPS/GLBA/ NRR-2021/2301. National Park Service, Fort Collins, Colorado. https://doi.org/10.36967/nrr-2287258.

This Report is brought to you for free and open access by the Environment and Society Student Works at DigitalCommons@USU. It has been accepted for inclusion in Environment and Society Student Research by an authorized administrator of DigitalCommons@USU. For more information, please contact digitalcommons@usu.edu.

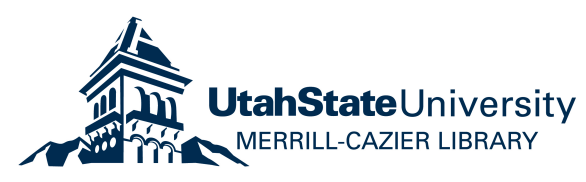


Service

U.S. Department of the Interior

Backcountry Visitor Experience and Social Science Indicators for Glacier Bay National Park

Natural Resource Report NPS/GLBA/NRR—2021/2301

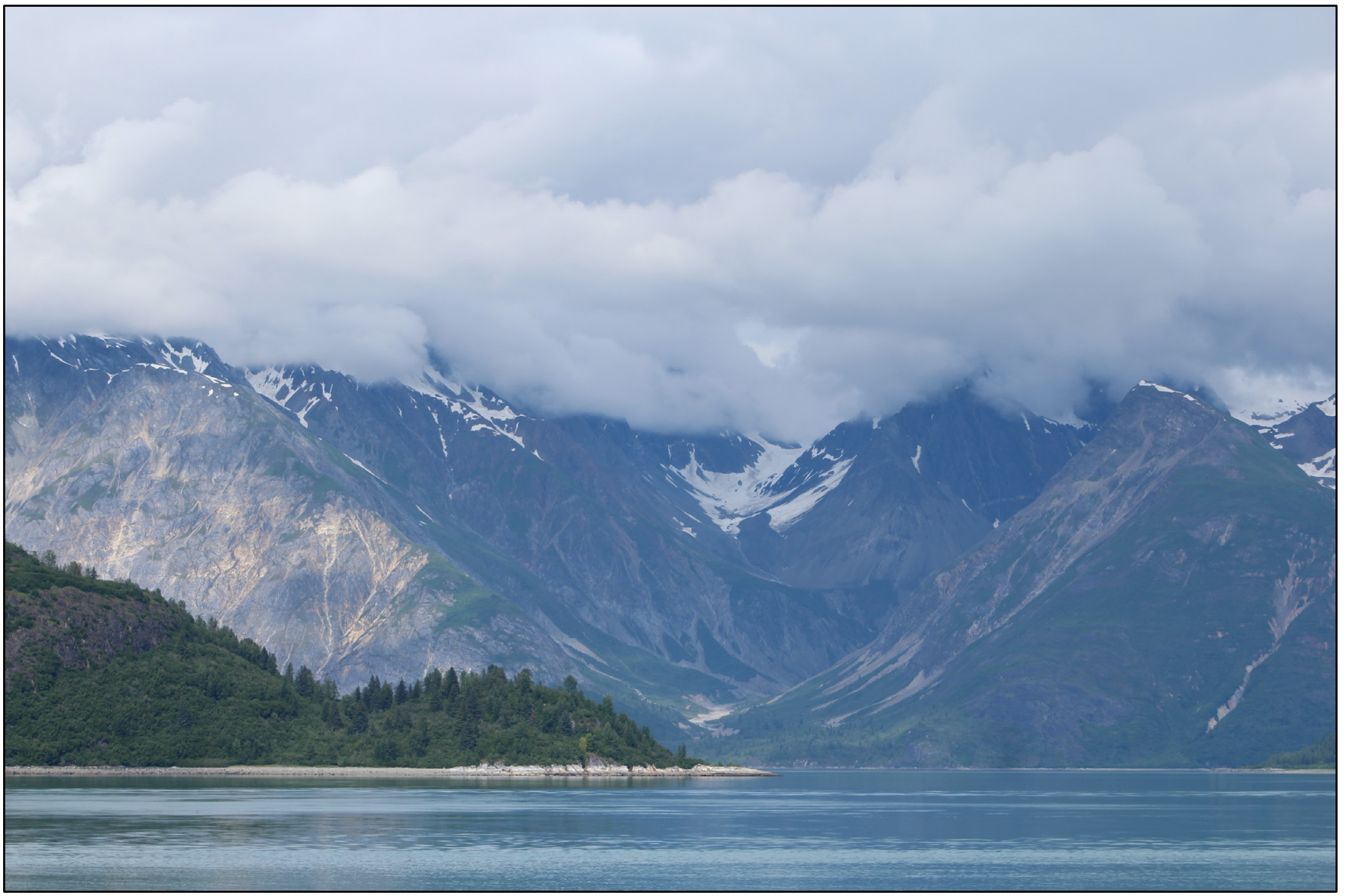




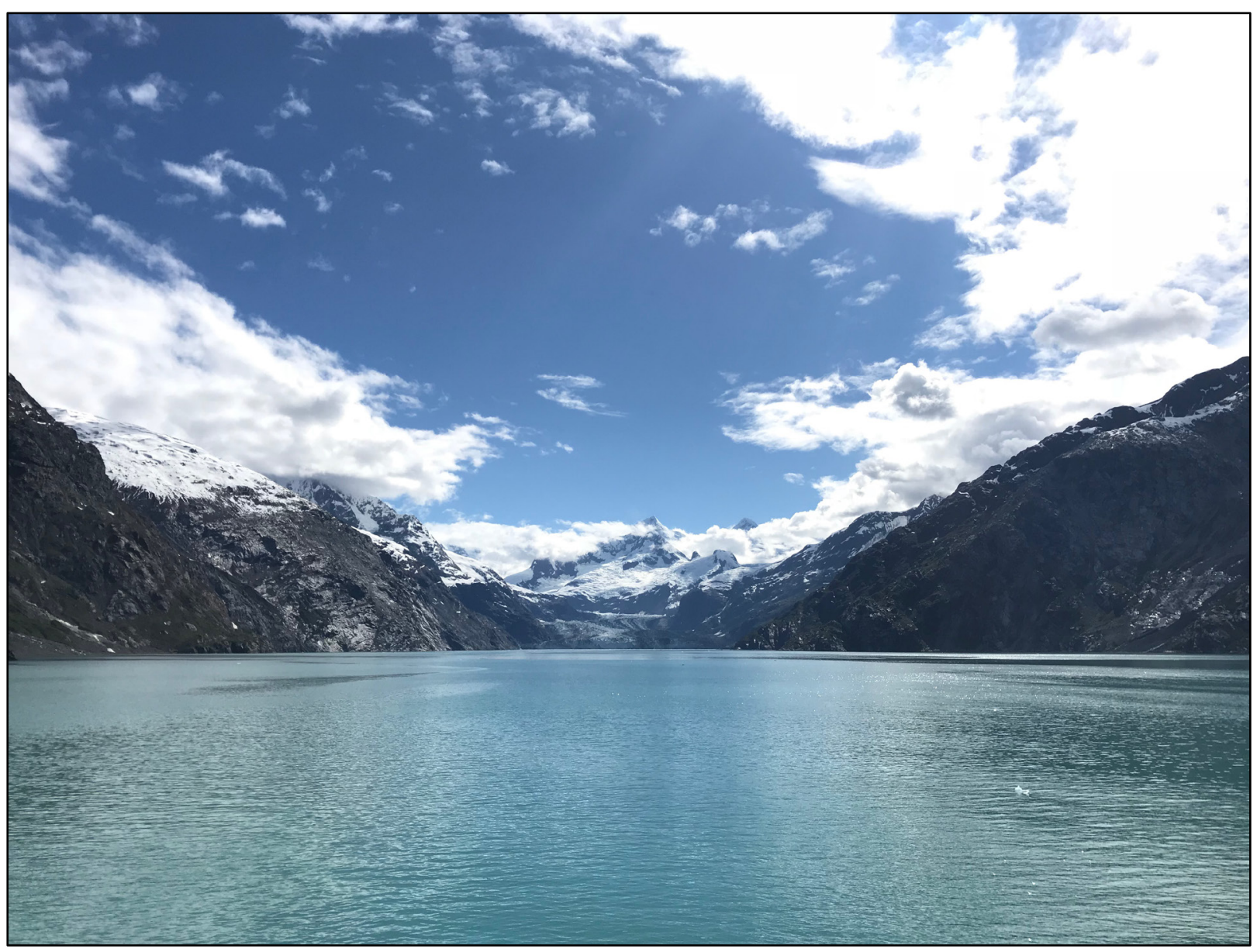

ON THIS PAGE

View of Johns Hopkins Glacier.

(C) GABRIELLA FURR)

\section{ON THE COVER}

View of Glacier Bay National Park.

(C GABRIELLA FURR) 


\section{Backcountry Visitor Experience and Social Science Indicators for Glacier Bay National Park}

Natural Resource Report NPS/GLBA/NRR—2021/2301

Gabriella Furr $^{12}$, Chase Lamborn², Abigail Sisneros-Kidd ${ }^{3}$, Christopher Monz $^{2}$, Shannon Wesstrom ${ }^{2}$

${ }^{1}$ National Park Service

Glacier Bay National Park \& Preserve

Bartlett Cove, Alaska 99826

${ }^{2}$ Utah State University

Department of Environment and Society, Institute of Outdoor Recreation and Tourism

Logan, UT 84322

${ }^{3}$ University of Wyoming

Haub School of Environment and Natural Resources

Laramie, WY 82072

August 2021

U.S. Department of the Interior

National Park Service

Natural Resource Stewardship and Science

Fort Collins, Colorado 
The National Park Service, Natural Resource Stewardship and Science office in Fort Collins, Colorado, publishes a range of reports that address natural resource topics. These reports are of interest and applicability to a broad audience in the National Park Service and others in natural resource management, including scientists, conservation and environmental constituencies, and the public.

The Natural Resource Report Series is used to disseminate comprehensive information and analysis about natural resources and related topics concerning lands managed by the National Park Service. The series supports the advancement of science, informed decision-making, and the achievement of the National Park Service mission. The series also provides a forum for presenting more lengthy results that may not be accepted by publications with page limitations.

All manuscripts in the series receive the appropriate level of peer review to ensure that the information is scientifically credible and technically accurate.

Views, statements, findings, conclusions, recommendations, and data in this report do not necessarily reflect views and policies of the National Park Service, U.S. Department of the Interior. Mention of trade names or commercial products does not constitute endorsement or recommendation for use by the U.S. Government.

This report is available in digital format from the Natural Resource Publications Management website. If you have difficulty accessing information in this publication, particularly if using assistive technology, please email irma@nps.gov.

Please cite this publication as:

Furr, G., C. Lamborn, A. Sisneros-Kidd, C. Monz, and S. Wesstrom. 2021. Backcountry visitor experience and social science indicators for Glacier Bay National Park. Natural Resource Report NPS/GLBA/NRR—2021/2301. National Park Service, Fort Collins, Colorado.

https://doi.org/10.36967/nrr-2287258.

NPS 132/177232, August 2021 


\section{Contents}

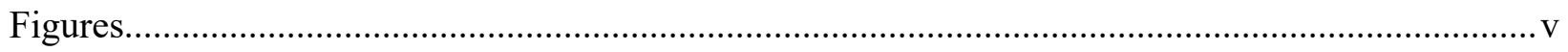

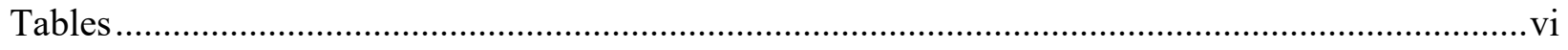

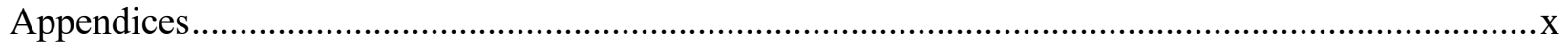

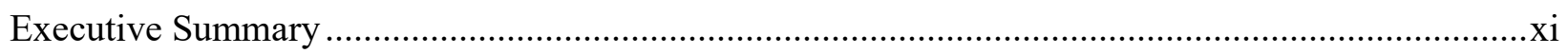

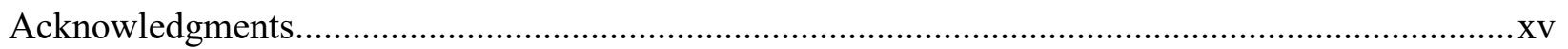

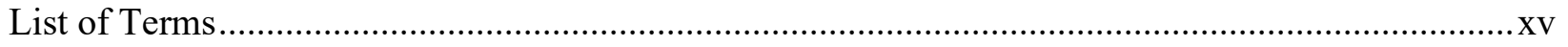

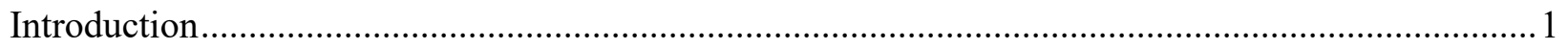

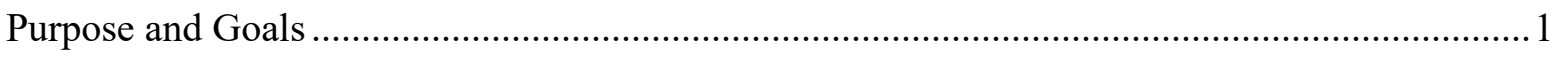

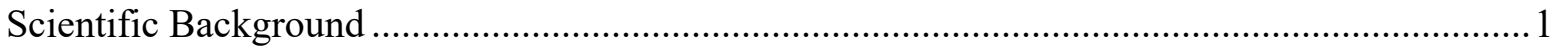

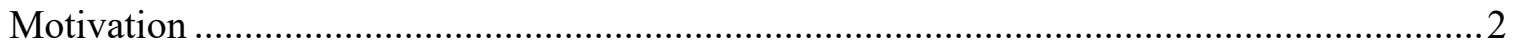

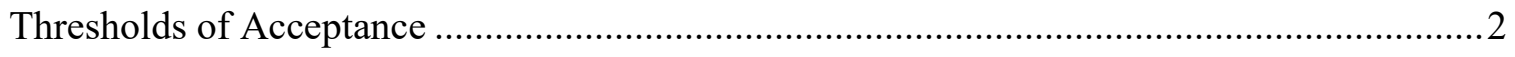

Spatial Behavior and Patterns of Impact ................................................................. 4

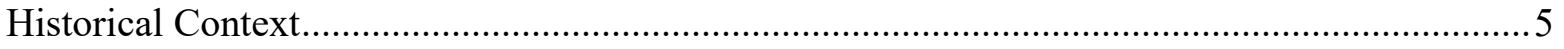

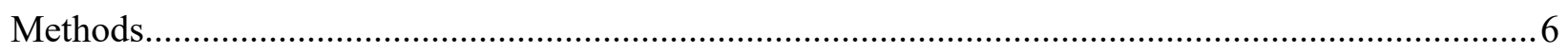

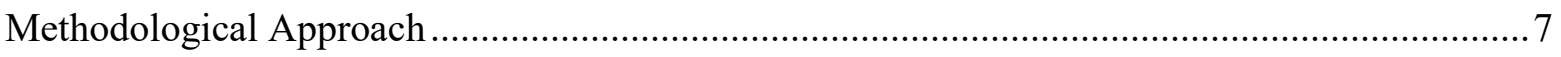

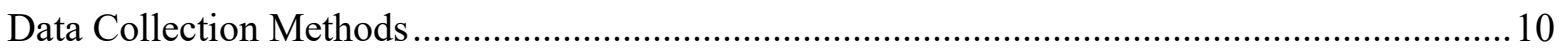

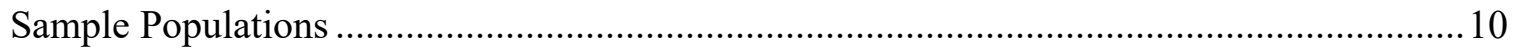

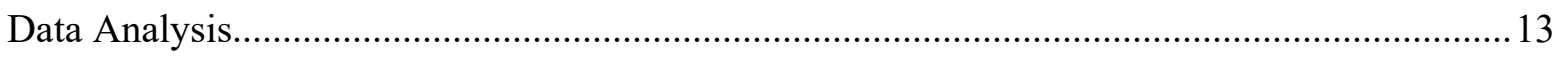

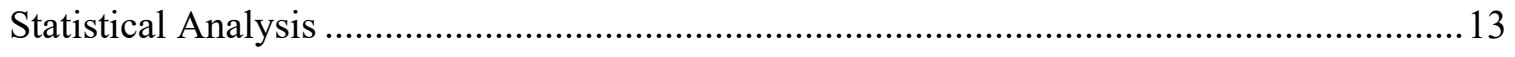

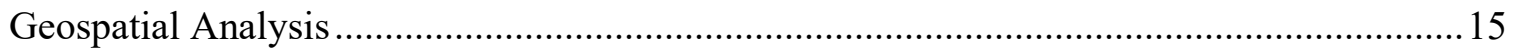

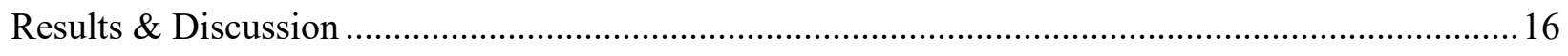

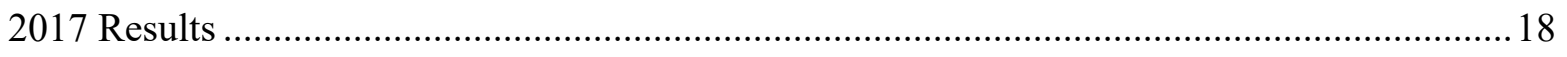

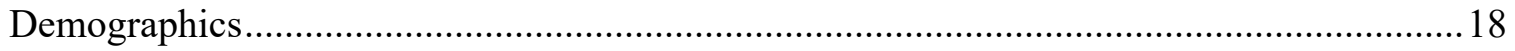

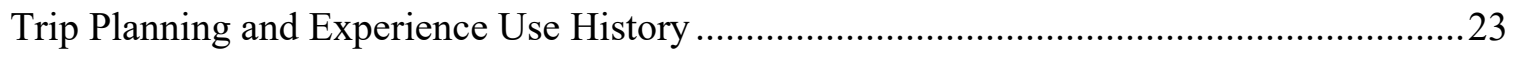

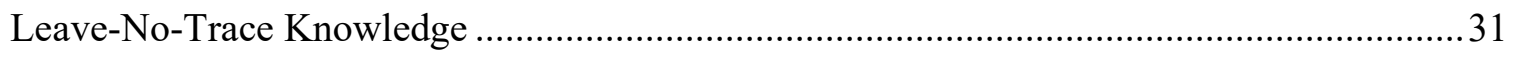

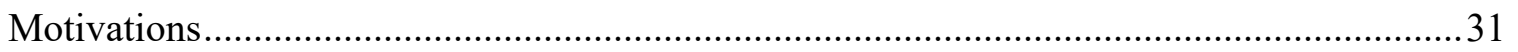




\section{Contents (continued)}

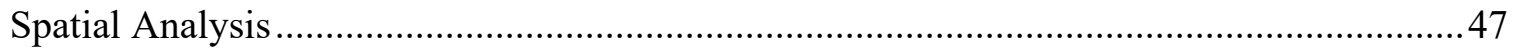

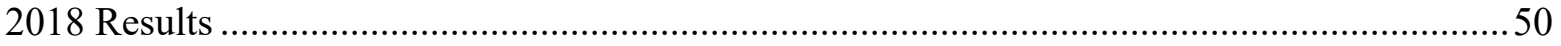

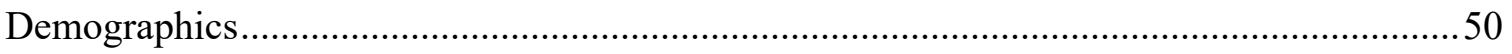

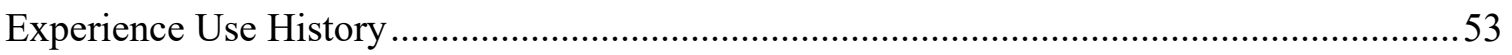

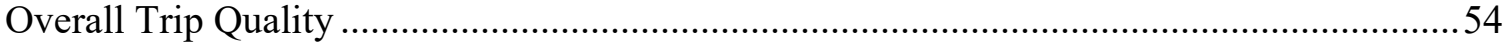

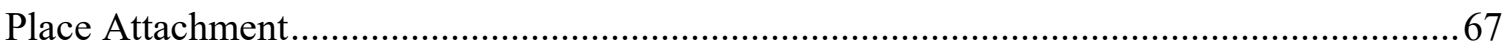

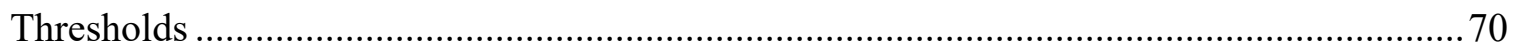

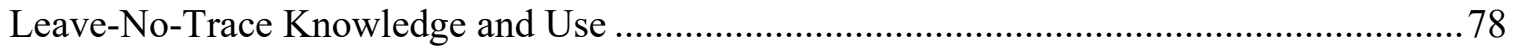

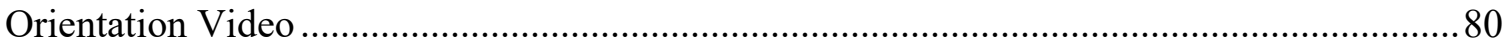

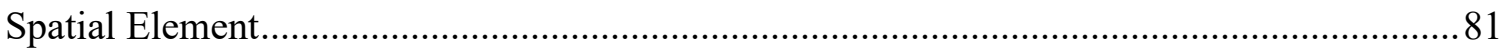

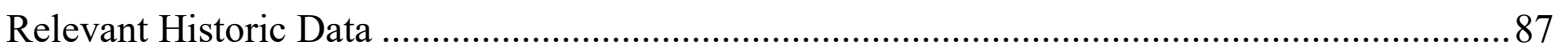

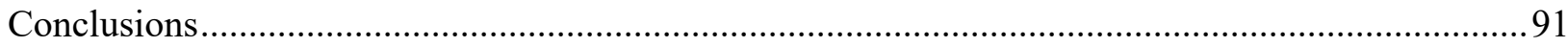

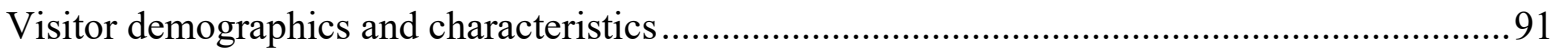

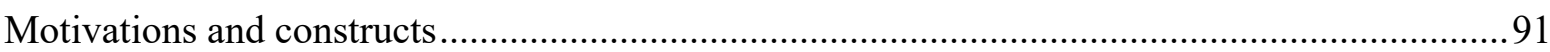

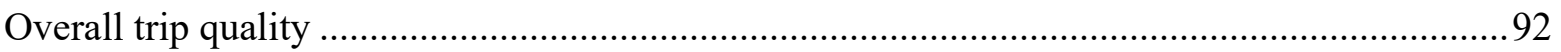

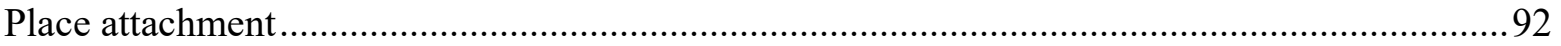

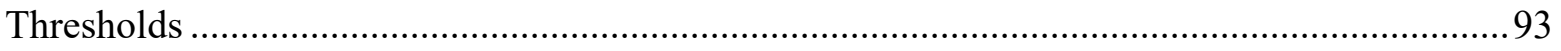

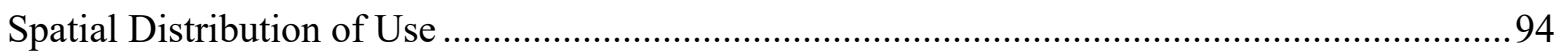

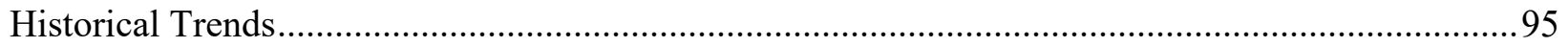

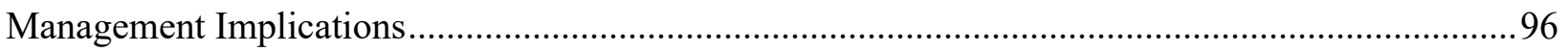

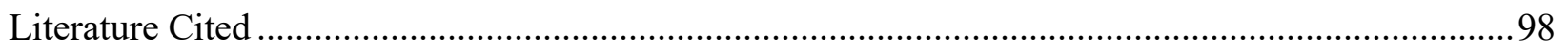




\section{Figures}

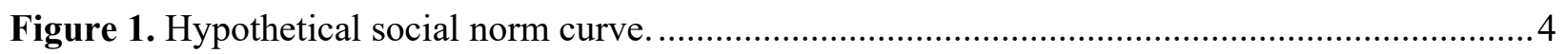

Figure 2. Map of Glacier Bay National Park. ............................................................................ 6

Figure 3. Photo series used to evaluate thresholds of acceptance for crowding and coastal

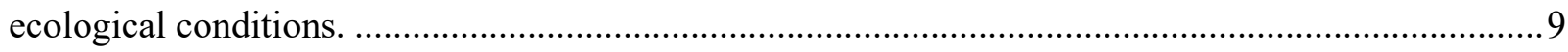

Figure 4. The full equation for the Potential for Conflict Index................................................ 15

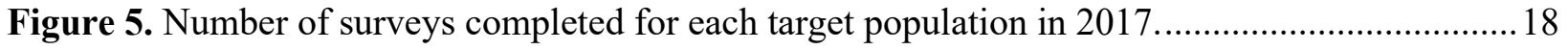

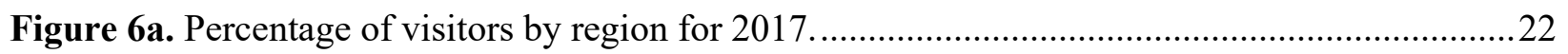

Figure 6b. Percentage of Alaskan visitors by borough for 2017 .............................................23

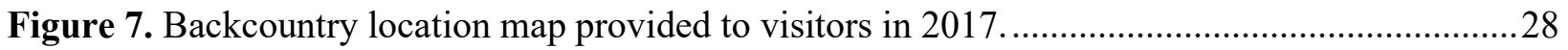

Figure 8. GPS tracks representing 2017 backcountry visitor spatial use in Glacier Bay

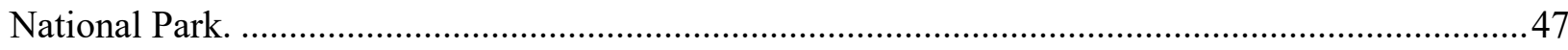

Figure 9. Kernel density map representing overall densities of 2017 backcountry visitor

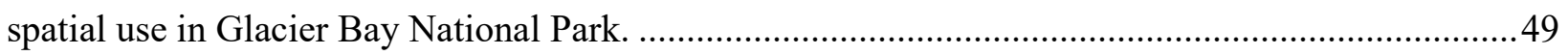

Figure 10. Number of surveys completed for each target population in $2018 \ldots \ldots \ldots \ldots \ldots \ldots \ldots \ldots \ldots \ldots \ldots . . . . .50$

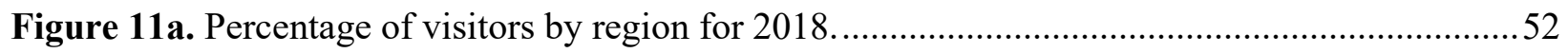

Figure 11b. Percentage of Alaskan visitors by borough for 2018 ............................................53

Figure 12. Social norm curve for crowding conditions in Glacier Bay National Park. .....................77

Figure 13. Social norm curve for coastal resource conditions in Glacier Bay National

Park. .78

Figure 14. GPS tracks representing 2018 backcountry visitor spatial use in Glacier Bay National Park. 83

Figure 15. Kernel density map representing overall densities of 2018 backcountry visitor spatial use in Glacier Bay National Park. 


\section{Tables}

Table 1. Detailed methodological protocols for data collection in 2017 and 2018........................ 12

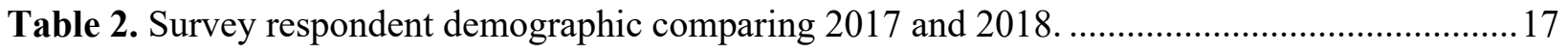

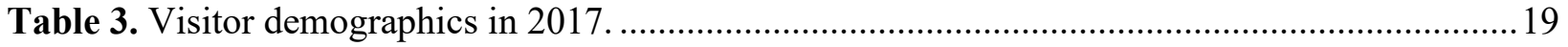

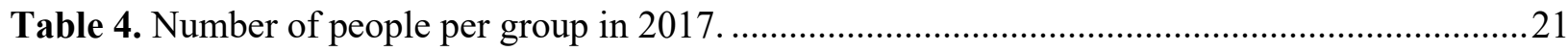

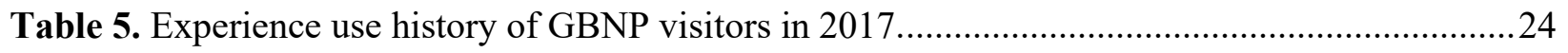

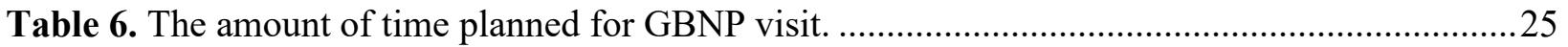

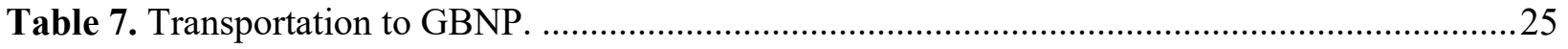

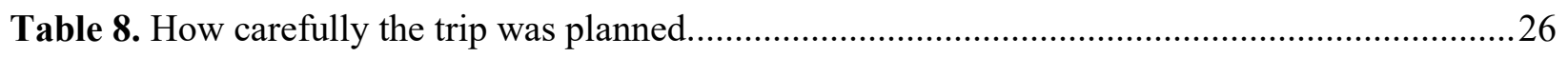

Table 9. Use of a paid guide and equipment rental.................................................................26

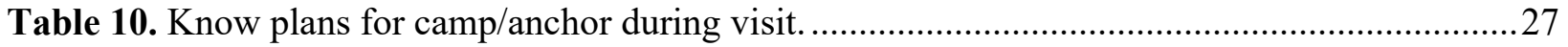

Table 11. Areas respondents planned on visiting during their trip into the backcountry..................28

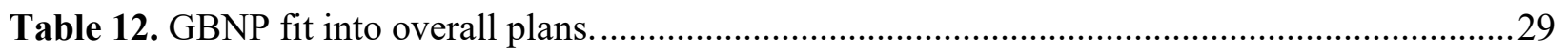

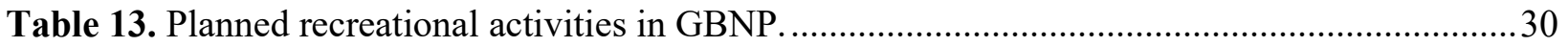

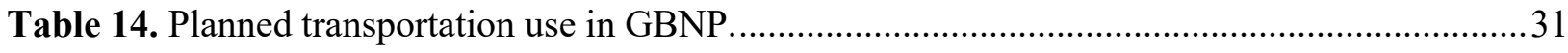

Table 15. Self-reported visitor knowledge of Leave-No-Trace practices. ......................................31

Table 16. Open-ended responses for the total population's overall purpose for visitation.................32

Table 17. Open-ended responses for independent backcountry visitors' overall purpose

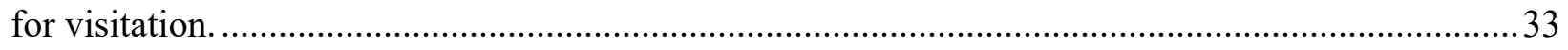

Table 18. Open-ended responses for day boat passengers' overall purpose for visitation..................34

Table 19. Open-ended responses for what the total population is seeking during their experience.

Table 20. Open-ended responses for what independent backcountry visitors are seeking during their experience.

Table 21. Open-ended responses for what day boat passengers are seeking during their experience.

Table 22. Wildlife that visitors expected to see during their visit. .38

Table 23. Factor analysis, reliability results and scale means for visitor experience scale. 40 


\section{Tables (continued)}

Table 24. Cluster analysis of factor scores from experience scales. 44

Table 25. Proportion of population distributed between clusters for each user group. 44

Table 26. Cluster analysis of factor scores from experience scales. 46

Table 27. Number of people per group in 2018. .51

Table 28. Visitor demographics in 2018. .51

Table 29. Experience use history of GBNP visitors in 2018 ........................................................5

Table 30. Time independent backcountry visitors spent in GBNP backcountry. ............................54

Table 31. Factors that added most to the visitor experience for the total sample population. .55

Table 32. Factors that added most to independent backcountry visitors' experience. .56

Table 33. Factors that added most to guided, motorized visitors' experience. .57

Table 34. Factors that detracted most from visitor experience for the total population. .58

Table 35. Factors that detracted most from visitor experience specific to guided, motorized visitors.

Table 36. Factors that detracted most from visitor experience specific to independent backcountry visitors.

Table 37. Elements that added most to visitors' ability to experience adventure for the total population.

Table 38. Elements that added most to independent backcountry visitors' ability to experience adventure.

Table 39. Elements that added most to guided, motorized visitors' ability to experience adventure.

Table 40. Frequency of visitors who felt a connection to nature.

Table 41. Total population responses from open-ended questions as to how visitors experienced a connection to nature.

Table 42. Total population responses as to why visitors did not experience a connection to nature.

Table 43. A comparison of mean experience quality by visitor type .66 


\section{Tables (continued)}

Table 44. Visitor interactions with wilderness by user group. 66

Table 45. Guided, motorized visitor responses from open-ended questions as to how they interacted with wilderness

Table 46. A comparison of mean place attachment by visitor type.

Table 47. Anthropogenic encounters and the effect on the visitor experience.

Table 48. A comparison of anthropogenic encounters and the effect on the visitor experience by population.

Table 49. How anthropogenic visitor encounters affected the quality of independent backcountry visitor experience. 74

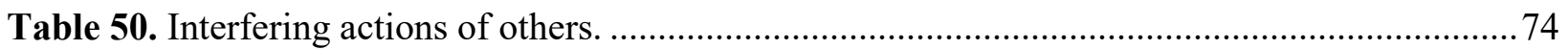

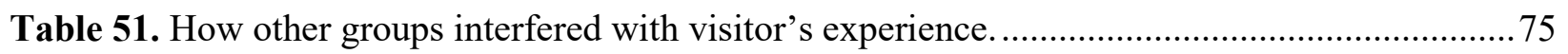

Table 52. Anthropogenic sounds heard by independent backcountry visitors................................ 76

Table 53. Effect on visitor wilderness experience based on possible future management facilities.

Table 54. A comparison of mean Leave No Trace knowledge by past five-year experience use history.

Table 55. A comparison of mean Leave No Trace knowledge by lifetime experience use history.

Table 56. A comparison of mean Leave No Trace knowledge by visitor type.

Table 57. Independent backcountry visitor reports of what prevented them from following LNT practices. 80

Table 58. Effect of VIS backcountry orientation video on visitor wilderness experience. .81

Table 59. Areas visited by backcountry users. 82

Table 60. Difficulty finding a place to camp/anchor for backcountry users. 82

Table 61. Attributes of tracks within high-density areas in 2018 .85

Table 62. A comparison of socio-economic characteristics of independent backcountry visitors from 1978, 1984, 2017, and 2018.

Table 63. Motivations for visiting the backcountry: Comparison of 1978, 1984, and 2017

Glacier Bay studies. 88 


\section{Tables (continued)}

Table 64. Evidence of human use seen in the backcountry: Comparison of 1978, 1984,

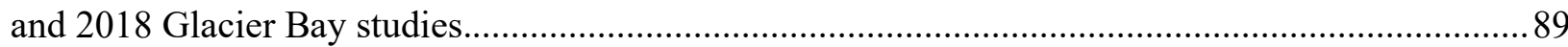

Table 65. Campers' reactions to sightings of other parties and crafts: Comparison of 1978 and 1984 Glacier Bay studies. 


\section{Appendices}

Page

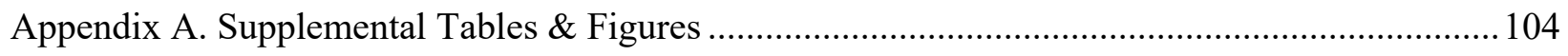

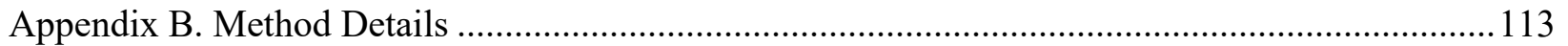

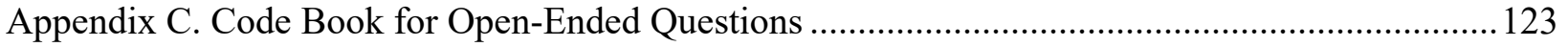




\section{Executive Summary}

Glacier Bay National Park (GBNP), located in the panhandle of southeast Alaska, preserves more than 3.2 million acres and provides for a range of visitor opportunities. Marine waters make up nearly one fifth of the park, and no point of land is more than 30 miles from the coast. A range of backcountry experiences are possible, both on land in designated Wilderness (e.g., camping and hiking) and on water (e.g., sea kayaking, fishing, sightseeing, natural and cultural interpretation, and wildlife viewing).

This study, conducted over a two-year period, consists of two separate data collection efforts with two purposes: 1) to characterize visitors engaging in independent recreation (often in designated Wilderness), compared to those experiencing the backcountry from targeted classes of motorized marine vessels within park waters (often using guided, commercial services); and 2) to gather backcountry visitor trip characteristics, motivations, expectations, and overall quality of experiences to guide management decisions, including the update of the 1989 Wilderness Visitor Use Management Plan.

Data collected in 2017 - the pre-experience survey — was focused on backcountry visitors' pre-trip planning, expectations, and motivations for visiting Glacier Bay National Park. Data collected in 2018 - the post-experience survey - was more evaluative and focused on the quality of the visitor experience. In both 2017 and 2018, spatial use data was collected from independent, non-motorized backcountry visitors, which mainly consisted of sea kayakers. In the context of this study, recreational opportunities outside of the Bartlett Cove developed area were considered backcountry experiences.

The populations surveyed in this study included people riding the day boat, independent backcountry visitors (sea kayakers and a few backpackers), independent private boaters, visitors on charter vessels and tour vessels, residents of Gustavus (the park's gateway community), and those who had visited the park and were leaving from the Gustavus Airport. Visitors not included were cruise ship passengers, flightseers, outer coast visitors, or Alsek River rafters.

\section{Visitor demographics and characteristics}

Overall, Glacier Bay National Park visitors were generally older (median age range is 50-59 years old), white, highly educated, and high earning individuals. Nearly half of the people who visited Glacier Bay were traveling from the western United States. Glacier Bay National Park is also a place that most people only visit once in their lifetime, with approximately $78 \%$ making only one visit. When they do visit, the majority of people planned on spending an average of five days in the park. The main activities people planned for their visit included viewing tidewater glaciers, observing nature and seeing wildlife.

\section{Motivations}

People are motivated to visit parks and protected areas for different reasons. Eight visitor motivations were identified among the different sample populations. All visitors were highly motivated by opportunities to experience glaciers. Independent backcountry visitors were more motivated by 
solitude and natural sounds, natural connection and renewal, and adventure, while those traveling via day boat were highly motivated by a guided wilderness experience. Overall, there were subtle differences in visitor motivations when compared across sample populations, suggesting that all visitors were motivated to visit the park for similar reasons. Motivations were also derived from open-ended questions, and through further analysis, similar motivational themes emerged further supporting the original findings.

\section{Overall trip quality}

In the post-experience survey, a variety of questions were asked to evaluate the quality of the visitor experience in the park. Viewing wildlife (44\%), learning (27\%), and experiencing glaciers (26\%) were elements that added most to the visitor experience. Nearly half (43\%) of visitors reported that "nothing" detracted from their experience. Some visitors (14\%) said the weather was a detraction, while $12 \%$ said seeing cruise ships detracted from their experience. When these data were separated by visitor type, cruise ships and anthropogenic sounds had the greatest effect on sea kayakers and backpackers, while the majority of visitors experiencing a more guided, motorized trip were the ones to report that nothing detracted from their experience.

Additionally, 95\% of visitors reported that they felt a connection to nature while in Glacier Bay. Visitors were able to connect to nature by viewing wildlife $(29 \%)$, the scenic beauty $(16 \%)$, by experiencing wilderness (13\%) and experiencing glaciers (12\%). Only 5\% said they were unable to connect to nature during their visit because of their motorized experience $(30 \%)$ and/or too many people $(21 \%)$. The vast majority of people who said they were unable to connect to nature were on a motorized, guided tour of the park.

\section{Place attachment}

Place identity and place dependence were measured to better understand place attachment. Place identity is defined as an emotional attachment to an area, whereas place dependence is a utilitarian attachment to a place for a specific activity/setting (e.g., sea kayaking in a glaciated region with little motorized use). Visitors to Glacier Bay National Park scored very high in place identity, indicating that visitors had a strong emotional attachment to GBNP. One common trait of place identity is that it is developed over time and after frequent interaction with a place; however, the vast majorityaround $80 \%$ - of visitors were visiting for the first time. This would suggest that visitors are having powerful interactions with Glacier Bay and quickly developing high levels of emotional attachment to the park. Independent backcountry visitors exhibited the highest degree of place identity, which makes sense given the intimate nature of their interaction with Glacier Bay's backcountry. Place dependence, on the other hand, relates to how well a place accommodates visitor objectives, goals, and activities. Park visitors exhibited lower levels of place dependence, most falling just above the "neutral" category. Independent backcountry visitors demonstrated a slightly stronger degree of place dependence than other populations, which may be due to their engagement in specialized activities that cannot be achieved in just any environment. Overall, data suggests that visitors do not feel dependent on Glacier Bay for wilderness and/or recreation experiences. 


\section{Thresholds}

Visitors were presented with a list of items they may have encountered in Glacier Bay, including litter, cruise ships, human waste, etc. They were asked to report if/how often they encountered them, and how much each encounter affected their experience. People on day boats, tour vessels, and at the Gustavus airport were most bothered by litter, but very few visitors encountered litter-only 6\%. The majority ( $86 \%$ ) of visitors on guided, motorized trips encountered cruise ships (two ships on average per trip) but reported that seeing them only bothered them slightly. Non-motorized backcountry visitors saw more cruise ships (six on average per trip); however, the level of bother was between "slight" and "moderate," indicating that backcountry encounters with cruise ships at current levels is not of great concern. Overall, visitors reported very few negative aspects about their experience in Glacier Bay National Park.

Backcountry visitors were then asked about additional encounters they may have had in the backcountry, such as campfire rings, human waste, and campsite impacts. Reports of encounters were low, and of those who did encounter them, the overall effect on their experience was very low-between "not at all" and "slightly." Therefore, it seems that conditions experienced by visitors are quite acceptable and have not yet reached or surpassed the point where they are diminishing the visitor experience.

Independent backcountry visitors were asked what they heard and how much each of those sounds bothered them. Backcountry visitors were most bothered by public addresses aboard commercial vessels; however, only $34 \%$ of visitors reported hearing these addresses, and the level of bother only reached "moderate." Many more visitors (79\%) heard motor boats while in the backcountry, but the level of bother from these sounds was only "slight" to "moderate." Overall, anthropogenic sounds in the backcountry of GBNP did detract from visitors' experiences, but not to a level that might reach great concern.

Visitors were asked if encountering other groups interfered with their experience, and only $12 \%$ said that they did. The two most common causes mentioned were other visitors and the presence of cruise ships.

A normative approach was utilized to better understand visitor thresholds of acceptance for both crowding and coastal resource conditions. Visitors were asked to rate the acceptability for different simulated conditions using a series of photos presented to them. Crowding conditions were represented using different numbers of tents and kayaks present on a beach, ranging from 0 ( 0 tents, 0 kayaks) to 20 (10 tents, 10 kayaks). For crowding conditions, the maximum acceptable condition was 3 tents and 3 kayaks on a beach at one time, also interpreted as a group of 6 . Coastal resource conditions were represented by the presence of tent rocks, ranging from 0 tent rocks to 20 tent rocks (including a fire ring), on a beach ideal for camping in GBNP. The maximum acceptable condition for coastal resource impacts was 8 to 9 tent rocks at one time, not including a fire ring.

With this information, managers can make more informed decisions on crowding and resource impacts. For example, management can suggest that backcountry visitors disperse as much as possible or limit the number of people permitted in one group. Managers could also encourage 
Leave-No-Trace principles for backcountry visitors specifically, in terms of dispersing any natural materials used for camping purposes.

\section{Spatial Distribution of Use}

In 2017, 68 backcountry visitors were sampled and 40 agreed to take a GPS unit with them on their trip into Glacier Bay. Use was concentrated in the Beardslee Islands, West Arm near glaciers, and the East Arm within the main inlet. In 2018, 124 backcountry visitors were sampled and 54 agreed to take a GPS unit. Use was concentrated in the West Arm near day boat drop off and pick up locations, as well as near Johns Hopkins Glacier. 


\section{Acknowledgments}

We thank the field assistants and graduate students, including D. Fadgen and S. Sidder, who helped to collect field data; Glacier Bay National Park \& Preserve for the grant and overall opportunity to fulfill this research; L. Sharman, S. Doyle, T. Lewis, L. Etherington, and W. Rapp for their support, guidance, and input throughout the project; W. Valliere for creating both photo series; and the

Glacier Bay National Park \& Preserve Visitor Information Station and Interpretive staff for helping researchers in the field.

\section{List of Terms}

Common acronyms:

- ANOVA - Analysis of Variance, used for statistical analyses

- GBNP - Glacier Bay National Park

- GPS - Global Positioning System, used to track independent backcountry travel

- VIS - Visitor Information Station located by the Bartlett Cove dock

Contextual definitions:

- Backcountry Experience - Visitor experiences that occurred both on land (in designated Wilderness) and on water outside of Bartlett Cove and adjacent developed areas.

- Designated Wilderness - Public lands designated under the Wilderness Act of 1964; and managed using 5 tangible wilderness character qualities: natural, untrammeled, undeveloped, opportunities for solitude, and other features of value.

Sample population references:

- Guided, motorized visitors - Those who were traveling via guided, motorized vessel. This included those who participated in a day boat, tour vessel or charter vessel experience. When appropriate, this also encompassed visitors sampled at the Gustavus airport.

- Independent backcountry visitor - Those who were traveling via non-motorized vessel (emphasis on human power), most frequently referring to kayakers. They may have been part of a motorized experience at some point (e.g., day boat ride for drop off/pick up), but most of their visit was specific to an independent backcountry experience.

- Independent Boaters - Non-guided, private motorized vessels, only surveyed in 2017. 


\section{Introduction}

\section{Purpose and Goals}

In 1989, the Wilderness Visitor Use Management Plan for Glacier Bay National Park (GBNP) outlined management strategies to minimize human impacts and to establish visitor use limits, with the purpose of preserving the natural and aesthetic values of Glacier Bay Wilderness. More recently, however, Glacier Bay backcountry use has increased resulting in an increasing demand on park resources. There is management concern that visitor experiences and the biological integrity of park resources may be compromised if unrestricted growth in visitation continues (Glacier Bay Wilderness Management, 2020). Therefore, in order to effectively manage these resources and wilderness character, the Park must understand current visitor experiences and overall use.

With the purpose of guiding these management decisions, this social science research report outlines findings from the 2017-2018 visitor use study conducted in Glacier Bay National Park. The study was designed to collect a diverse set of data from both independent recreationists (often in designated Wilderness) and those that experienced the backcountry from motorized marine vessels within park waters (often using guided, commercial services). Specific objectives for this program of research were to:

- Provide demographic information and trip characteristics (e.g., pre-trip planning efforts, planned activities, modes of transportation, etc.) for Glacier Bay National Park visitors

- Identify visitor motivations for visiting Glacier Bay National Park

- Identify visitor-perceived indicators of quality for backcountry social and recreation resource conditions

- Evaluate visitor experience quality

- Provide spatial use data from independent backcountry visitors

- Explore the broad historical trends based on previous visitor use surveys (1978 \& 1984)

Key questions addressed in this research include:

- What elements impel visitors to travel to and experience Glacier Bay National Park?

- Are visitors having quality experiences? If yes, how? And if not, why?

- What are acceptable social (i.e., crowding) and coastal resource conditions?

- How are independent backcountry visitors spatially using the landscape?

- Has the backcountry experience changed over time?

\section{Scientific Background}

Visitation to parks and protected areas (PPAs) has been on the rise for decades and continues to increase (Machlis \& Tichnell, 2019). With increases in visitation, there is potential for natural resource degradation and negative impacts on visitor experiences (Hammitt, Cole, \& Monz, 2015; Manning, 2011; Manning \& Krymkowski, 2010). Understanding who visitors are, their motivations, what conditions they find acceptable, and how they are using natural areas can help predict and 
mitigate these impacts. A brief overview of the theoretical frameworks that underpin this study has been provided to provide context.

\section{Motivation}

Motivation theory, derived from social psychology, helps explain why motivation is key to understanding human behavior. Motivation is one of many drivers that attempts to explain why a person or group behaves in a certain way and makes certain decisions (Kanfer, 1990). It is important to understand that recreational user groups are diverse, varying in their preferred outdoor activity, socioeconomic/demographic characteristics, feelings towards management, and motivations for recreating (Manning \& Lime, 2000).

Iso-Ahola (1982) argues there are two main motivational forces linked to overall satisfaction with outdoor recreation experience-approach (seeking) and avoidance (escape). The concept of approach refers to an action resulting in intrinsic rewards, such as adventure, while avoidance refers to leaving a typical routine behind for solitude or renewal. Others, however, suggest there are "push" and "pull" factors that motivate individuals, especially when it comes to tourism (Crompton, 1979; Dann, 1977, 1981). Push factors relate to internal values or emotions, while pull factors are more external, like natural landscapes and wildlife (Devesa et al., 2010). Although there are two differing sets of terminology for these broad motivations, the overarching concept of being pushed or pulled into outdoor settings is the same. Understanding these underlying motivations can help identify what is driving recreation visitation and behavior in specific settings, which in turn can help inform management.

Motivations from different recreational user groups have been studied using open-ended questions (Hendee, Clark, \& Dailey, 1977; Towler, 1977), while Driver and associates developed a scale to measure motivations (Manning, 2011). This scale has been refined and empirically tested to determine its reliability and validity (Manfredo, Driver, \& Tarrant, 1996; Manning, 2011). Given the utility of motivation research in outdoor recreation, and the goals of this study, both methods were used for determining motivations (i.e., open-ended questions and quantitative motivational scale items). This approach allowed for multiple means of assessing individual motivations for visiting Glacier Bay National Park and helped guide the formulation of questions used to evaluate visitor experience in the second phase of this study. By identifying visitors' motivations, recreational experiences in the park were also evaluated to see if visitor motivations and experiences aligned.

\section{Thresholds of Acceptance}

Normative theory, a framework developed in social psychology, has been broadly applied to understanding and developing "standards by which elements of behavior may be judged" (Manning, 1999, p.324). Although norms are not tangible, but rather constructs created to describe human cognition or a response to a situation (Manning, 2011; Vaske \& Whittaker, 2004), they often lead to administrative changes, forming of public policy and changes in law when accepted on a societal level (Manning \& Krymkowski, 2010; Manning, 2007). Normative judgements can be influenced by the characteristics of the visitor, social encounters, and other situational variables (Heywood, Manning, \& Vaske, 2002; Manning, 1999; Manning, Valliere, Minteer, Wang, \& Jacobi, 2000). Normative theory has been used in recreation research to help determine visitors' thresholds of 
acceptability for a variety of factors - such as crowding, resource impacts/conflict based on type of use, motivations, and experience expectations.

Thresholds of acceptability are often developed using normative theory, as it produces subjective judgements based on individual visitor perceptions. Past research has used the "importanceperformance" framework (Hollenhorst \& Stull-Gardner 1992; Hunt, Scott \& Richardson, 2003; Pilcher, Newman, \& Manning, 2009), in which visitors are "asked to rate the importance of potential indicator variables," followed by "a series of normative questions regarding standards of quality for each indicator variable" (Manning, 2011, p.142-43). However, some argue that visually based questions are often more effective when asking about ecological or social situations which may be difficult to communicate using written or numerical descriptions (Manning, 2011; Manning \& Krymkowski, 2010). Images representing certain conditions provide an opportunity for participants to observe the impact being considered. Using visual methods can create a more standardized approach to reach judgements and acceptable thresholds across the population.

Considerable research has been conducted on crowding norms with varying indicators of quality. This research ranges from how many individuals are at a destination or site at one time (Heberlein \& Vaske, 1977; Manning, Lime, Hof, \& Freimund, 1995; Vaske, Donnelly, \& Petruzzi, 1996; Manning, 1997) to waiting times for amenities (Kim \& Shelby, 1998; Manning, Leung, \& Budruk, 2005).

Thresholds of acceptance surrounding ecological impacts have also been studied, including campsite impacts (Shelby, Vaske, \& Harris, 1988), fire rings (Shelby \& Shindler, 1992), and river or stream flows (Shelby \& Whittaker, 1995; Shelby, Brown, \& Baumgartner, 1992). Normative thresholds are important to understand when adapting current management plans, as the majority of visitors are expecting a satisfactory experience - which could be impacted by both social and ecological variables (Manning, 2011).

To better visualize and understand thresholds within a population, Manning (1999) suggests representing mean scores for each threshold within a social norm curve. Figure 1 represents a strong hypothetical social norm curve. The highest point on the curve may be interpreted as the optimal or preferred condition, while the lowest point may be considered the least acceptable condition. There is a range of acceptable conditions that include all points along the curve before it dips below the minimum acceptable condition. The minimum acceptable condition is the point at which the curve crosses the zero point along the acceptability scale (y-axis) and can be found using a linear equation in point-slope form. Norm crystallization, often determined by the standard deviations for mean responses, suggests the level of agreement among respondents (Manning, 1999). The social norm curve and the information derived from graphing mean-scale points may be used to better interpret and understand standards of quality for both resource and social conditions. 


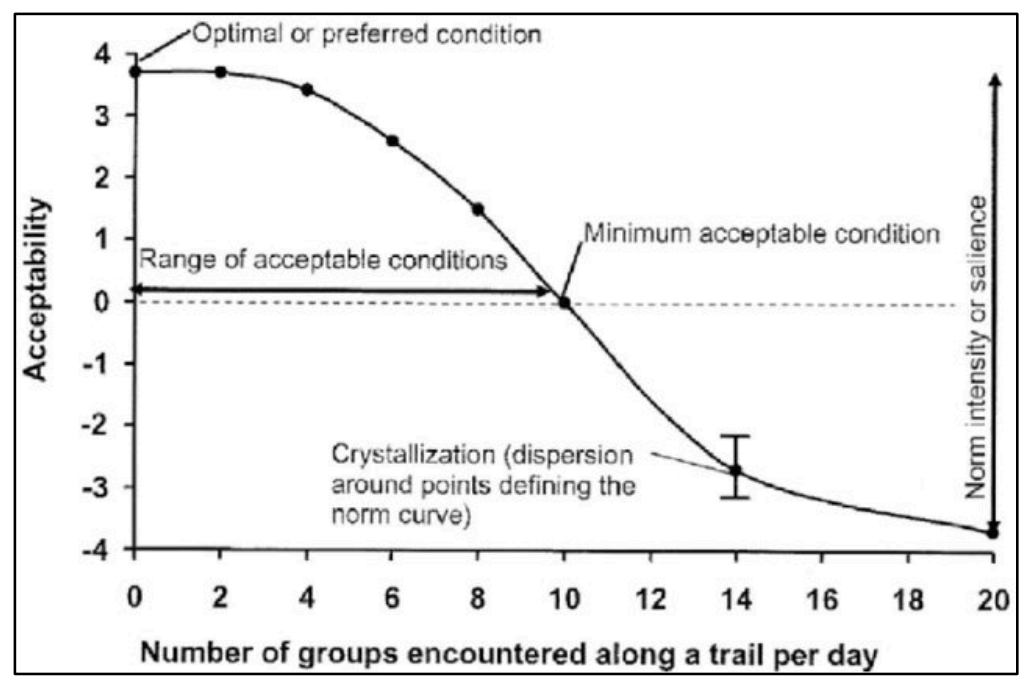

Figure 1. Hypothetical social norm curve (Source: Manning, 1999).

\section{Spatial Behavior and Patterns of Impact}

Understanding visitors' spatial behavior and patterns is critical when considering management of park resources and visitor experiences (D’Antonio et al., 2010; Orellana et al., 2012). Human movement may be affected by environmental, biological, and cultural factors (Baldassare, 1978). It is important to consider the variety of factors that influence spatial behavior when implementing management strategies in parks and protected areas.

Spatial patterns tend to be self-reinforcing, as patterns of prior use are visible to other visitors, ultimately influencing them to follow the same path in both concentrated and dispersed use areas (Hammitt et al., 2015). These patterns of use have lasting resource impacts on trails (Cole, 1991; Marion, 1985), campsites (LaPage, 1967), vegetation (Cole 1981), and soil (Cole \& Hall 1992). In order to examine how spatial behavior affects ecological and social conditions, detailed information on visitor behavior and movement is needed - including destinations, time spent in each location, and directionality (Kidd et al., 2018; Orellana et al., 2012).

Methodologies for collecting spatial behavior have changed dramatically in recent years. Historical approaches include 1) self-counting, 2) direct-counting, and 3) indirect-counting (D'Antonio et al., 2010; Hollenhorst, Whisman, \& Ewert, 1992). Each method has benefits, but there are inevitable inaccuracies and limitations when detailed visitor information is needed with spatial behavior data (Arrowsmith \& Chhetri, 2003; D’Antonio et al., 2010; Leatherberry \& Lime, 1981; Shoval \& Issacson, 2007).

To account for these shortfalls, methodologies have changed from automated visitor counters, paper diaries, and researcher observations to global positioning system (GPS) technology (D'Antonio et al., 2010; Hallo et al., 2012; Stamberger, van Riper, Keller, Brownlee, \& Rose, 2018). GPS technology provides insight into spatial patterns, flows, and densities (D’Antonio et al., 2010; Hallo, Manning, Valliere, \& Budruk, 2005). Several studies have used GPS-tracking as an approach to connect human movement to certain social and ecological impacts in parks and protected areas (e.g., D'Antonio et 
al., 2010; Hallo et al., 2005; Kidd et al., 2018). GPS-tracking allows for a less burdensome, more accurate way to collect spatial patterns and distribution (Kidd et al., 2018), and therefore provides an opportunity to understand visitor use more holistically (Beeco, Hallo, \& Brownlee, 2014).

\section{Historical Context}

Visitor use studies were conducted in 1978 and 1984 to inform the development of a general management plan for Glacier Bay National Monument (see Johnson, 1979; Salvi \& Johnson, 1985). Data collected in 1978 was used as baseline data for the later study, and comparisons were made with 1984 data. The study population included all backcountry campers, except those that experienced GBNP via charter company and NPS/Glacier Bay Lodge employees. Salvi and Johnson (1985) state that "based upon similar high response rates for the two studies and the similarities [of question content], it is strongly felt that the 1984 results can be compared with those obtained in 1978" (p. 14). Visitor dimensions (i.e., demographics, characteristics, etc.), motivations, and elements of overall experiences specific to backcountry campers were selected for discussion. Relevant data will be presented in the following results section. 


\section{Methods}

Glacier Bay National Park protects 3.2 million acres of unique landscapes and wilderness, sitting on the coastline of Alaska's Inside Passage (National Park Service, 2017). Marine waters make up nearly one fifth of the park, and no point of land is more than 30 miles from the coast. A range of backcountry experiences are possible, both on land in designated Wilderness and on water outside the Bartlett Cove developed area. The majority of surveyed visitors experienced the park by traveling through the East Arm, West Arm, or Beardslee Islands (Figure 2) using a concessionaire catamaran, personal or rented kayaks, commercial ships, or personal vessels. The pre-experience survey was administered during the summer of 2017, and the post-experience survey was administered the summer of 2018. For both sampling periods, GPS data were collected from one sample population to identify independent, non-motorized backcountry routes. All other data were collected using visitor surveys created by Utah State University in collaboration with GBNP (see 2017 survey [USU and NPS 2021a]; 2018 survey [USU and NPS 2021b, 2021c]).

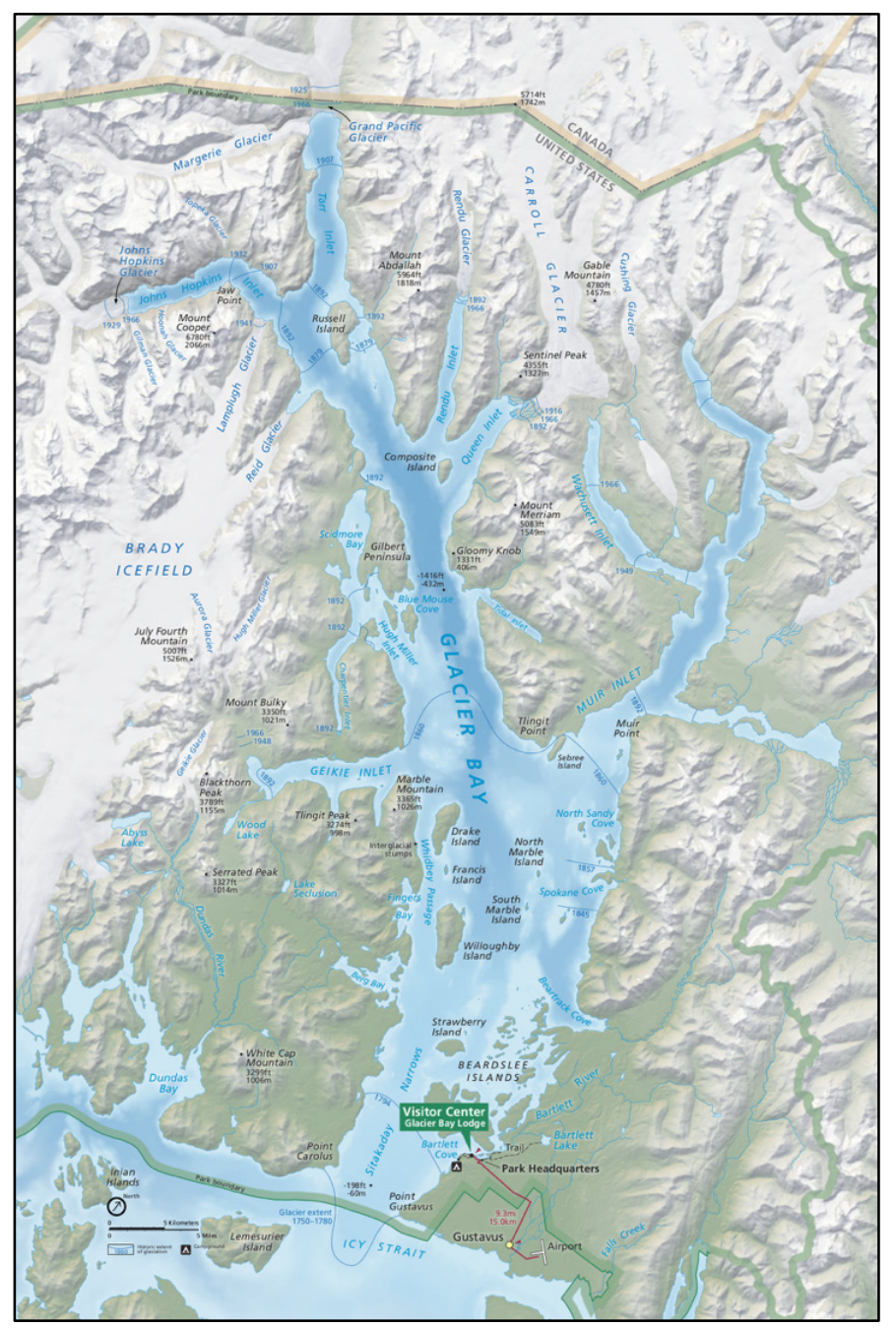

Figure 2. Map of Glacier Bay National Park (Source: National Park Service, 2018). 


\section{Methodological Approach}

A mixed-methods approach was applied over the two-year study period, including the use of a survey and global positioning system (GPS) technology (Hallo et al., 2012; Kidd et al., 2018). These two methods were chosen based on several factors, including the remoteness of GBNP, the limited peak season available for sampling (June-August), targeted sample size of 500 or more responses, several different sampling populations, and visitor spatial movement in a dispersed open-water based environment. The National Park Service Pool of Known Questions (2015) served as a fundamental basis for the formulation of the project and development of both surveys, utilizing both qualitative and quantitative questions to encourage non-directed responses.

In the pre-experience survey (administered in 2017), visitor motivations were determined using a 29question scale (see question 14 in USU and NPS 2021a) based on Driver's Recreation Experience Preference Scale (Driver, 1983; Manfredo et al.,1996; Manning, 2011). All scale items were adapted to fit GBNP recreationists, environment, and available opportunities. Two additional open-ended questions were added to collect qualitative data measuring motivations and expectations of the visitor experience (see questions 11, 12 in USU and NPS 2021a). The post-experience survey (administered in 2018) included questions informed by 2017 visitor motivations, such as quality of the visitor experience and normative thresholds surrounding resource impacts and crowding. For both the preand post-experience surveys, a set of 3-5 survey questions were administered to anyone declining to complete the survey to assess non-response bias (see Appendix B).

Two approaches were used to help determine social and ecological thresholds. First, an experiencebased approach was utilized, asking visitors the conditions they encountered during their visit to Glacier Bay. This was followed by a series of questions asking how those conditions affected the visitor's experience in GBNP. Second, following well-established theoretical methods, a visual simulation approach was used to determine visitor thresholds around potential crowding and coastal resource conditions (see Appendix A).

Many studies use manipulated imagery to depict indicator impacts associated with recreation and tourism use (Bell, Needham, \& Szuster, 2011, p. 503; Manning, 2007). A series of photographs were used to evaluate thresholds of acceptance, as opposed to using an open-ended, qualitative approach. It has been argued that photograph series can be more burdensome on the participant, however using them tends to yield more accurate information overall (Manning, 2011). Normative thresholds, included in the post-experience survey, were measured using visual simulation questions, or images modified to represent certain hypothetical situations at the same location. For each question, the photos used were computer-edited with Adobe Photoshop - the base-layer remained the same with different levels of impact overlaid. At the end of the independent backcountry visitor survey administered in 2018, five computer-edited photos were presented per question in a random, nonstratified order. Each participant was asked to rate their normative acceptance of each photograph from low (-3) to high (+3). These acceptance ratings were then plotted in a norm curve to better understand norm intensity, optimum and minimum acceptable conditions, and crystallization (Bell et al., 2011; Manning, 2011). Two dimensions, the number of kayaks and tents and the number of tent rocks, were used to measure crowding and resource impact norms (Figure 3). Crowding was 
represented by a series of five photographs: $0,2,4,6$, and 10 kayaks and tents. It is important to note that the maximum permitted number of individuals in a group for backcountry use is 12 , which is why the photos do not suggest more than 12 kayaks and tents. Resource impacts were represented by a series of five photographs with increasing numbers of tent rocks: $0,5,10,15$ and 20 (plus a fire ring). A tent rock is a medium- to large-sized moveable rock that may be transplanted to a campsite in order to tie down a tarp or tent. If tent rocks are not dispersed after leaving a campsite, they are often associated with visitor disturbance (Goonan et al., 2014). The location of each photo series is in Glacier Bay, but the number of tents, kayaks, and tent rocks were added to each location to represent changes in conditions. 


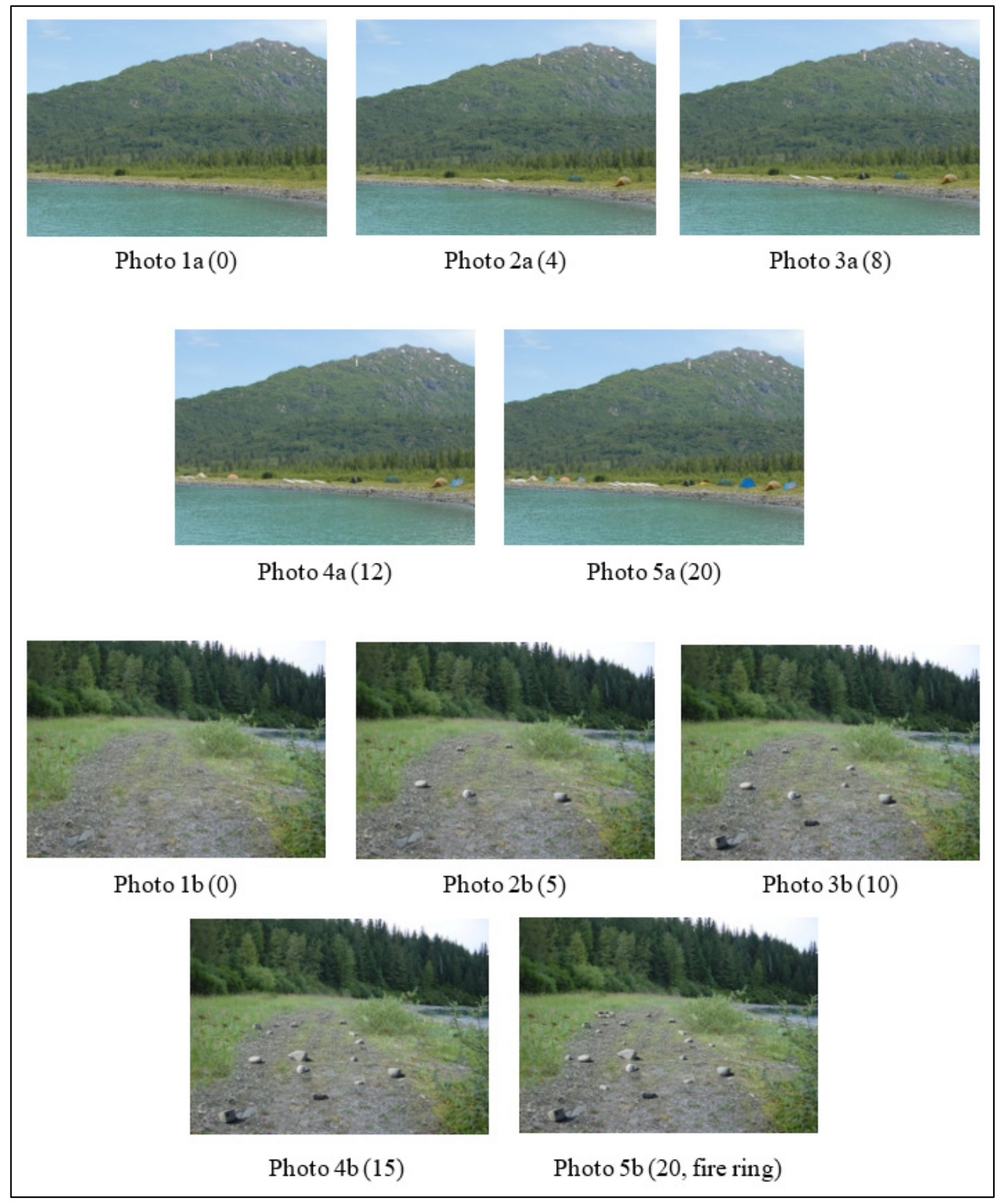

Figure 3. Photo series used to evaluate thresholds of acceptance for (a) crowding and (b) coastal ecological conditions. Respective labels indicate the number of (a) kayaks/tents and (b) tent rocks/fire ring on a beach within each photo. See Appendix A for enlarged photos. 
In GBNP there are only two formal land trails near the visitor center-the most common backcountry activity is sea kayaking with only limited backcountry hiking available. Overnight sea kayakers and backpackers up bay were the only population that were issued GPS-tracking devices for the survey. Spatial data was collected in congruence with the survey data, assuming the individual accepted both. GPS-tracking coupled with visitor surveys provided high-quality, detailed, and accurate data that can be applied to many research and managerial questions.

Most independent backcountry users were multi-day recreationists, meaning data was collected from the moment the GPS-tracker was accepted to the moment they returned to Bartlett Cove and returned the device to the researcher or Visitor Information Station (VIS). The GPS tracking device used throughout both sampling periods was the Super Trackstick. In 2017, visitors were given a preexperience survey, and once completed, given a GPS unit to carry during their time in the backcountry. In 2018, the GPS unit was issued, and the post-experience survey was completed upon return. Each Super Trackstick was secured in a locked Pelican Case that inhibited participant manipulation of the device or water damage. Super Tracksticks collected positions every 10 to 60 seconds, unless at a stop for long periods of time. Based on the low battery performance during 2017 sampling (about four days of battery life), the devices used for 2018 data collection were modified with additional batteries in order to extend battery life to around 14 days. The modified Super Trackstick units were tested in Logan, UT before issuing them in GBNP to ensure they worked properly.

\section{Data Collection Methods}

Eligible participants for this study included adults (18 years or older) within one of the following sample populations: residents of Gustavus, AK (the Park's gateway community), independent backcountry visitors (sea kayakers and a few backpackers), independent private boaters, passengers riding the day boat, tour vessels, or charter vessels, and those who had visited Glacier Bay and were leaving from the Gustavus Airport. Visitors not included were cruise ship passengers, flightseers, outer coast visitors, or Alsek River rafters. Sampling occurred from June 16, 2017 to August 9, 2017 for the pre-experience survey and June 8, 2018 to August 28, 2018 for the post-experience survey. In 2018, target populations were refined based on sampling experiences from 2017, NPS staff input, and a better understanding of available visitor populations. Targeted sample sizes and survey administration differed depending on the population (see Appendix B).

\section{Sample Populations}

The year-round resident population for Gustavus, AK fluctuates between 418 and 459 individuals, according to the U.S. Census Bureau and Alaska Department of Labor and Workforce Development (State of Alaska Department of Commerce, Community, and Economic Development, 2008).

Residents are involved with GBNP on multiple levels, including direct employment, indirect employment (Gustavus inns, commercial fishing, and seasonal opportunities), and personal visitation. Many of the residents and community members - such as business owners - access their mail through P.O. boxes located in town. Sampling of this population was done by inviting residents to participate in an online version of the pre-trip survey by dropping postcards off in their P.O. boxes. 
Each postcard had a unique access codes that allowed residents to access the survey, which protected against individuals completing more than one survey per household.

Independent backcountry visitors are those that recreate in GBNP wilderness, including kayakers and backpackers. All are required to obtain permits and participate in a backcountry orientation at the VIS before they travel outside of Bartlett Cove. Based on communication with park staff, it was determined that there tended to be relatively low kayak/backpack visitation, with a total of 291 groups between June 1, 2016 and September 1, 2016. Due to this low number, surveyors attempted to intercept all backcountry visitor groups to maximize the sample size. Independent backcountry visitors were the only population carrying GPS trackers, as they have the opportunity to freely explore the backcountry and also return to Bartlett Cove at the end of their trip. Backpackers have the ability to explore Lester Island by crossing the Beardslee Island cut when the tide is low, but to explore the upper reaches of the bay, they must travel via personal vessel, or ride the day boat to be dropped off at one of two designated locations available each day during the on-season (Sebree, Scidmore, Mt. Wright, Sundew, or Ptarmigan). Sea kayakers can either depart from Bartlett Cove, or board the day boat to be dropped off with their kayak and gear at one of the designated locations listed above for no additional cost.

Independent private boaters are those who travel in Bartlett Cove or up bay in private vessels. All private boaters are required to obtain permits and participate in an annual orientation, similar to independent, non-motorized backcountry visitors. This population was surveyed similarly to nonmotorized backcountry visitors, but only for a two-week period as surveying ceased because it was determined that the population fell outside the scope and approval of the study. Therefore, the sample size for this population is quite small.

The commercial "day boat" use associated with GBNP is a concessionaire catamaran that carries visitors from Bartlett Cove up bay for an 8-hour park experience, operating every day (7:30 am-3:30 pm) June through mid-September. A park interpreter is on board providing information to visitors regarding cultural, natural, and social elements of the park. On average, 75 visitors board the day boat each day, with groups varying roughly between 1-20 individuals.

Tour vessels are commercial vessels that arrive in GBNP from other ports, such as Skagway, Juneau or Haines, AK. These vessels carry an average of 80 visitors (as low as 25, as high as 120 individuals) into GBNP, spending anywhere from 14 to 24 hours in GBNP. A park interpreter is on board whenever the vessel is in GBNP, boarding during the night or the morning at 6 a.m. before heading into GBNP. Many vessels dock at Bartlett Cove after their up bay experience and encourage visitors to explore the area, including the interpretive materials, the Forest Loop Trail (one-mile loop from the dock area), the Huna Tribal House and the Glacier Bay Lodge.

Charter vessels are private expeditions, often accommodating less than 15 guests, who travel within park boundaries anywhere from 1- to 10-days. There are several charter companies that have commercial contracts that authorize them to navigate throughout Glacier Bay waters, and they often disembark outside Bartlett Cove (where most sampling occurred). A limited number of surveys were presented to charter vessel staff before departure; however, surveying ceased as it was determined 
that the population fell outside the scope and approval of the study. Therefore, the sample size for this population is quite small.

The Gustavus Airport was introduced as a 2018 target population to better capture visitors who were part of charter vessel tours by establishing a more standardized sampling protocol. This sampling location allowed for visitors that had not been approached on the day boat or through the VIS to participate in the study as well. As mentioned earlier, the Gustavus Airport is an important resource for visitors traveling to and from Gustavus, AK and GBNP as the only way to reach Gustavus is by air or boat. There is an estimated 9,242 people departing the Gustavus Airport each year (U.S. Department of Transportation, n.d.), with 84 flights (arriving and departing) in 2017. There is one commercial jet (Alaska Airlines) flight that arrives in Gustavus between 4:30 p.m. and 5:30 p.m. daily, depending on weather. Alaska Airlines only offers flights to Gustavus, AK from roughly the first week of June to the last week of August. There are no commercial jet flights offered during GBNP off-season (September to May), as only small air taxi services operate year-round.

Given the complexity of this study, several sampling strategies were used (Table 1).

Table 1. Detailed methodological protocols for data collection in 2017 and 2018.

\begin{tabular}{|c|c|c|}
\hline Sample Population & 2017 Pre-Experience Survey ${ }^{1}$ & 2018 Post-Experience Survey ${ }^{1,2}$ \\
\hline Residents & $\begin{array}{l}\text { - Received postcard with online link and } \\
\text { access code. }\end{array}$ & Not included in 2018 sample \\
\hline Independent Backcountry & $\begin{array}{l}\text { - Census of population (target } \mathrm{n}=100 \text { ) } \\
\text { - Intercepted at the VIS after each } \\
\text { backcountry orientation (10 a.m., } 3 \\
\text { p.m., } 6 \text { p.m.) or after receiving their } \\
\text { permit. } \\
\text { - GPS unit was given to survey } \\
\text { participant. }\end{array}$ & $\begin{array}{l}\text { - Census of population (target } \mathrm{n}=100 \text { ) } \\
\text { - Intercepted at the VIS after each } \\
\text { backcountry orientation (10 a.m., } 3 \\
\text { p.m., } 6 \text { p.m.), after receiving their } \\
\text { permit or on the day boat before daily } \\
\text { departure ( } 7 \text { a.m.). } \\
\text { - GPS unit was given to survey } \\
\text { participant. }\end{array}$ \\
\hline Independent Boaters & $\begin{array}{l}\text { - Intercepted at the VIS after each } \\
\text { orientation or after receiving boater } \\
\text { permit. }^{3}\end{array}$ & Not included in 2018 sample \\
\hline
\end{tabular}

${ }^{1}$ Non-response bias questions were asked when possible.

2 For 2018 sample: Independent backcountry visitors were administered surveys specific to an independent, non-motorized experience, including visual simulation questions. Day boat and tour vessel visitors were administered surveys specific to a guided, motorized experience. Gustavus Airport visitors were administered surveys specific to the visitor's experience, either guided, motorized or independent, non-motorized.

${ }^{3}$ Sampling ceased as it was determined that the population fell outside the scope and approval of the study.

${ }^{4}$ For tour vessels, 12 sampling events were scheduled but only 11 were completed due to changes in tour vessel schedules. 
Table 1 (continued). Detailed methodological protocols for data collection in 2017 and 2018.

\begin{tabular}{|c|c|c|}
\hline Sample Population & 2017 Pre-Experience Survey ${ }^{1}$ & 2018 Post-Experience Survey1, 2 \\
\hline Day Boat & $\begin{array}{l}\text { Census of population (target } \mathrm{n}=300 \text { ), } \\
\text { daily (June, July, August). } \\
\text { Surveys were administered between } \\
\text { 7-7:20 a.m. on-board the day boat } \\
\text { before departure. }\end{array}$ & $\begin{array}{l}\text { - Census of population (target } n=300 \text { ), } \\
5-8 \text { random days each month (June, } \\
\text { July, August). } \\
\text { - Administered surveys after } 2 \text { p.m. on } \\
\text { return to Bartlett Cove. }\end{array}$ \\
\hline Tour Vessel & $\begin{array}{l}\text { - Random sampling (target } n=100), 9 \\
\text { sampling events in August. } \\
\text { - Park interpreters administered surveys } \\
\text { after vessels left the dock and all safety } \\
\text { announcements were given. }\end{array}$ & $\begin{array}{l}\text { - Census of population (target } n=100 \text { ), } \\
12 \text { random sampling events }{ }^{4} \text { ( } 4 \text { in } \\
\text { June, July, and August). } \\
\text { - Surveys administered on-board on the } \\
\text { return to Bartlett Cove, or on the } \\
\text { Bartlett Cove dock as passengers } \\
\text { return to their tour vessel. }\end{array}$ \\
\hline Charter Vessel & $\begin{array}{l}\text { - Surveys were given to charter vessel } \\
\text { staff in Bartlett Cove before departure } \\
\text { for dispersal. }{ }^{3}\end{array}$ & Not included in 2018 sample \\
\hline Gustavus Airport & Not included in 2017 Sample & $\begin{array}{l}\text { - Census of population (target } n=100) \text {, } \\
15 \text { random sampling events ( } 5 \\
\text { days/month in June, July, and August). }\end{array}$ \\
\hline \multicolumn{3}{|c|}{${ }^{1}$ Non-response bias questions were asked when possible. } \\
\hline \multicolumn{3}{|c|}{$\begin{array}{l}2 \text { For } 2018 \text { sample: Independent backcountry visitors were administered surveys specific to an independent, } \\
\text { non-motorized experience, including visual simulation questions. Day boat and tour vessel visitors were } \\
\text { administered surveys specific to a guided, motorized experience. Gustavus Airport visitors were administered } \\
\text { surveys specific to the visitor's experience, either guided, motorized or independent, non-motorized. }\end{array}$} \\
\hline \multicolumn{3}{|c|}{${ }^{3}$ Sampling ceased as it was determined that the population fell outside the scope and approval of the study. } \\
\hline \multicolumn{3}{|c|}{$\begin{array}{l}{ }^{4} \text { For tour vessels, } 12 \text { sampling events were scheduled but only } 11 \text { were completed due to changes in tour } \\
\text { vessel schedules. }\end{array}$} \\
\hline
\end{tabular}

\section{Data Analysis}

Qualtrics, an online survey forum, was used to create, collect, and organize all survey data, allowing pre-coded answers for all quantitative questions. Survey data were summarized and analyzed using SPSS statistical software (v.25, SPSS, Inc. Chicago, IL). All GPS tracks were imported, cleaned, and analyzed using ArcGIS software (v.10.3, Environmental Systems Research Institute, Redlands, CA), projected in a State Plane Coordinate System for the Southeastern Alaska region (NAD 1983 UTM Zone $8 \mathrm{~N})$.

\section{Statistical Analysis}

Both univariate and multivariate statistical approaches were used to analyze both pre- and postexperience data (Furr, 2019). Frequencies and descriptive statistics were used to examine basic distributional characteristics for all survey data, including experience use history, basic demographics, and quality of experience (Vaske, 2008). An exploratory factor analysis (principal components analysis with varimax rotation) was used as a data reduction method to reduce the 29item motivation scale into interpretable constructs. Following those results, a one-way analysis of 
variance (ANOVA) was used to determine significant differences in motivations between user groups, followed by either a Hochberg or Games-Howell post-hoc test to determine where the differences are within the data. The Hochberg post-hoc is used when sample sizes are very different, while the Games-Howell post-hoc is used when there is doubt about homogeneity of variance (Field, 2013). Finally, a K-means cluster analysis on the standardized factor scores was used to classify visitors based on motivations following an approach used by Kidd et al. (2018). This approach is common when reducing large survey scales and classifying variables into groups (Jolliffe, 2002; Kidd et al., 2018).

Data from the post-experience survey were analyzed similarly (Furr, 2019). In order to determine visitors' quality of experience, visitors were asked to rate the quality of the five motivational factors derived from the 2017 data reduction process. An ANOVA was then completed to determine differences between visitor groups (i.e., independent backcountry, day boat, tour vessel, or visitors at the Gustavus Airport) and their quality of experience. Additional ANOVA's were completed to determine differences among other variables, including experience use history and Leave No Trace knowledge, experience use history and visitor groups, place attachment and visitor groups, and the effect of anthropogenic visitor encounters and visitor groups. Each ANOVA was followed by a posthoc test, either Hochberg or Games-Howell, to determine where the differences fell within the data.

As Wilson (2009) suggests, a coding protocol was created for all open-ended qualitative questions for both sets of data in order to standardize across populations and time (Furr, 2019). The data were coded using NVivo (v.12.3.0, QSR International, Melbourne, Australia) qualitative data analysis software. For each open-ended question, raw responses were separated in SPSS using the split file option based on sample population. All separated responses were pasted into individual Microsoft Word (v.16.16.8, Microsoft Corporation, Bellevue, WA) documents where spelling and grammar were edited for better coding and searchability. Each data document was then uploaded to NVivo. Before coding began, nodes (a filing system to organize, store and count coding entries) were created in NVivo for each question being analyzed based on common terms that are grounded in motivational theory (e.g., solitude, escape, exploration, adventure), as well as specific place-based concepts informed by park management and common responses (e.g., experiencing glaciers, wildlife, boat trips, kayaking). For each data document, each response was coded by dragging the comment into the respective node based on integrated themes, concepts or words that appeared. There were no limits to the number of nodes a response could be coded into, which means one response could have been moved into one or more nodes, depending on content.

Although there were different questions asked for the pre- and post- surveys, the coding process was similar, and common concepts were used between years when possible. There were, however, different themes, resulting in the use of new terms for post-experience survey data. Coding for each question was completed by the same person for the total population, with an additional peer-review process for responses that were not clearly interpretable (e.g., "Pushing personal limits" was coded as "Adventure"). A code book (see Appendix C) was developed to present each coding item and paired data references for transparency and replicability. These analyses provided interpretable results that were presented to park managers in hopes of informing management planning. 
Normative thresholds surrounding crowding and resource impacts were determined through the use of visual simulation questions. Each visitor completing the independent backcountry survey was asked to evaluate the acceptability of a range for both kayaks/tents on a beach and tent rocks on a beach. These data were then combined to find a mean value, and graphed, forming a social norm curve.

To better understand the agreement levels between survey responses, Manfredo, Vaske, and Teel (2003) devised the Potential for Conflict Index (PCI). The index incorporates how many people responded to each possible answer from the Likert Scale (-3 to 3) and multiplies the number of responses to the corresponding Likert Scale value. The full equation used to find the PCI can be found in Figure 4. In this equation, $\mathrm{Xa}$ are the acceptable conditions (responses $>0$ ); $\mathrm{Xu}$ are the unacceptable conditions (responses $<0$ ); and $Z$ is the maximum sum of all scores $(Z=3 n)$. Possible answers to this equation range from 0 to 1 . A result of 0 implies complete agreement, whereas 1 implies complete disagreement.

$$
\begin{gathered}
\mathrm{PCI}=\left[1-\left|\frac{\sum_{i=1}^{n_{a}}\left|\mathrm{X}_{\mathrm{a}}\right|}{\mathrm{X}_{t}}-\frac{\sum_{i=1}^{n_{u}}\left|\mathrm{X}_{\mathrm{u}}\right|}{\mathrm{X}_{t}}\right|\right] \times \frac{\mathrm{X}_{\mathrm{t}}}{\mathrm{Z}} \\
\mathrm{X}_{t}=\sum_{i=1}^{n_{a}}\left|\mathrm{X}_{\mathrm{a}}\right|+\sum_{i=1}^{n_{u}}\left|\mathrm{X}_{\mathrm{u}}\right|
\end{gathered}
$$

Figure 4. The full equation for the Potential for Conflict Index (Source: Vaske et al., 2006).

\section{Geospatial Analysis}

In recent years, the process for basic analysis of GPS tracks has become relatively standard across studies (Beeco et al., 2014; D’Antonio et al., 2010; Hallo et al., 2012). Each GPS track was downloaded as point features, then visually examined them in geographic information system software (ArcGIS). Irrelevant GPS data points were eliminated (Kidd et al., 2018; Monz, D'Antonio, \& Heaslip, 2014). Irrelevant data points refer to both erroneous points, those that were collected in error due to a loss in satellite connection, and points that were collected before the visitor's trip began or after it ended. Erroneous points were discovered visually with cross-referencing time and location in the attribute table. The official start and end points of the visitor's trip were based on location (i.e., Bartlett Cove or day boat drop off/ pick up sites), date, time and speed. 


\section{Results \& Discussion}

The pre-experience survey data provided insight into visitor demographics, motivations, overall trip planning, and expectations (USU and NPS 2021a), with a total of 472 survey participants, 40 GPS tracks and 23 GPS tracks paired with survey data. An overall response rate (number of visitors who completed a survey/total number of visitors asked to complete a survey) for 2017 was not calculated as total rejections/total approach data were not collected for all populations due to different sampling protocols. Response rates were calculated for the following populations: $98.4 \%$ for day boat passengers, $93.2 \%$ for independent backcountry visitors, and $90 \%$ for independent boaters. The response rate for residents of Gustavus, AK was $12.9 \%$ with 34 individuals out of 264 responding to the post-card prompt. Sampling on tour and charter vessels was conducted by NPS staff and total approach data were not recorded; therefore, response rates could not be calculated. Among the populations with response rates, there were two rejections and two non-response bias checks, which does not provide an adequate non-response sample for comparison.

Based on GBNP 2017 recreation use records and accounting for an average of 3 individuals per group (based on survey data, Table 4), the overall proportion of visitors surveyed relative to total visitation for sampled populations was $6.6 \%$, with variations due to differing sampling protocols: $23.2 \%$ for independent backcountry visitors, $11.9 \%$ for day boat passengers, $6.8 \%$ for residents, $5.0 \%$ for private boaters $2.5 \%$ for tour vessel passengers and $1.2 \%$ for charter passengers (Appendix A1).

The post-experience survey provided evaluative input from visitors including demographics, overall quality of experience, and assessments of thresholds of acceptability for both resource impacts and crowding (USU and NPS 2021b, 2021c), with a total of 843 survey participants, 52 GPS tracks and 44 GPS tracks paired with survey data. The overall response rate for 2018 was $93.6 \%$, with variable response rates among sample populations: $95.9 \%$ for day boat passengers, $94.1 \%$ for those at the Gustavus airport, $91.7 \%$ for tour vessel passengers, and $89.9 \%$ for independent backcountry visitors. Only eight non-response bias checks were completed among all survey respondents, representing $<1 \%$ of those surveyed $(8 / 843=0.9 \%)$, which does not provide an adequate non-response sample for comparison. Among others, a language barrier, general lack of energy or not enough time were common responses for not completing the survey.

Based on GBNP 2018 recreation use records and accounting for an average of 4 individuals per group (based on survey data, Table 27), the overall proportion of visitors surveyed relative to total visitation for sampled populations was $21.6 \%$, with variations due to differing sampling protocols: $60.2 \%$ for independent backcountry visitors, $22.1 \%$ for day boat passengers, and $9.8 \%$ for tour vessel passengers (Appendix A2). The Gustavus Airport was sampled to better capture visitors who were part of charter vessel tours; however, it also captured visitors who had not been surveyed on the day boat or through the VIS. Therefore, the proportion of individuals surveyed relative to total visitation within that sample population was not calculated as it captured multiple populations.

When studies are completed over time, visitor demographics can provide insight into if/how the people visiting an area are changing. Since data were collected for two consecutive years, a chisquared analysis (Table 2) was used to compare demographic information from people visiting 
GBNP in 2017 to those in 2018. Age and gender were two variables asked on both surveys. The 2017 survey asked for all ages and genders of people within the group (up to five individuals), while the 2018 survey asked only for the respondent to record their own age/gender. For 2017 data, the first column available to record gender was used in the analysis (as this was the designated spot for the respondent to record their own age/gender). In 2017, age was asked using pre-determined categories (e.g., ages 18-19, 20-29... 70+), while the 2018 survey asked for the actual age of the respondent. Both survey year data were binned into categories for analyses. There were no statistically significant differences $(p>.05)$ between the age and gender of visitors from 2017 and 2018, except for gender within the day boat population. Reported gender for day boat passengers was statistically significantly different $(\mathrm{p}<.05)$ between the two years, with $52 \%$ reporting female in 2017 and $63 \%$ in 2018. Given that this was the only difference, and all other comparisons of age and gender were not statistically significant, this analysis suggests that there were just more women riding the day boat in 2018 than in 2017. The higher percentage of women in 2018 is not anticipated to affect results of this study. By comparing these two years of data and finding only one difference in the percentage of female visitors riding the day boat, the following was determined: 1) visitors were relatively similar between the two years and 2) the sampling protocols for each year were designed in a way which collected data consistently between the two sampling periods.

Table 2. Survey respondent demographic comparing 2017 and 2018.

\begin{tabular}{|c|c|c|c|c|c|c|}
\hline \multirow[b]{2}{*}{ Demographic Group } & \multicolumn{2}{|c|}{$2017^{2}$} & \multicolumn{2}{|c|}{2018} & \multirow[b]{2}{*}{$x^{2}$} & \multirow[b]{2}{*}{$p$-value } \\
\hline & Frequency & Percent ${ }^{1}$ & Frequency & Percent $^{1}$ & & \\
\hline Gender & - & - & - & - & 6.99 & .008 \\
\hline Female & 226 & 51.1 & 477 & 58.9 & - & - \\
\hline Male & 216 & 48.9 & 333 & 41.1 & - & - \\
\hline Age & - & - & - & - & 2.89 & .823 \\
\hline $18-19$ & 12 & 2.7 & 19 & 2.4 & - & - \\
\hline $20-29$ & 42 & 9.6 & 84 & 10.5 & - & - \\
\hline $30-39$ & 61 & 13.9 & 112 & 14.0 & - & - \\
\hline $40-49$ & 60 & 13.7 & 92 & 11.5 & - & - \\
\hline $50-59^{3}$ & 85 & 19.4 & 157 & 19.6 & - & - \\
\hline $60-69$ & 130 & 29.7 & 231 & 28.8 & - & - \\
\hline $70+$ & 48 & 11.0 & 107 & 13.3 & - & - \\
\hline
\end{tabular}

${ }^{1}$ Based on valid data only.

22017 pre-experience survey asked for gender and age of each group member. The gender and age for the respondent (specified on the survey) was used for this analysis.

${ }^{3}$ Median $=5$, the median age range for visitors was between $50-59$ years of age; SD = 1.65. 
Historical data from 1978 and 1984 were compared to current independent backcountry visitor data when appropriate.

\section{Results}

The pre-experience 2017 survey included questions surrounding visitor demographics, experience use history, overall trip planning, and motivations. The results have been organized accordingly.

\section{Demographics}

In 2017, a total of 472 surveys were completed. Of these, 440 surveys were completed by recreational visitors in Glacier Bay National Park, and 34 were completed by Gustavus residents. Overall, data was collected from six distinct populations: Gustavus residents, people riding the day boat, independent backcountry visitors, people aboard tour vessels, independent boaters, and people aboard charter vessels (Figure 5).

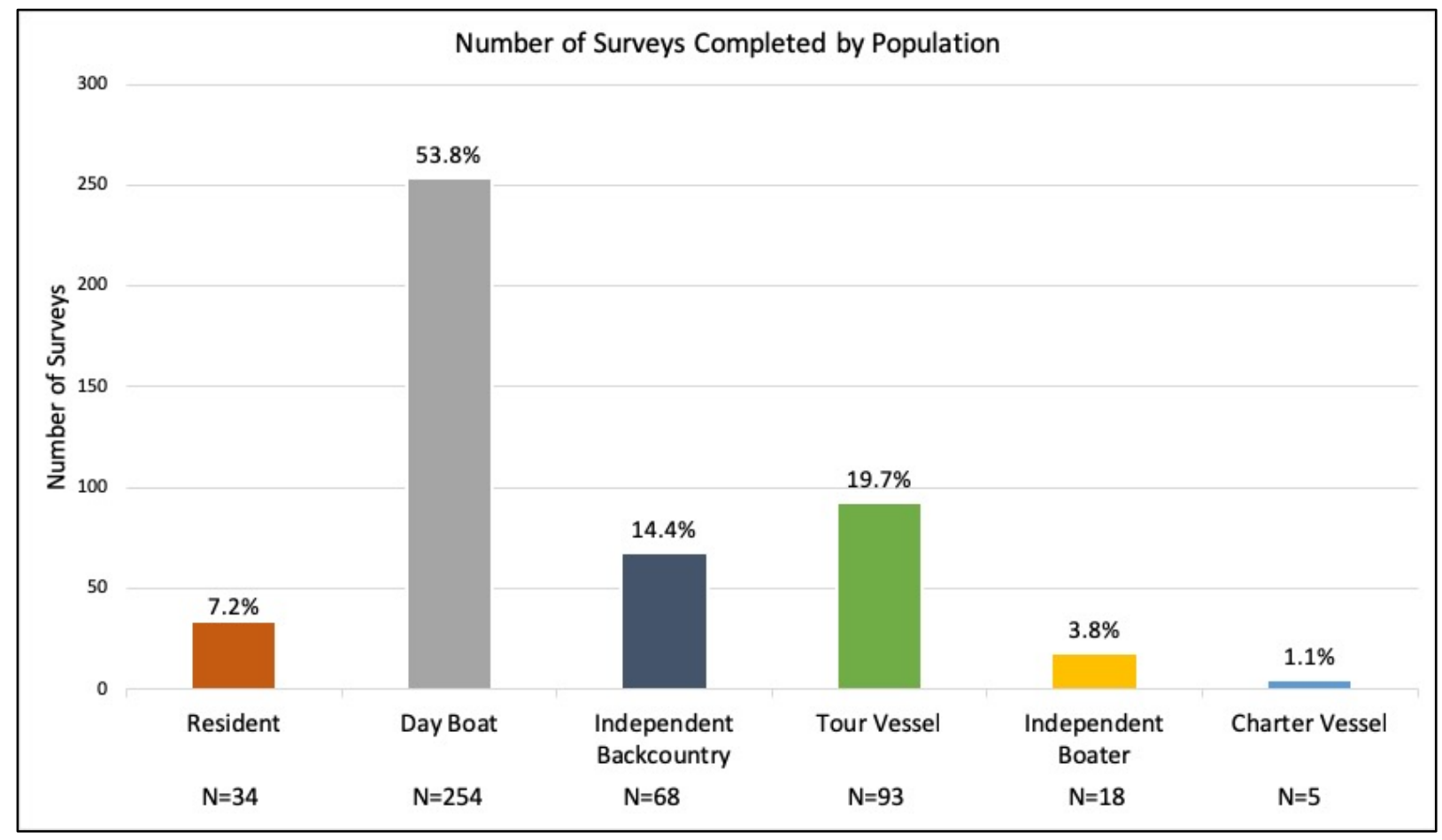

Figure 5. Number of surveys completed for each target population. Percentages illustrate the proportion of visitors sampled per target population to the total number of visitors sampled in 2017.

In the 2017 pre-experience survey, a variety of demographic information were collected from park visitors and Gustavus residents. This information included gender, age, race, education, and annual household income. These data help provide an understanding of who is visiting Glacier Bay National Park.

Slightly more females (54\%) visited GBNP than males (46\%). Sixty-six percent of visitors were over the age of 40 , and $35 \%$ were over the age of 60 . The majority of visitors identified as white (91.5\%). Visitors were highly educated, with $85 \%$ of visitors having received at least a four-year college 
degree, and over half (52\%) with a graduate level degree. Visitors also reported having high incomes, with nearly $60 \%$ having an annual household income of $\$ 100,000$ or more. Overall, Glacier Bay National Park visitors were generally older, white, highly educated, and high-earning individuals. Table 3 represents all demographic information gathered during the 2017 pre-experience survey.

Table 3. Visitor demographics in 2017.

\begin{tabular}{|c|c|c|c|}
\hline Demographic Category & Demographic Group & Frequency ${ }^{1}$ & Percent $^{2}$ \\
\hline \multirow[t]{2}{*}{ Gender $^{3}$} & Female & 666 & 53.67 \\
\hline & Male & 575 & 46.33 \\
\hline \multirow[t]{8}{*}{$\mathrm{Age}^{4}$} & Under 16 & 87 & 7.0 \\
\hline & $16-19$ & 53 & 4.3 \\
\hline & $20-29$ & 133 & 10.7 \\
\hline & $30-39$ & 149 & 12.0 \\
\hline & $40-49$ & 150 & 12.1 \\
\hline & $50-59$ & 229 & 18.5 \\
\hline & $60-69$ & 302 & 24.4 \\
\hline & $70+$ & 136 & 10.98 \\
\hline \multirow[t]{7}{*}{ Race ${ }^{5}$} & American Indian or Alaska Native & 6 & 0.5 \\
\hline & Asian & 48 & 3.9 \\
\hline & Black or African & 5 & .4 \\
\hline & Native Hawaiian or other Pacific Islander & 1 & .1 \\
\hline & White & 1135 & 91.5 \\
\hline & Other & 14 & 1.1 \\
\hline & Don't Know & 32 & 2.6 \\
\hline
\end{tabular}

1 There were only five spaces for surveyors to answer gender, age, and race of visitors per group, which is why values are less than total $\mathrm{N}$ of visitors.

2 Based on valid data only, invalid data ranged per question.

${ }^{3} \mathrm{~N}$ for Gender $=1241$

${ }^{4} \mathrm{~N}$ for Age $=1239$

${ }^{5} \mathrm{~N}$ for Race $=1241$

${ }^{6} \mathrm{~N}$ for Highest Level of Education $=454$

${ }^{7} \mathrm{~N}$ for Annual Household Income $=374$ 
Table 3 (continued). Visitor demographics in 2017.

\begin{tabular}{llrr}
\hline Demographic Category & Demographic Group & Frequency $^{1}$ & Percent $^{2}$ \\
\hline Highest Level of Education $^{6}$ & Less than High School & 1 & .2 \\
& Some High School & 3 & .7 \\
& High School Graduate & 15 & 3.3 \\
& Vocational/Trade School Certificate & 6 & 1.3 \\
& Some College & 27 & 5.9 \\
& Two-year College Degree & 15 & 3.3 \\
& Four-year College Degree & 149 & 32.8 \\
& Master's Degree & 157 & 34.6 \\
& Ph.D., M.D., J.D., or equivalent & 81 & 17.8 \\
Annual Household Income ${ }^{7}$ & Less than $\$ 25,000$ & 20 & 5.3 \\
& $\$ 25,000-\$ 34,999$ & 12 & 3.2 \\
& $\$ 35,000-\$ 49,999$ & 22 & 5.9 \\
& $\$ 50,000-\$ 74,999$ & 52 & 13.9 \\
& $\$ 75,000-\$ 99,999$ & 54 & 14.4 \\
$\$ 100,000-\$ 149,999$ & 81 & 21.7 \\
$\$ 150,000-\$ 199,999$ & 36 & 9.6 \\
$\$ 200,000$ or more & 97 & 25.9 \\
\hline
\end{tabular}

${ }^{1}$ There were only five spaces for surveyors to answer gender, age, and race of visitors per group, which is why values are less than total $\mathrm{N}$ of visitors.

2 Based on valid data only, invalid data ranged per question.

${ }^{3} \mathrm{~N}$ for Gender $=1241$

${ }^{4} \mathrm{~N}$ for Age $=1239$

${ }^{5} \mathrm{~N}$ for Race $=1241$

${ }^{6} \mathrm{~N}$ for Highest Level of Education $=454$

${ }^{7} \mathrm{~N}$ for Annual Household Income $=374$

Visitors were asked how many people they were traveling with during their trip to Glacier Bay National Park. Very few people were traveling solo (2.3\%). Nearly 30\% of visitors were traveling as a couple, $45 \%$ were in groups of three to five people, and $24 \%$ of visitors were traveling in a group with more than five people (Table 4). 
Table 4. Number of people per group in 2017.

\begin{tabular}{lrr}
\hline Number of People & Frequency & Percent $^{1}$ \\
\hline 1 per group & 34 & 2.3 \\
2 per group & 420 & 29.0 \\
3 per group & 171 & 11.8 \\
4 per group & 336 & 23.2 \\
5 per group & 140 & 9.7 \\
$6+$ per group & 347 & 24.0 \\
\hline N = 1448; Mean = 3.20; SD =2.32 & &
\end{tabular}

Respondents were asked to provide their home ZIP code in order to better understand the geographical reach of visitors (Figure 6a). In the analysis, ZIP codes were grouped into general regions. More than a third (36\%) of Glacier Bay visitors were from the Western United States. The next most common region was the Southern region of the United States (18\%), followed by foreign visitors (17\%), Midwest visitors (12\%), and visitors from the Northeast (10\%). Gustavus residents were not included in this analysis in order to avoid skewing results; however, $6.2 \%$ of visitors reported living in Alaska. Visitors from specific Alaskan boroughs can be found in Figure $6 \mathrm{~b}$. 


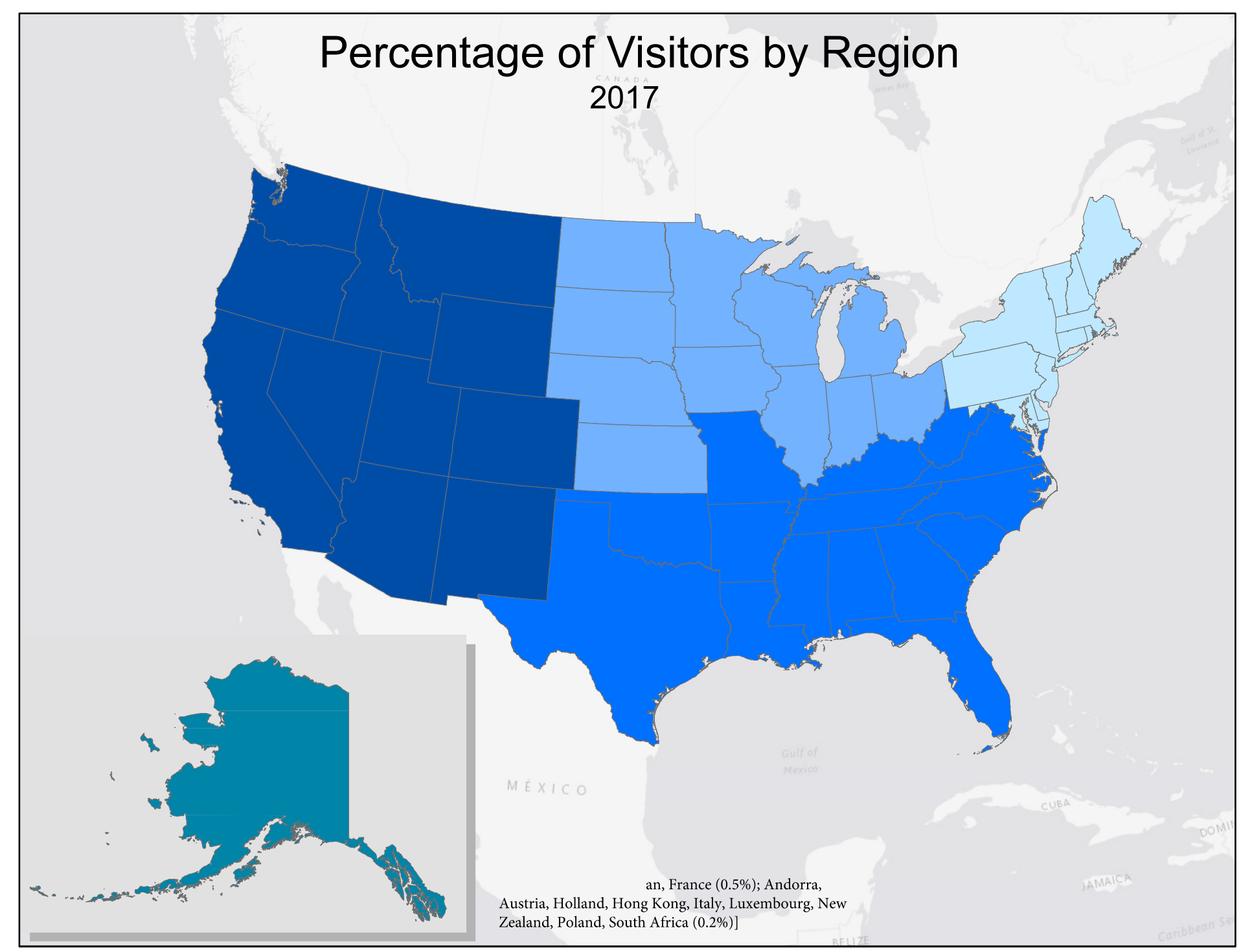

Figure 6a. Percentage of visitors by region for 2017. $\mathrm{N}=430$. 


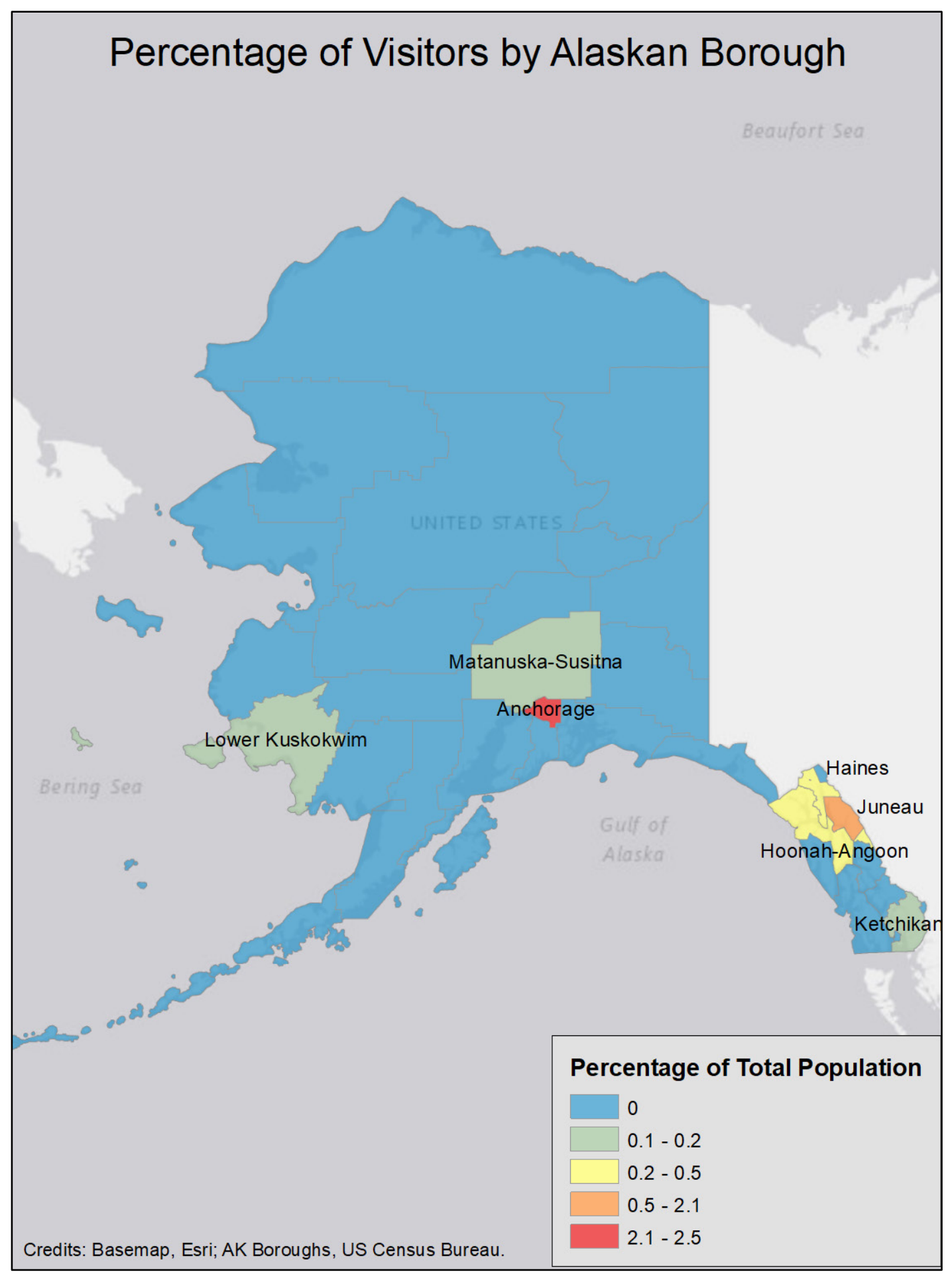

Figure 6b. Percentage of Alaskan visitors by borough for 2017 (6.21\% of total population).

\section{Trip Planning and Experience Use History}

To help gain a better understanding of Glacier Bay National Park visitors, a variety of questions were asked regarding what informational sources they used to plan their trip, their pre-experience planning 
process, and plans they had made for their visit to GBNP. Visitors were also asked if they had been to the park before, and if they had, how many times they had visited in the last five years, and how many times they had visited in their lifetime (Table 5).

Table 5. Experience use history of GBNP visitors in 2017.

\begin{tabular}{|c|c|c|c|c|}
\hline \multirow[b]{2}{*}{ Number of Visits } & \multicolumn{2}{|c|}{ Visits in the Past 5 Years ${ }^{2}$} & \multicolumn{2}{|c|}{ Visits in a Lifetime ${ }^{3}$} \\
\hline & Frequency & Percentage $^{1}$ & Frequency & Percentage $^{1}$ \\
\hline First Visit & 389 & 85.9 & 335 & 73.5 \\
\hline 2 & 23 & 5.1 & 61 & 13.4 \\
\hline 3 & 12 & 2.6 & 13 & 3.3 \\
\hline $4-10$ & 13 & 2.9 & 19 & 4.2 \\
\hline$>10$ & 16 & 3.5 & 26 & 5.7 \\
\hline $11-25$ & 7 & 1.5 & 6 & 1.3 \\
\hline $26-50$ & 7 & 1.5 & 6 & 1.3 \\
\hline$>50$ & 2 & 0.4 & 14 & 3.1 \\
\hline
\end{tabular}

Respondents were asked where they had sought information about Glacier Bay National Park to help them plan their trip. Results showed that different user groups (i.e., day boat, kayakers, etc.) used different sources of information. Forty-six percent of all visitors used word-of-mouth as a source of information. Similarly, other websites were used commonly by most visitor groups (46\%), with the exception of residents. The GBNP website (57\%), maps, brochures and pamphlets (47\%), and travel guides/tour books (35\%) were some of the more commonly used sources. Independent backcountry visitors and independent boaters both used visitor centers as a source more than other visitor groups ( $41 \%$ and $44 \%$ respectively). Both charter and tour vessel visitors used packaged tour or guiding company sources more frequently than any other visitor, at $80 \%$ and $62 \%$ respectively. To be expected, residents used previous visits most often (82\%), and more than any other visitor group. Radio/TV and printed articles were the least utilized sources by all populations. See Appendix A for further details by population.

When asked how long visitors planned on staying in the park, $27 \%$ said they were only staying one day, but their visit was quite long, averaging over 10 hours. Those who planned on staying multiple days were staying an average of five days in Glacier Bay National Park (Table 6). 
Table 6. The amount of time planned for GBNP visit.

\begin{tabular}{lrrr}
\hline Visit Duration & Frequency & Percent $^{1}$ & Mean \\
\hline One-day visit & 114 & 26.7 & 10.6 (hours) $^{2}$ \\
Multi-day visit & 313 & 73.3 & 5.4 (days) $^{3}$ \\
\hline
\end{tabular}

$\mathrm{N}=427$, excluding residents.

${ }^{1}$ Based on valid data only.

${ }^{2}$ Average number of hours.

${ }^{3}$ Average number of days.

Respondents were asked how they traveled to Glacier Bay National Park (Table 7), and the most common mode of transportation was the commercial jet flight to Gustavus (54\%). The next most common mode of travel was smaller (i.e., less than 12 passengers) tour/charter boats $(23 \%)$ and the Alaska Marine Highway System Ferry (21\%). It is important to keep in mind that these data represent our sample, which is largely composed of people on the day boat, tour vessels, and independent backcountry visitors.

Table 7. Transportation to GBNP.

\begin{tabular}{lcr}
\hline Transportation Mode & Frequency $^{1}$ & Percentage $^{2}$ \\
\hline Commercial Flight to Gustavus & 238 & 54.34 \\
Tour/Charter Boat >12 passengers & 102 & 23.29 \\
Alaska Marine Highway System & 91 & 20.78 \\
Ferry & & \\
Personal Vehicle & 23 & 5.25 \\
Personal Motor Boat & 15 & 3.42 \\
Tour/Charter Boat <12 passengers & 5 & 1.14 \\
Other: & 39 & 8.90 \\
Private/Charter Aircraft & 6 & 1.37 \\
Bicycle & 2 & 0.46 \\
Taxi/Shuttle/Bus & 22 & 5.02 \\
Rental Car & 1 & 0.28 \\
Private Charter from Gustavus & 1 & 0.46 \\
Private Sail Boat & 5 & 0.28 \\
Flight to Sitka/Juneau & 2 & 1.14 \\
\hline N & & \\
\hline
\end{tabular}

$\mathrm{N}=438$, excluding residents.

${ }^{1}$ Values are greater than $\mathrm{N}$ because individuals could choose all transportation types that applied.

2 Based on valid data only. 
Over half (61\%) of respondents reported they planned their trip to Glacier Bay National Park "carefully," while over a quarter (28\%) said they did "some pre-planning" before arriving in the park and $11 \%$ said they minimally planned (Table 8 ). Many respondents from the tour vessels commented on their survey that their National Park visit was part of a package and was, therefore, already planned for them. Others, like independent backcountry visitors (on average), put a great deal more effort into planning their visit to Glacier Bay.

Table 8. How carefully the trip was planned.

\begin{tabular}{lrr}
\hline Level of Planning & Frequency & Percent $^{1}$ \\
\hline Carefully planned & 265 & 61.3 \\
Some pre-planning & 119 & 27.5 \\
Minimal planning & 48 & 11.1 \\
\hline N $=432$, excluding residents. & & \\
${ }^{1}$ Based on valid data only. & &
\end{tabular}

Thirty-six percent of respondents said they planned to use an outfitter or guide during their visit to GBNP, while the majority (64\%) said they were not. When asked if they were going to rent equipment from an outfitter, $26 \%$ said they would, while the majority said they were not (64\%). Table 9 presents the number of respondents that planned on using a guide and respondents that planned on renting equipment during their visit to Glacier Bay National Park.

Table 9. Use of a paid guide and equipment rental.

\begin{tabular}{llrr}
\hline Guides and Rentals & Response & Frequency & Percent $^{1}$ \\
\hline Use of guide $^{2}$ & Yes & 154 & 35.7 \\
& No & 277 & 64.3 \\
Rented equipment $^{3}$ & Yes & 111 & 26.0 \\
& No & 316 & 74.0 \\
\hline
\end{tabular}

\footnotetext{
${ }^{1}$ Based on valid data only, excludes residents.

$2 \mathrm{~N}$ for Use of Guides $=431$.

${ }^{3} \mathrm{~N}$ for Rented Equipment $=427$.
}

Additionally, respondents were asked if they knew where they wanted to camp and/or anchor during their visitor to GBNP (Table 10), and 48\% said they did, while others said they did not (52\%). Although this was asked to all visitors within the sample, visitors outside of independent backcountry and boaters rarely camp during their visit. Of the independent backcountry sample, $75 \%$ said they knew where they planned to camp/anchor, while $25 \%$ said they did not know. For independent boaters, $77.8 \%$ said they knew where they planned to camp/anchor, while $22.2 \%$ said they did not. 
Table 10. Know plans for camp/anchor during visit.

\begin{tabular}{llrr}
\hline Visitor Type & Response & Frequency & Percent $^{1}$ \\
\hline Total Population $^{2}$ & Yes & 178 & 48.4 \\
& No & 190 & 51.6 \\
Independent Backcountry Visitors $^{3}$ & Yes & 48 & 75.0 \\
& No & 16 & 25.0 \\
Independent Boaters $^{4}$ & Yes & 14 & 77.8 \\
& No & 4 & 22.2 \\
\hline${ }^{1}$ Based on valid data only. & & & \\
${ }^{2} \mathrm{~N}$ for total population $=368$, excluding residents. & & \\
${ }^{3} \mathrm{~N}$ for Independent Backcountry Visitors $=68$. & & \\
${ }^{4} \mathrm{~N}$ for Independent Boaters $=18$. & &
\end{tabular}

To gain a better understanding of where respondents were planning on going during their backcountry visit, a map was provided to respondents (Figure 7) and they were asked to identify areas they planned on visiting (Table 11). Many respondents planned on visiting the West Arm (79\%), Mid Bay (73\%), and the Lower Bay (69\%), which seems fitting, as these are the main travel corridors of Glacier Bay. The areas where most respondents had not planned on visiting included the Outer Coast (64\%), Dundas Bay and Taylor Bay/Fern Harbor (63\%), and the Inland areas of the park (61\%). Other areas respondents did not plan on visiting were the Beardslee Islands (55\%), and nonmotorized waters of Glacier Bay. Half said they did not plan on visiting the East Arm (51\%). Another important note is that a large portion of our sample included those riding the day boat, which operates on a planned route that includes the West Arm (not the East Arm). 


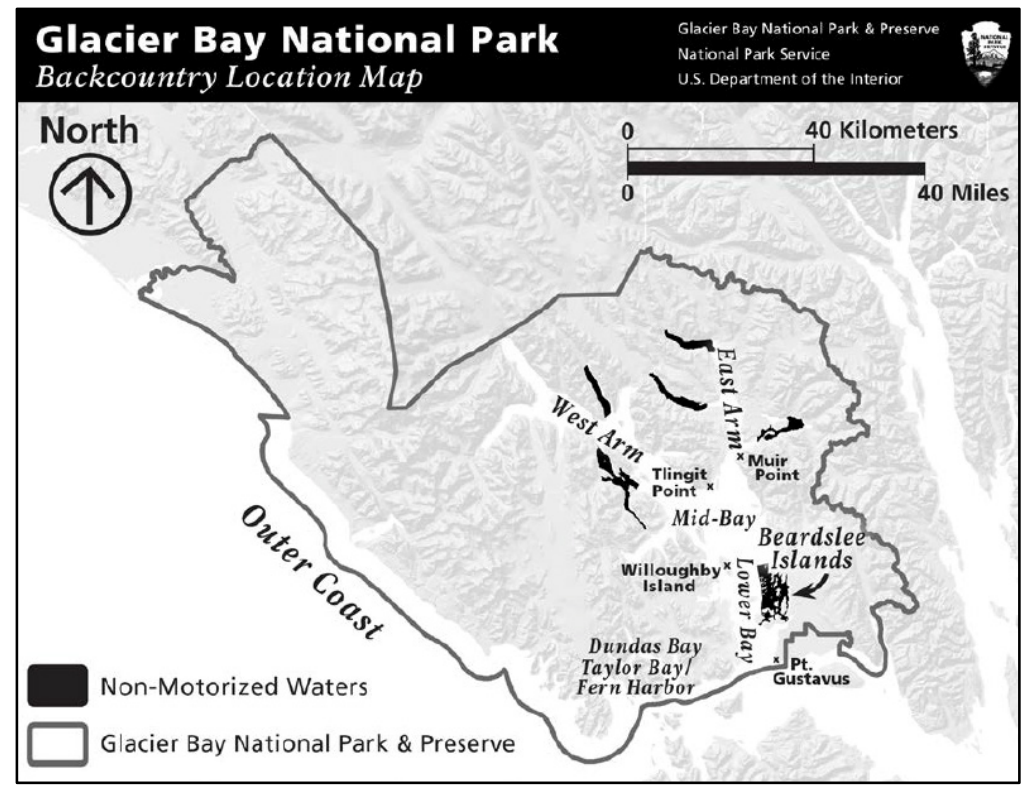

Figure 7. Backcountry location map provided to visitors in 2017 survey for reference to the following question (Table 11).

Table 11. Areas respondents planned on visiting during their trip into the backcountry.

\begin{tabular}{|c|c|c|c|c|c|c|}
\hline \multirow[b]{2}{*}{ Backcountry Area } & \multicolumn{2}{|c|}{ Yes } & \multicolumn{2}{|c|}{ No } & \multicolumn{2}{|c|}{ Not Sure } \\
\hline & Frequency & Percent $^{1}$ & Frequency & Percent $^{1}$ & Frequency & Percent $^{1}$ \\
\hline $\begin{array}{l}\text { West Arm Glacier Bay } \\
\text { (Northwest of Tlingit Point) }\end{array}$ & 337 & 78.9 & 36 & 8.4 & 54 & 12.6 \\
\hline $\begin{array}{l}\text { Mid Bay (Willoughby Island North } \\
\text { of Tlingit Point and Muir Point) }\end{array}$ & 307 & 72.6 & 56 & 13.2 & 60 & 14.2 \\
\hline $\begin{array}{l}\text { Lower Bay (North of Pt. } \\
\text { Gustavus, South of Willoughby } \\
\text { Island, and excluding the } \\
\text { Beardslee Islands) }\end{array}$ & 293 & 69.1 & 70 & 16.5 & 61 & 14.4 \\
\hline $\begin{array}{l}\text { Non-motorized waters of Glacier } \\
\text { Bay }\end{array}$ & 87 & 22.0 & 216 & 54.7 & 92 & 23.3 \\
\hline Beardslee Islands & 72 & 18.1 & 218 & 54.8 & 108 & 27.1 \\
\hline $\begin{array}{l}\text { East Arm Glacier Bay (North of } \\
\text { Muir Point) }\end{array}$ & 59 & 14.9 & 201 & 50.9 & 135 & 34.2 \\
\hline $\begin{array}{l}\text { Inland areas of the park (more } \\
\text { than on mile inland from the } \\
\text { shoreline) }\end{array}$ & 41 & 10.5 & 241 & 61.8 & 108 & 27.7 \\
\hline
\end{tabular}

$\mathrm{N}=472$

${ }^{1}$ Based on valid data only, invalid data ranged per location. 
Table 11 (continued). Areas respondents planned on visiting during their trip into the backcountry.

\begin{tabular}{lcccccc}
\hline & \multicolumn{2}{c}{ Yes } & \multicolumn{2}{c}{ No } & \multicolumn{2}{c}{ Not Sure } \\
\cline { 2 - 7 } Backcountry Area & Frequency & Percent $^{1}$ & Frequency & Percent $^{1}$ & Frequency $^{\text {Percent }^{1}}$ \\
\hline Outer Coast & 29 & 7.3 & 254 & 64.0 & 114 & 28.7 \\
$\begin{array}{l}\text { Dundas Bay, Taylor Bay/Fern } \\
\text { Harbor }\end{array}$ & 20 & 5.1 & 250 & 63.3 & 125 & 31.6 \\
Other Location(s) & 7 & 7.0 & 68 & 68.0 & 25 & 25.0 \\
\hline
\end{tabular}

$\mathrm{N}=472$

${ }^{1}$ Based on valid data only, invalid data ranged per location.

There was interest in knowing how a trip to Glacier Bay National Park fit into respondents' overall trip plans. For example, was GBNP their primary destination or was it one of several destinations? Although $28 \%$ of respondents said GBNP was their primary destination, around $72 \%$ had planned their visit to GBNP as one of several places they intended to visit during their overall trip (Table 12). Twenty percent of sampled visitors were traveling via tour vessel (Figure 5), so it can be expected that GBNP was only part of a larger trip.

Table 12. GBNP fit into overall plans.

\begin{tabular}{lrr}
\hline Reason for Visit & Frequency & Percent $^{1}$ \\
\hline One of Several Destinations & 327 & 71.9 \\
Primary Destination & 128 & 28.1 \\
\hline $\mathrm{N}=455$ & & \\
${ }^{1}$ Based on valid data only, invalid data $=17$. & &
\end{tabular}

To gauge planned recreational activities among visitors, a pre-formatted question asked respondents to choose their primary and secondary activity (Table 13). The most common primary activity was viewing tidewater glaciers (41\%), followed by observing nature and wildlife (20\%) and kayaking in the backcountry (16\%). Respondents were able to choose multiple secondary activities. The most common secondary activities were observing nature and wildlife (32.6\%), hiking/walking on trails in Bartlett Cove (32\%), hiking/walking on backcountry beaches $(25 \%)$, and viewing tidewater glaciers (24\%). Overall, seeing tidewater glaciers was the most common primary activity respondents planned during their visit to GBNP. 
Table 13. Planned recreational activities in GBNP.

\begin{tabular}{|c|c|c|c|c|}
\hline \multirow[b]{2}{*}{ Planned Activity } & \multicolumn{2}{|c|}{ Primary choice ${ }^{1}$} & \multicolumn{2}{|c|}{ Secondary choice ${ }^{2}$} \\
\hline & Frequency & Percent & Frequency & Percent \\
\hline Viewing tidewater glaciers & 124 & 40.7 & 114 & 24.2 \\
\hline Nature/Wildlife observation & 62 & 20.3 & 154 & 32.6 \\
\hline Kayaking in the backcountry & 49 & 16.1 & 40 & 8.5 \\
\hline Other & 14 & 4.6 & 7 & 1.5 \\
\hline $\begin{array}{l}\text { Hiking/Walking on developed trails in Bartlett } \\
\text { Cove }\end{array}$ & 10 & 3.3 & 151 & 32.0 \\
\hline Motor boating & 10 & 3.3 & 26 & 5.5 \\
\hline Kayaking in Bartlett Cove & 8 & 2.6 & 69 & 14.6 \\
\hline Hiking/Walking on backcountry beaches & 6 & 2.0 & 120 & 25.4 \\
\hline Recreational fishing (saltwater) & 6 & 2.0 & 47 & 10.0 \\
\hline $\begin{array}{l}\text { Hiking/Walking in backcountry upland/alpine } \\
\text { areas }\end{array}$ & 5 & 1.6 & 63 & 13.3 \\
\hline Camping in the backcountry & 4 & 1.3 & 51 & 10.8 \\
\hline Sail boating & 2 & .7 & 8 & 1.7 \\
\hline Recreational fishing (freshwater) & 2 & .7 & 20 & 4.2 \\
\hline Flightseeing (overflight) & 2 & .7 & 28 & 5.9 \\
\hline Walking on glaciers/technical mountaineering & 1 & .3 & 27 & 5.7 \\
\hline Camping in Bartlett Cove & 0 & 0 & 36 & 7.6 \\
\hline
\end{tabular}

${ }^{1} \mathrm{~N}$ for Primary Choice $=305$. Based on valid data only, invalid data for primary choice $=167$.

$2 \mathrm{~N}$ for Secondary Choice $=472$. Values are greater than sample size because individuals could choose more than one activity.

Respondents were asked to choose their primary and secondary modes of transportation upon arrival to Glacier Bay National Park (Table 14). Because GBNP is largely a water-based park, it was not surprising that tour and charter boats were the most common primary mode of transportation inside the park (56\%). Hiking/walking was the second most common (18\%) of the primary modes of transportation, followed by kayaking (rented $=12 \%$, and personal $=5 \%$ ). The most common secondary mode of transportation was hiking/walking (42\%), followed by tour and charter boats (21\%), and kayaking (15\%). Keep in mind that data presented in Table 14 are not representative of all GBNP, but reflect only our sample, largely composed of people riding the day boat and independent backcountry visitors. 
Table 14. Planned transportation use in GBNP.

\begin{tabular}{lrrrr}
\hline & \multicolumn{2}{c}{ Primary choice ${ }^{1}$} & \multicolumn{2}{c}{ Secondary choice $^{2}$} \\
\cline { 2 - 5 } Transportation Mode & Frequency & Percent & Frequency & Percent \\
\hline Tour boat/Charter boat & 202 & 56.3 & 91 & 20.8 \\
Hiking/Walking & 65 & 18.1 & 187 & 42.7 \\
Kayaking (rental kayak) & 42 & 11.7 & 64 & 14.6 \\
Kayaking (personal kayak) & 19 & 5.3 & 20 & 4.6 \\
Personal motor boat & 15 & 4.2 & 9 & 2.1 \\
Air taxi/Charter & 5 & 1.4 & 24 & 5.5 \\
Personal sail boat & 5 & 1.4 & 5 & 1.1 \\
Other & 5 & 1.4 & 6 & 1.4 \\
Personal aircraft & 1 & .3 & 8 & 1.8 \\
Pack raft or other non-motorized vessel & 0 & 0 & 9 & 2.1 \\
(besides kayak) & & & & \\
\hline
\end{tabular}

${ }^{1} \mathrm{~N}$ for Primary Choice $=359$. Based on valid data only, invalid data for primary choice $=79$. Excludes residents as to not skew results.

${ }^{2} \mathrm{~N}$ for Secondary Choice $=438$.

\section{Leave-No-Trace Knowledge}

Visitors were asked how familiar they were with Leave-No-Trace practices, and many said they had "expert" knowledge of the practices, followed by nearly the same (46\%) saying they had intermediate knowledge. Only 14\% said they were a "novice" regarding Leave-No-Trace practices (Table 15).

Table 15. Self-reported visitor knowledge of Leave-No-Trace practices.

\begin{tabular}{lrr}
\hline Visitor Knowledge & Frequency & Percent $^{1}$ \\
\hline Novice & 63 & 13.9 \\
Intermediate & 207 & 45.7 \\
Expert & 183 & 40.4 \\
\hline \multicolumn{1}{c}{$\mathrm{N}=453$} & & \\
${ }^{1}$ Based on valid data only, invalid data $=19$. & &
\end{tabular}

\section{Motivations}

A mixed-method approach was used to understand what motivated visitors to recreate in Glacier Bay National Park (Furr, 2019). This included using open-ended questions, as well as a measurement tool developed by Driver and colleagues (1983). 
To explore factors that motivate visitation within GBNP, respondents were asked what the overall purpose of their trip was using an open-ended format. In order to analyze this data, the responses were coded based on common themes (i.e., wildlife, glaciers, boat trip) or theoretical concepts (i.e., solitude, escape, adventure). For a more detailed description of the coding structure, refer to Appendix C.

Respondents reported their overall purpose for visiting GBNP (Table 16). Each respondent was asked to list up to three factors that contributed to their overall trip purpose (which is why the overall percentage is greater than $100 \%)$. Viewing wildlife (53\%) and experiencing glaciers (44\%) were the most common responses, while $15 \%$ of the population reported exploring, spending time with family and friends, or experiencing wilderness as their overall purpose. Less common factors reported include viewing scenic beauty (11\%), opportunities to experience nature $(10 \%)$, and experiencing Alaska (10\%). Other factors $(15 \%)$ not reported in the table include any response category that did not reach $>2.5 \%$ of the whole. These factors include motivations such as recreation $(2.3 \%)$, work $(1.6 \%)$, to experience culture $(0.9 \%)$, geology $(0.7 \%)$ and finding solace $(0.2 \%)$.

Table 16. Open-ended responses for the total population's overall purpose for visitation.

\begin{tabular}{|c|c|c|}
\hline Purpose of Visit & Frequency $^{1}$ & Total Response $\%^{1,2}$ \\
\hline View wildlife & 231 & 52.62 \\
\hline Experience glaciers & 193 & 43.96 \\
\hline To explore & 68 & 15.49 \\
\hline Time with family/friends & 67 & 15.26 \\
\hline Experience wilderness & 66 & 15.03 \\
\hline Scenic beauty & 48 & 10.93 \\
\hline Experience nature & 45 & 10.25 \\
\hline Unique Alaska experience & 42 & 9.57 \\
\hline To escape & 39 & 8.88 \\
\hline Have an adventure & 36 & 8.20 \\
\hline Kayaking & 36 & 8.20 \\
\hline National Park visit & 31 & 7.06 \\
\hline Part of larger tour & 28 & 6.38 \\
\hline Solitude & 27 & 6.15 \\
\hline Experience via boat tour & 18 & 4.10 \\
\hline
\end{tabular}


Table 16 (continued). Open-ended responses for the total population's overall purpose for visitation.

\begin{tabular}{lrr}
\hline Purpose of Visit & Frequency $^{1}$ & Total Response \% $^{\mathbf{1 , 2}}$ \\
\hline Fishing & 16 & 3.64 \\
To learn & 16 & 3.64 \\
Sightseeing & 16 & 3.64 \\
Hiking/Walking & 15 & 3.42 \\
Photography & 13 & 2.96 \\
Relaxation & 13 & 2.96 \\
\hline
\end{tabular}

$\mathrm{N}=439$

${ }^{1}$ Frequencies and percentages exceed $100 \%$ because multiple answers could be given per survey.

${ }^{2}$ Reported percentages refer to concepts that were conveyed by $>2.5 \%$ of the population.

To provide a better understanding of motivations among different user groups, responses were separated by user group for both independent backcountry visitors and day boat passengers.

Although many motivations were relatively similar between populations, there were a few slight differences. Both visitor groups reported wildlife ( $>50 \%)$ most frequently (Table 1differences. Both visitor groups reported wildlife ( $>50 \%$ ) most frequently (Table 17-18). Independent 8 ). Independent backcountry users reported kayaking (34\%), experiencing wilderness (29\%), and spending time with family and friends (26\%) more often than other factors (Table 17). Viewing or experiencing glaciers was reported less often among independent backcountry visitors than day boat passengers. Visitors traveling via day boat reported viewing wildlife (58\%) and experiencing glaciers $(53 \%)$ as the highest factors for their overall trip purpose, while 11\% reported one of their purposes was solely based on Glacier Bay being a National Park (Table 18).

Table 17. Open-ended responses for independent backcountry visitors' overall purpose for visitation.

\begin{tabular}{lcc}
\hline Purpose of Visit & Frequency $^{\mathbf{1}}$ & ${\text { Total Response } \mathbf{\%}^{\mathbf{1 , 2}}}$ \\
\hline Viewing wildlife & 33 & 50.77 \\
Kayaking & 22 & 33.85 \\
Experience wilderness & 19 & 29.23 \\
Time with family/friends & 17 & 26.15 \\
Experiencing glaciers & 15 & 23.08 \\
Have an adventure & 13 & 20.00 \\
Solitude & 11 & 16.92 \\
\hline $\mathrm{N}=65$ & & \\
1 Frequencies and percentages exceed $100 \%$ because multiple answers could be given per survey. \\
2 Reported percentages refer to concepts that were conveyed by $>2.5 \%$ of the population.
\end{tabular}


Table 17 (continued). Open-ended responses for independent backcountry visitors' overall purpose for visitation.

\begin{tabular}{|c|c|c|}
\hline Purpose of Visit & Frequency ${ }^{1}$ & Total Response $\% 1$ \\
\hline Experience nature & 11 & 16.92 \\
\hline To explore & 10 & 15.38 \\
\hline Scenic beauty & 9 & 13.85 \\
\hline To escape & 9 & 13.85 \\
\hline Overall experience & 5 & 7.69 \\
\hline Photography & 3 & 4.62 \\
\hline Remoteness & 2 & 3.08 \\
\hline To learn & 2 & 3.08 \\
\hline Camping & 2 & 3.08 \\
\hline
\end{tabular}

$N=65$

${ }^{1}$ Frequencies and percentages exceed $100 \%$ because multiple answers could be given per survey.

${ }^{2}$ Reported percentages refer to concepts that were conveyed by $>2.5 \%$ of the population.

Table 18. Open-ended responses for day boat passengers' overall purpose for visitation.

\begin{tabular}{lrr}
\hline Purpose of Visit & Frequency $^{1}$ & ${\text { Total Response } \text { \% }^{1,2}}$ \\
\hline Viewing wildlife & 142 & 57.96 \\
Experiencing glaciers & 130 & 53.06 \\
To explore & 49 & 20.00 \\
Time with family/friends & 34 & 13.88 \\
Overall experience & 30 & 12.24 \\
Experience wilderness & 28 & 11.43 \\
Experience nature & 28 & 11.43 \\
National Park visit & 27 & 11.02 \\
Scenic beauty & 23 & 9.39 \\
Have an adventure & 13 & 5.31 \\
Experience via boat tour & 12 & 4.90 \\
Sightseeing & 11 & 4.49 \\
Hiking/Walking & 11 & 4.49 \\
\hline
\end{tabular}

$N=245$

${ }^{1}$ Frequencies and percentages exceed $100 \%$ because multiple answers could be given per survey.

2 Reported percentages refer to concepts that were conveyed by $>2.5 \%$ of the population. 
Table 18 (continued). Open-ended responses for day boat passengers' overall purpose for visitation.

\begin{tabular}{lrr}
\hline Purpose of Visit & Frequency $^{1}$ & Total Response ${ }^{1{ }^{1,2}}$ \\
\hline Solitude & 10 & 4.08 \\
Photography & 10 & 4.08 \\
Fishing & 10 & 4.08 \\
Kayaking & 9 & 3.67 \\
Remoteness & 7 & 2.86 \\
Relaxation & 7 & 2.86 \\
To learn & 7 & 2.86 \\
\hline \multicolumn{1}{c}{$\mathrm{N}=245$} & & \\
$\quad{ }^{1}$ Frequencies and percentages exceed $100 \%$ because multiple answers could be given per survey. \\
${ }^{2}$ Reported percentages refer to concepts that were conveyed by $>2.5 \%$ of the population.
\end{tabular}

Respondents were then asked to report what backcountry experiences they sought in Glacier Bay. Visitors reported similar answers to the previous question regarding the overall purpose of their trip. Common responses for the total population (Table 19) included wildlife (58\%), experiencing glaciers (31\%), scenic beauty (20\%) and wilderness $(20 \%)$. When responses were separated by population, both independent backcountry visitors and day boat passengers responded with viewing wildlife most frequently, 59\% and $65 \%$ respectively. Independent backcountry responses included wilderness (31\%), solitude (28\%) and having an adventure (26\%) as other highly important elements sought during their experience (Table 20). Day boat passenger responses included experiencing glaciers (39\%), scenic beauty (20\%) and observing nature (15\%) as highly important elements of their guided, motorized experience (Table 21).

Table 19. Open-ended responses for what the total population is seeking during their experience.

\begin{tabular}{lcc}
\hline Experiences Sought & Frequency $^{\mathbf{1}}$ & Total Response \% $^{\mathbf{1 , 2}}$ \\
\hline Viewing wildlife & 198 & 57.56 \\
Experiencing glaciers ${ }^{3}$ & 107 & 31.10 \\
Scenic beauty & 70 & 20.35 \\
Experience wilderness & 69 & 20.06 \\
Solitude & 48 & 13.95 \\
Experience nature & 46 & 13.37 \\
\hline N = 344 & \\
${ }^{1}$ Frequencies and percentages exceed 100\% because multiple answers could be given per survey. \\
${ }^{2}$ Reported percentages refer to concepts that were conveyed by >2.5\% of the population. \\
${ }^{3}$ Experiencing glaciers general category includes 4\% wanting to witness calving specifically.
\end{tabular}


Table 19 (continued). Open-ended responses for what the total population is seeking during their experience.

\begin{tabular}{lrr}
\hline Experiences Sought & Frequency $^{{ }^{1}}$ & ${\text { Total Response } \text { \% }^{1,2}}$ \\
\hline Unique Alaskan experience & 28 & 11.43 \\
To learn & 32 & 9.30 \\
Hiking/Walking & 29 & 8.43 \\
Have an adventure & 28 & 8.14 \\
Natural quiet & 24 & 6.98 \\
Kayaking & 23 & 6.69 \\
To escape & 18 & 5.23 \\
Time with family/friends & 17 & 4.94 \\
Experience via boat tour & 16 & 4.65 \\
Nature immersion & 15 & 4.36 \\
To explore & 13 & 3.78 \\
Connection to nature & 11 & 3.20 \\
\hline
\end{tabular}

$N=344$

${ }^{1}$ Frequencies and percentages exceed $100 \%$ because multiple answers could be given per survey.

${ }^{2}$ Reported percentages refer to concepts that were conveyed by $>2.5 \%$ of the population.

${ }^{3}$ Experiencing glaciers general category includes $4 \%$ wanting to witness calving specifically.

Table 20. Open-ended responses for what independent backcountry visitors are seeking during their experience.

\begin{tabular}{|c|c|c|}
\hline Experiences Sought & Frequency ${ }^{1}$ & Total Response $\%^{1,2}$ \\
\hline Viewing wildlife & 36 & 59.02 \\
\hline Experience wilderness & 19 & 31.15 \\
\hline Solitude & 17 & 27.87 \\
\hline Have an adventure & 16 & 26.23 \\
\hline Experiencing glaciers $^{3}$ & 15 & 24.59 \\
\hline Scenic beauty & 14 & 22.95 \\
\hline Kayaking & 12 & 19.67 \\
\hline Natural quiet & 9 & 14.75 \\
\hline
\end{tabular}

$\mathrm{N}=61$

${ }^{1}$ Frequencies and percentages exceed $100 \%$ because multiple answers could be given per survey.

${ }^{2}$ Reported percentages refer to concepts that were conveyed by $>2.5 \%$ of the population.

${ }^{3}$ Experiencing glaciers general category includes $2 \%$ wanting to witness calving specifically. 
Table 20 (continued). Open-ended responses for what independent backcountry visitors are seeking during their experience.

\begin{tabular}{lrr}
\hline Experiences Sought & Frequency $^{1}$ & Total Response $^{\text {\% }^{1,2}}$ \\
\hline Experience nature & 9 & 14.75 \\
Unique Alaskan experience & 9 & 14.75 \\
Time with family/friends & 6 & 9.84 \\
To escape & 6 & 9.84 \\
Nature immersion & 5 & 8.20 \\
To explore & 4 & 6.56 \\
Photography & 2 & 3.28 \\
To learn & 2 & 3.28 \\
Connection to nature & 2 & 3.28 \\
\hline
\end{tabular}

$\mathrm{N}=61$

${ }^{1}$ Frequencies and percentages exceed $100 \%$ because multiple answers could be given per survey.

${ }^{2}$ Reported percentages refer to concepts that were conveyed by $>2.5 \%$ of the population.

${ }^{3}$ Experiencing glaciers general category includes $2 \%$ wanting to witness calving specifically.

Table 21. Open-ended responses for what day boat passengers are seeking during their experience.

\begin{tabular}{lrr}
\hline Experiences Sought & Frequency $^{1}$ & Total Response $^{\text {\% }^{1,2}}$ \\
\hline Viewing wildlife & 115 & 65.34 \\
Experiencing glaciers $^{3}$ & 69 & 39.20 \\
Scenic beauty & 36 & 20.45 \\
Experience nature & 27 & 15.34 \\
Unique Alaskan experience & 21 & 11.93 \\
Hiking/Walking & 20 & 11.36 \\
Experience wilderness & 19 & 10.80 \\
To learn & 18 & 10.23 \\
Solitude & 15 & 8.52 \\
\hline
\end{tabular}

$\mathrm{N}=176$

${ }^{1}$ Frequencies and percentages exceed $100 \%$ because multiple answers could be given per survey.

${ }^{2}$ Reported percentages refer to concepts that were conveyed by $>2.5 \%$ of the population.

${ }^{3}$ Experiencing glaciers general category includes $6 \%$ wanting to witness calving specifically. 
Table 21 (continued). Open-ended responses for what day boat passengers are seeking during their experience.

\begin{tabular}{lrr}
\hline Experiences Sought & Frequency $^{1}$ & Total Response $^{\mathbf{\%}^{\mathbf{1 , 2}}}$ \\
\hline Experience via boat tour & 13 & 7.39 \\
Natural quiet & 6 & 3.41 \\
Time with family/friends & 6 & 3.41 \\
Nature immersion & 6 & 3.41 \\
Kayaking & 5 & 2.84 \\
To escape & 5 & 2.84 \\
Fishing & 5 & 2.84 \\
Photography & 5 & 2.84 \\
\hline
\end{tabular}

$N=176$

${ }^{1}$ Frequencies and percentages exceed $100 \%$ because multiple answers could be given per survey.

${ }^{2}$ Reported percentages refer to concepts that were conveyed by $>2.5 \%$ of the population.

${ }^{3}$ Experiencing glaciers general category includes $6 \%$ wanting to witness calving specifically.

Visitors expected to see bears (83\%), whales (88\%), and a variety of bird species during their trip to Glacier Bay. About half expected to see moose (57\%), mountain goats (44.7\%), and a variety of small mammals (65\%). A quarter of visitors expected to see wolves (27\%) (Table 22).

Table 22. Wildlife that visitors expected to see during their visit.

\begin{tabular}{lcr}
\hline Expected Wildlife Viewing & Frequency $^{1}$ & Percent $^{2}$ \\
\hline Whales & 416 & 88.1 \\
Bears & 393 & 83.3 \\
Birds & 389 & 82.4 \\
Small Mammals & 306 & 64.8 \\
Moose & 272 & 57.6 \\
Mountain Goats & 211 & 44.7 \\
Wolves & 126 & 26.7 \\
\hline
\end{tabular}

$\mathrm{N}=472$

${ }^{1}$ Values are greater than sample size because individuals could choose more than one choice for expected wildlife.

2 Based on valid data only. 
Table 22 (continued). Wildlife that visitors expected to see during their visit.

\begin{tabular}{lrr}
\hline Expected Wildlife Viewing & Frequency $^{1}$ & Percent $^{2}$ \\
\hline Other & 61 & 12.9 \\
Sea Otters & 34 & 7.2 \\
Harbor Seals & 25 & 5.3 \\
Sea Lions & 19 & 4.0 \\
Porpoises & 8 & 1.7 \\
\hline
\end{tabular}

$\mathrm{N}=472$

${ }^{1}$ Values are greater than sample size because individuals could choose more than one choice for expected wildlife.

${ }^{2}$ Based on valid data only.

A series of 29 questions were used to understand visitor motivations and desired experiences while visiting the backcountry of GBNP. A principal component analysis (PCA) with varimax rotation was conducted (Table 23) to reduce the dataset to a smaller number of more interpretable themes (Furr, 2019). The 29-items included in the visitor experience scale were reduced to eight constructs reflecting visitors' motivations for visiting the park and accounted for $62.9 \%$ of the variability in the data. All variables were included in the analysis as each had a factor loading of .4 or above. A Cronbach's alpha test on the resulting constructs suggests acceptable reliability throughout (Vaske, 2008). Initially, the factor that explained $19.86 \%$ of the variance in the data was the category "Alaskan wilderness experience;" however, this factor was separated into two distinct factors for a more specific interpretation.

Due to high factor loadings for "To experience solitude," "To experience natural sound," and "To be away from crowds," Factor 1 was interpreted as Solitude and Natural Sounds. Factor 2 has high loadings for "To experience psychological renewal" and "To experience a spiritual connection to nature," leading to an interpretation of Natural Connection and Renewal. Loadings of the variables "To share an experience with other people" and "To experience risk" lead to Factor 3, Adventure. Factor 4 was interpreted as Learning due to high loadings on the variables "To learn about the plants and wildlife in Glacier Bay National Park" and "To learn about nature conservation and preservation values in the park." Factor 5 was interpreted as Experience Glaciers, with loadings of "To experience a recently glaciated, dynamic landscape," "To view glaciers," and "To view scenic beauty." Loadings of variables "To fish for sport" and "To catch fish to eat" were joined into Factor 6, interpreted as Fishing. Factor 7 was termed Guided Wilderness Experience due to high factor loadings on "To view/photograph wildlife" and "To be near others who could help if you needed." Lastly, high loadings of the variables "To be in control of things that happen" and "To be where things are fairly safe" resulted in Factor 8 interpreted as Safety. All factors accounted for $62.9 \%$ of the variability in the data. 
Table 23. Factor analysis, reliability results and scale means for visitor experience scale.

\begin{tabular}{|c|c|c|c|c|c|c|}
\hline Factors and Scale Items & $\begin{array}{r}\text { Rotated Factor } \\
\text { Loadings }\end{array}$ & Mean Scores & $\begin{array}{l}\text { Item Total } \\
\text { Correlation }\end{array}$ & $\begin{array}{r}\text { Cronbach's } \\
\text { Alpha }\end{array}$ & Eigenvalue & $\begin{array}{r}\% \text { of Variation } \\
\text { (cumulative) }\end{array}$ \\
\hline Alaskan Wilderness Experience ${ }^{1}$ & - & - & - & - & 5.769 & 19.86 \\
\hline Solitude/Natural Sounds & - & - & - & .836 & - & - \\
\hline To experience solitude & .800 & 3.36 & .70 & - & - & - \\
\hline To experience natural quiet & .786 & 3.89 & .68 & - & - & - \\
\hline To enjoy the sounds of nature & .699 & 3.98 & .63 & - & - & - \\
\hline To be away from crowds of people & .733 & 3.76 & .67 & - & - & - \\
\hline Natural Connection/Renewal & - & - & - & .858 & - & - \\
\hline To experience psychological renewal & .725 & 2.88 & .73 & - & - & - \\
\hline To be self-reliant in wilderness & .500 & 2.36 & .53 & - & - & - \\
\hline To be in touch with my spiritual values & .709 & 2.60 & .69 & - & - & - \\
\hline To experience a sense of connection w/nature & .689 & 4.11 & .64 & - & - & - \\
\hline To feel small in a vast landscape & .617 & 3.35 & .63 & - & - & - \\
\hline To experience a spiritual connection w/nature & .735 & 3.07 & .72 & - & - & - \\
\hline To experience a positive change in mood/emotion & .400 & 2.59 & .51 & - & - & - \\
\hline
\end{tabular}

${ }^{1}$ Overall factor includes Solitude/Natural Sounds and Natural Connection/ Renewal. 
Table 23 (continued). Factor analysis, reliability results and scale means for visitor experience scale.

\begin{tabular}{|c|c|c|c|c|c|c|}
\hline Factors and Scale Items & $\begin{array}{r}\text { Rotated Factor } \\
\text { Loadings }\end{array}$ & Mean Scores & $\begin{array}{l}\text { Item Total } \\
\text { Correlation }\end{array}$ & $\begin{array}{r}\text { Cronbach's } \\
\text { Alpha }\end{array}$ & Eigenvalue & $\begin{array}{r}\% \text { of Variation } \\
\text { (cumulative) }\end{array}$ \\
\hline Adventure & - & - & - & .750 & 2.727 & 29.26 \\
\hline To be self-reliant in wilderness & .514 & 2.36 & .54 & - & - & - \\
\hline To experience risk & .621 & 1.99 & .54 & - & - & - \\
\hline To experience a sense of challenge & .558 & 3.12 & .42 & - & - & - \\
\hline To share an experience with other people & .755 & 2.79 & .54 & - & - & - \\
\hline To experience a positive change in mood/emotion & .528 & 2.59 & .50 & - & - & - \\
\hline $\begin{array}{l}\text { To experience wildlife to have a memorable story to } \\
\text { tell others }\end{array}$ & .583 & 3.21 & .39 & - & - & - \\
\hline Learning & - & - & - & .782 & 2.565 & 37.76 \\
\hline $\begin{array}{l}\text { To learn about the history and cultural significance of } \\
\text { Glacier Bay National Park }\end{array}$ & .726 & 3.50 & .61 & - & - & - \\
\hline $\begin{array}{l}\text { To learn about the plants and wildlife in Glacier Bay } \\
\text { National Park }\end{array}$ & .766 & 3.60 & .61 & - & - & - \\
\hline $\begin{array}{l}\text { To learn about nature conservation and preservation } \\
\text { values in the park }\end{array}$ & .734 & 3.22 & .64 & - & - & - \\
\hline Experience Glaciers & - & - & - & .696 & 2.306 & 45.72 \\
\hline To view scenic beauty & .635 & 4.73 & .43 & - & - & - \\
\hline To view glaciers & .631 & 4.48 & .40 & - & - & - \\
\hline To experience a recently glaciated, dynamic landscape & .771 & 4.02 & .60 & - & - & - \\
\hline To experience the diversity of the natural world & .618 & 4.10 & .53 & - & - & - \\
\hline
\end{tabular}

${ }^{1}$ Overall factor includes Solitude/Natural Sounds and Natural Connection/ Renewal. 
Table 23 (continued). Factor analysis, reliability results and scale means for visitor experience scale.

\begin{tabular}{|c|c|c|c|c|c|c|}
\hline Factors and Scale Items & $\begin{array}{r}\text { Rotated Factor } \\
\text { Loadings }\end{array}$ & Mean Scores & $\begin{array}{l}\text { Item Total } \\
\text { Correlation }\end{array}$ & $\begin{array}{r}\text { Cronbach's } \\
\text { Alpha }\end{array}$ & Eigenvalue & $\begin{array}{r}\% \text { of Variation } \\
\text { (cumulative) }\end{array}$ \\
\hline Fishing & - & - & - & .804 & 1.808 & 51.95 \\
\hline To fish for sport & .853 & 1.49 & .67 & - & - & - \\
\hline To catch fish to eat & .871 & 1.57 & .67 & - & - & - \\
\hline Guided Wilderness Experience & - & - & - & .503 & 1.736 & 57.94 \\
\hline To view/photograph wildlife & .753 & 4.40 & .32 & - & - & - \\
\hline To have an adventure & .473 & 4.16 & .31 & - & - & - \\
\hline To be near others who could help if you needed & .609 & 3.06 & .31 & - & - & - \\
\hline Safety & - & - & - & .462 & 1.434 & 62.88 \\
\hline To be in control of things that happen & .626 & 2.17 & .30 & - & - & - \\
\hline To be where things are fairly safe & .831 & 2.66 & .30 & - & - & - \\
\hline
\end{tabular}

${ }^{1}$ Overall factor includes Solitude/Natural Sounds and Natural Connection/ Renewal. 
All factor scores from the PCA were saved, and a K-means cluster analysis was completed using these scores to classify visitors based on motivation (Furr, 2019). A three-cluster solution resulted from several iterations of the K-means procedure (Table 24), where higher cluster center scores suggest that the factor is an important component of a cluster. By interpreting the results, each cluster represents a visitor type based on visitor responses from the 29-item experience scale question ("Indicate how important each experience is to you on your visit to the park"). Cluster 1, accounting for $16 \%$ (58) of visitors, scored highly for "experiencing glaciers." Cluster 2, accounting for $42 \%$ (147) of visitors reported high levels of importance for "a guided wilderness experience," and "safety." Cluster 3 comprised of $42 \%$ (148), rated "Alaskan wilderness experience," (i.e., solitude and natural sounds), "adventure," "learning," and "fishing" as highly important. Based on these cluster means and the survey results, three descriptive names were assigned to each cluster: 1) Glacier Experience; 2) Guided Wilderness Experience; and 3) Remote Wilderness Experience.

Table 25 provides further details about how sample populations fit within each cluster grouping. A smaller proportion of visitors within each user group, except charter vessel visitors, fall into cluster 1 (Glacier Experience), with $61 \%$ of day boat passengers falling within cluster 2 (Guided Wilderness Experience), and a $69 \%$ of independent backcountry visitors falling within cluster 3 (Remote Wilderness Experience). Although almost two-thirds of day boat passengers were motivated by a guided wilderness experience and over two-thirds of independent backcountry visitors were motivated by a remote wilderness experience, these broad groupings based off motivations are spread across activity types. This suggests there are no definitive patterns across populations, implying that management should not categorize visitors based simply on mode of travel or activity type-but rather consider a range of motivations within different populations. 
Table 24. Cluster analysis of factor scores ${ }^{1}$ from experience scales.

\begin{tabular}{|c|c|c|c|}
\hline \multirow[b]{2}{*}{ Factor Name } & \multicolumn{3}{|c|}{ Classification of Visitors $^{2}$} \\
\hline & $\begin{array}{r}\text { Glacier } \\
\text { Experience }\end{array}$ & $\begin{array}{r}\text { Guided Wilderness } \\
\text { Experience }\end{array}$ & $\begin{array}{r}\text { Remote Wilderness } \\
\text { Experience }\end{array}$ \\
\hline Alaskan Wilderness Experience & -0.348 & -0.364 & $0.498^{(3)}$ \\
\hline Adventure & -0.132 & -0.295 & $0.344^{(3)}$ \\
\hline Learning & -0.239 & -0.261 & $0.352^{(3)}$ \\
\hline Experience Glaciers & $-1.621^{(3)}$ & 0.3850 & 0.253 \\
\hline Fishing & 0.042 & 0.155 & -0.171 \\
\hline Guided Wilderness Experience & -0.386 & $0.669(3)$ & -0.514 \\
\hline Safety & 0.039 & -0.071 & 0.055 \\
\hline $\mathrm{N}$ & 58 & 147 & 148 \\
\hline \multicolumn{4}{|l|}{$N=353$} \\
\hline \multicolumn{4}{|l|}{${ }^{1}$ Mean factor scores. } \\
\hline \multicolumn{4}{|c|}{${ }^{2}$ Cluster results: $1=$ Glacier Experience; $2=$ Guided Wilderness Experience; $3=$ Remote Wilderness Experience. } \\
\hline \multicolumn{4}{|c|}{$\begin{array}{l}{ }^{3} \text { Numbers highlighted in gray signify higher cluster center scores suggesting that factor is an important } \\
\text { component of a cluster, which then can be interpreted to represent different visitor types. }\end{array}$} \\
\hline
\end{tabular}

Table 25. Proportion of population distributed between clusters for each user group.

\begin{tabular}{lrrrrrr}
\hline & \multicolumn{7}{c}{ Visitor Group } \\
\cline { 2 - 7 } $\begin{array}{l}\text { Cluster } \\
\text { (Type of Visitor) }\end{array}$ & $\begin{array}{r}\text { Independent } \\
\text { Backcountry }\end{array}$ & $\begin{array}{r}\text { Day } \\
\text { Boat }\end{array}$ & $\begin{array}{r}\text { Tour } \\
\text { Vessel }\end{array}$ & $\begin{array}{r}\text { Independent } \\
\text { Boater }\end{array}$ & $\begin{array}{r}\text { Charter } \\
\text { Vessel }\end{array}$ & Resident \\
\hline Glacier Experience & 11 & 22 & 16 & 4 & - & 5 \\
Guided Wilderness Experience & 6 & 122 & 13 & 4 & 1 & 1 \\
Remote Wilderness Experience & 37 & 57 & 32 & 7 & 2 & 13 \\
$\mathrm{~N}$ & 54 & 201 & 61 & 15 & 3 & 19 \\
\hline
\end{tabular}

Total $\mathrm{N}=353$

An Analysis of Variance (ANOVA) was completed to understand the differences in motivations between each visitor group (Table 26). Although the mean scores for motivations may be statistically different between groups, each visitor group, except residents, scored highest for being motivated by seeking a glacial experience. All groups were least motivated by fishing, but independent boaters and residents scored higher than other groups in this category. In addition to experiencing glaciers, day boat passengers were highly motivated by a guided wilderness experience and solitude/natural sounds. Independent backcountry visitors were highly motivated by solitude/natural sounds and natural connection/renewal. Tour vessel users were highly motivated by learning, while independent boaters were interested in solitude/natural sounds and a guided wilderness experience. Visitors on 
charter vessels were highly motivated by solitude/natural sounds, natural connection/renewal and learning. The highest score for residents is solitude/natural sounds, followed by experiencing glaciers and natural connection/renewal. Independent backcountry visitors were more motivated by adventure, and independent boaters were more motivated by safety than any other group.

To better understand differences among visitor groups, we interpreted similarities based on the number of motivations ( $>5$ factors) that were not statistically significantly different from the others. All visitor groups were similar to charter vessel $(n=5)$ and independent boaters $(n=18)$. Residents $(n=34)$ were more similar to independent backcountry visitors $(n=68)$, and day boat passengers $(n=254)$ were more similar to tour vessel users $(n=93)$. Tour vessel users are similar to both independent backcountry visitors and day boat passengers, but less similar to charter vessels and independent boaters than other groups. 
Table 26. Cluster analysis of factor scores ${ }^{1}$ from experience scales.

\begin{tabular}{|c|c|c|c|c|c|c|c|c|c|}
\hline \multirow[b]{2}{*}{ Constructs $^{2}$} & \multirow[b]{2}{*}{ Sub-Construct } & \multicolumn{5}{|c|}{ Visitor Group ${ }^{1}$} & \multirow[b]{2}{*}{ Residents } & \multirow[b]{2}{*}{ F-ratio } & \multirow[b]{2}{*}{ P-value } \\
\hline & & $\begin{array}{l}\text { Independent } \\
\text { Backcountry }\end{array}$ & Day Boat & $\begin{array}{r}\text { Tour } \\
\text { Vessel }\end{array}$ & $\begin{array}{r}\text { Independent } \\
\text { Boater }\end{array}$ & $\begin{array}{l}\text { Charter } \\
\text { Vessel }\end{array}$ & & & \\
\hline \multirow{2}{*}{$\begin{array}{l}\text { Alaskan Wilderness } \\
\text { Experience }\end{array}$} & Solitude/Natural Sounds ${ }^{4}$ & $4.35^{\mathrm{a}}$ & $3.65^{b}$ & $3.17^{c}$ & $3.85^{\mathrm{abc}}$ & $4.50^{\mathrm{ab}}$ & $4.48^{a}$ & 21.34 & .000 \\
\hline & Natural Connection/Renewal ${ }^{3}$ & $3.90^{\mathrm{a}}$ & $2.83^{\mathrm{cd}}$ & $2.56^{d}$ & $3.07^{\mathrm{bd}}$ & $3.89^{a b c}$ & $3.64^{\mathrm{ab}}$ & 23.27 & .000 \\
\hline Adventure ${ }^{3}$ & - & $3.61^{a}$ & $2.47^{\mathrm{b}}$ & $2.30^{\mathrm{b}}$ & $3.15^{\mathrm{a}}$ & $3.02^{\mathrm{ab}}$ & $3.16^{a}$ & 30.59 & .000 \\
\hline Learning $^{3}$ & - & $3.17^{\mathrm{bc}}$ & $3.53^{a}$ & $3.58^{\mathrm{ac}}$ & $3.24^{\mathrm{ab}}$ & $3.60^{\mathrm{ab}}$ & $2.89^{b}$ & 4.72 & .022 \\
\hline $\begin{array}{l}\text { Experience } \\
\text { Glaciers }^{3}\end{array}$ & - & $4.35^{\mathrm{a}}$ & $4.45^{a}$ & $4.23^{a}$ & $4.15^{\mathrm{ab}}$ & $4.50^{\mathrm{ab}}$ & $3.74^{\mathrm{b}}$ & 7.74 & .000 \\
\hline Fishing ${ }^{4}$ & - & $1.48^{\mathrm{bcd}}$ & $1.51^{\mathrm{bc}}$ & $1.17^{d}$ & $2.68^{a}$ & $1.20^{\mathrm{cd}}$ & $2.14^{\mathrm{ab}}$ & 9.12 & .000 \\
\hline $\begin{array}{l}\text { Guided Wilderness } \\
\text { Experience }^{4}\end{array}$ & - & $3.71^{\mathrm{b}}$ & $3.95^{a}$ & $3.39^{b c}$ & $3.54^{\mathrm{abc}}$ & $3.45^{\mathrm{abc}}$ & $3.03^{c}$ & 13.96 & .000 \\
\hline Safety ${ }^{3}$ & - & $2.53^{\mathrm{ab}}$ & $2.46^{\mathrm{ab}}$ & $2.09^{b}$ & $2.94^{\mathrm{a}}$ & $2.20^{\mathrm{ab}}$ & $2.58^{\mathrm{ab}}$ & 3.35 & .006 \\
\hline
\end{tabular}

1 Values are means.

${ }^{2}$ Concepts are derived from factor analysis of all 29 questions and are coded on a 5-point scale identical to that of the variables: "Extremely" $=5$, "Very" $=4$, "Moderately" = 3, "Slightly" = 2, "Not at All" = 1.

${ }^{3}$ Means followed by the same letter are not significantly different with the Hochberg procedure at $p<.05$.

${ }^{4}$ Means followed by the same letter are not significantly different with the Games-Howell procedure at $p<.05$. 


\section{Spatial Analysis}

All 2017 GPS tracks that were successfully collected are represented in Figure 8. In total, 68 backcountry visitors completed a survey, 40 agreed to take a GPS unit, and 23 tracks successfully paired with a completed survey. Due to the GPS units' low battery retention, backcountry trips in 2017 were not fully documented, resulting mostly in partial tracks.

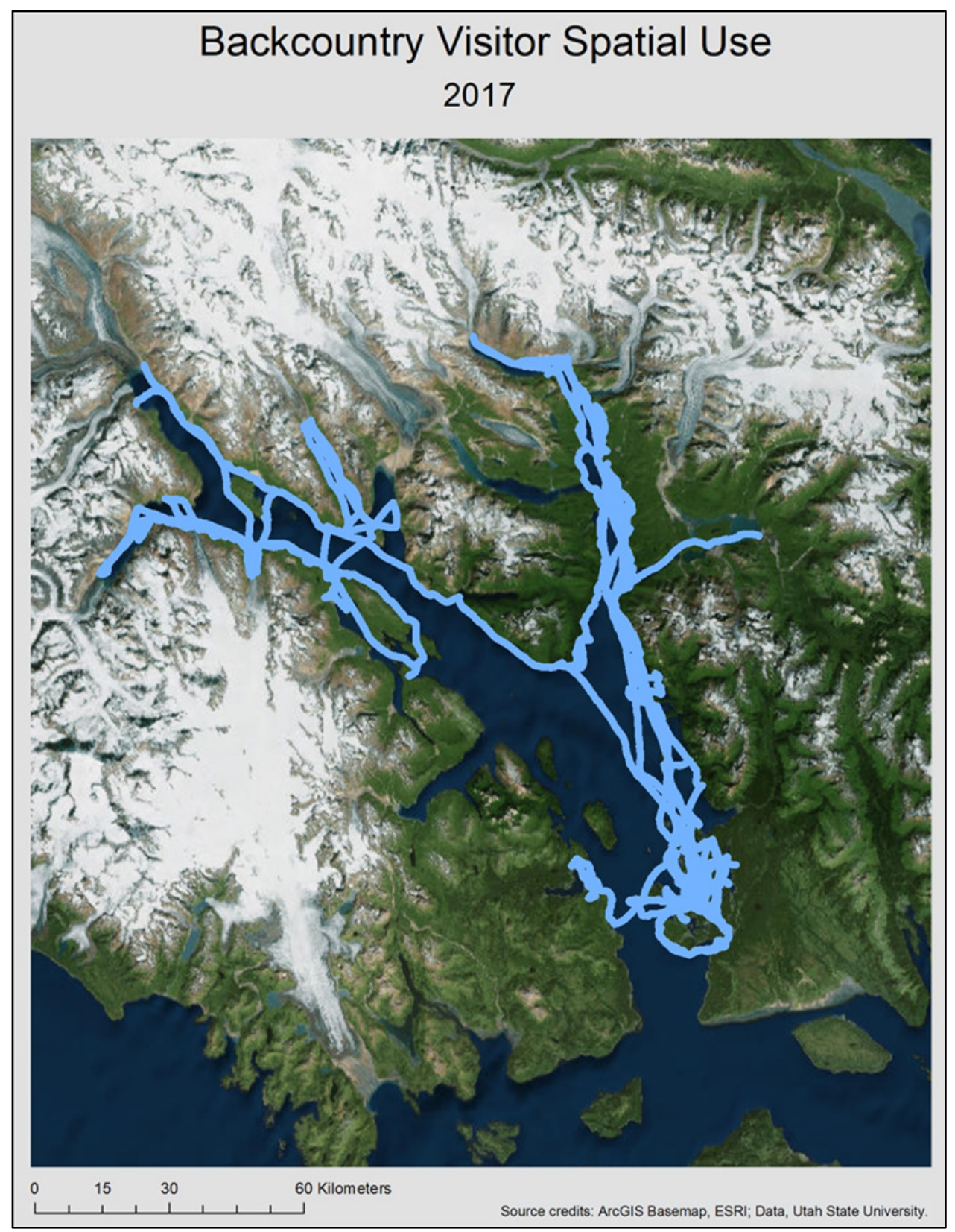

Figure 8. A total of 40 GPS tracks representing 2017 backcountry visitor spatial use in Glacier Bay National Park. Not all tracks are paired to valid survey data.

The kernel density map (Figure 9) represents the level of use for all 2017 GPS tracks, ranging from very low use (dark green) to high use (red). Based on classifications collected from the ArcGIS 
Kernel Density (Spatial Analyst) tool, there were high use centers in the Beardslee Islands, West Arm (the base of Johns Hopkins and Lamplugh Glaciers, Composite Island just south of Queen Inlet, and just north of Reid Glacier), and East Arm (center of Muir Inlet). There was moderate to low use in the Beardslee Islands, East Arm (throughout Muir Inlet, Mt. Wright drop off, and Sturgess Island/Sandy Cove), and West Arm (throughout Johns Hopkins Inlet, to Reid Inlet, around Gilbert Peninsula including Ptarmigan and Scidmore Bay drop off, and the entrances to Rendu Inlet and Queen Inlet). There was low to very low use in Berg Bay, the outer limits of the Beardslee Islands, West Arm (Tarr Inlet, Rendu Inlet and the Northeast side of the West Arm split) and most of East arm (Sebree Island drop off, Muir Inlet and Adams Inlet), but no use in Geikie Inlet or Wachusett Inlet (East Arm). 


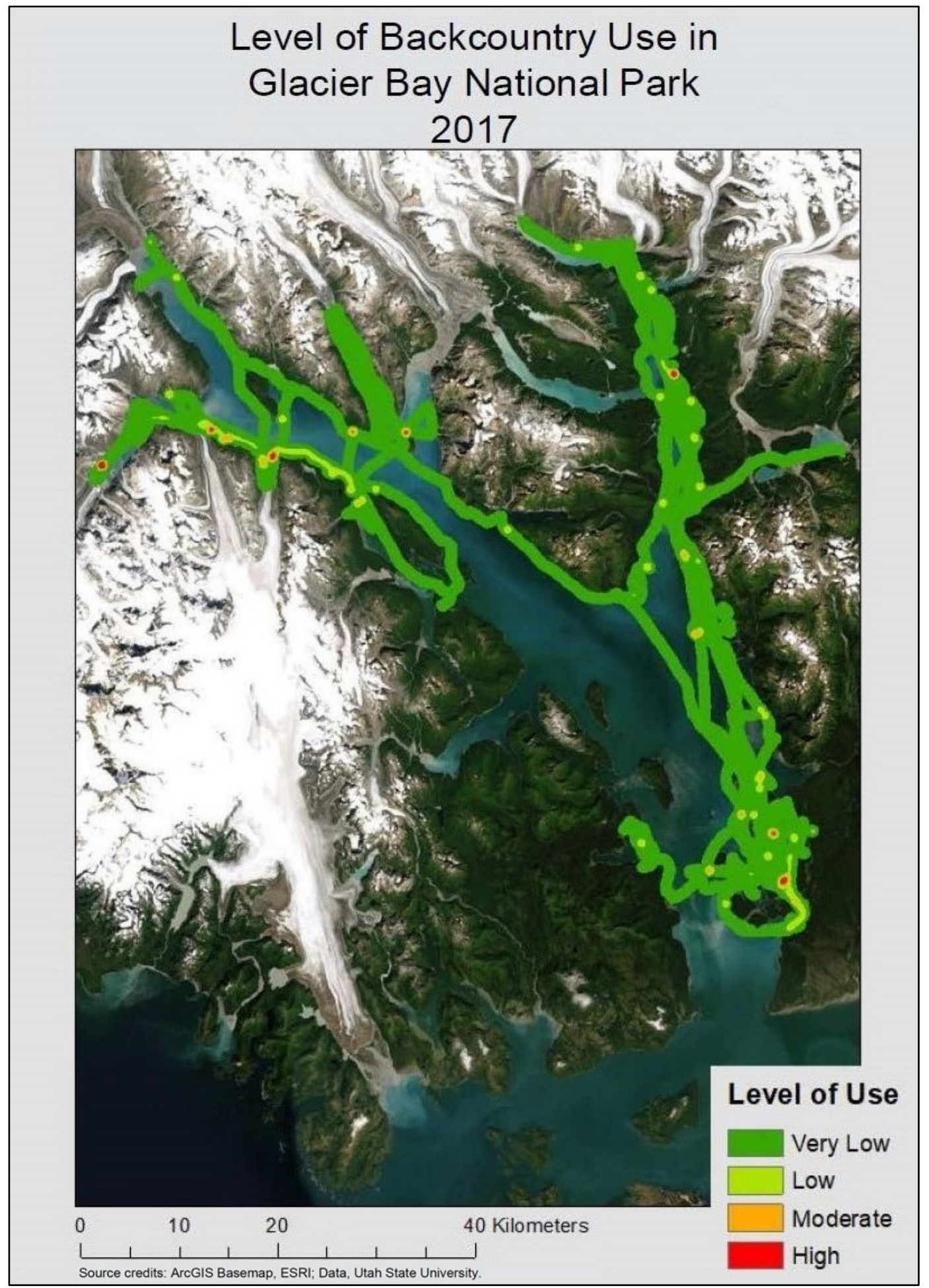

Figure 9. Kernel density map representing overall densities of total 2017 backcountry visitor spatial use in Glacier Bay National Park. Areas of high density are colored red. 


\section{Results}

The post-experience survey was conducted in the summer of 2018, and gathered information on visitor demographics, experience use history, satisfaction and trip quality, acceptable thresholds for social and resource conditions, Leave-No-Trace knowledge and use, visitor spatial patterns, and opinions about the backcountry orientation at the Visitor Information Station. Results have been organized into the above categories.

A total of 822 surveys were completed in 2018 from four distinct populations: people riding the day boat $(\mathrm{N}=372)$, independent backcountry visitors $(\mathrm{N}=124)$, people aboard tour vessels $(\mathrm{N}=198)$, and people leaving Gustavus at the Gustavus airport $(\mathrm{N}=128)$. It is important to note that independent backcountry visitors consisted of mainly kayakers, with a few backpackers included in the sample. Visitors included in the Gustavus airport sample were mainly individuals that experienced the day boat, with a small proportion who were part of a charter vessel experience. Figure 10 presents the number of surveys completed for each target population.

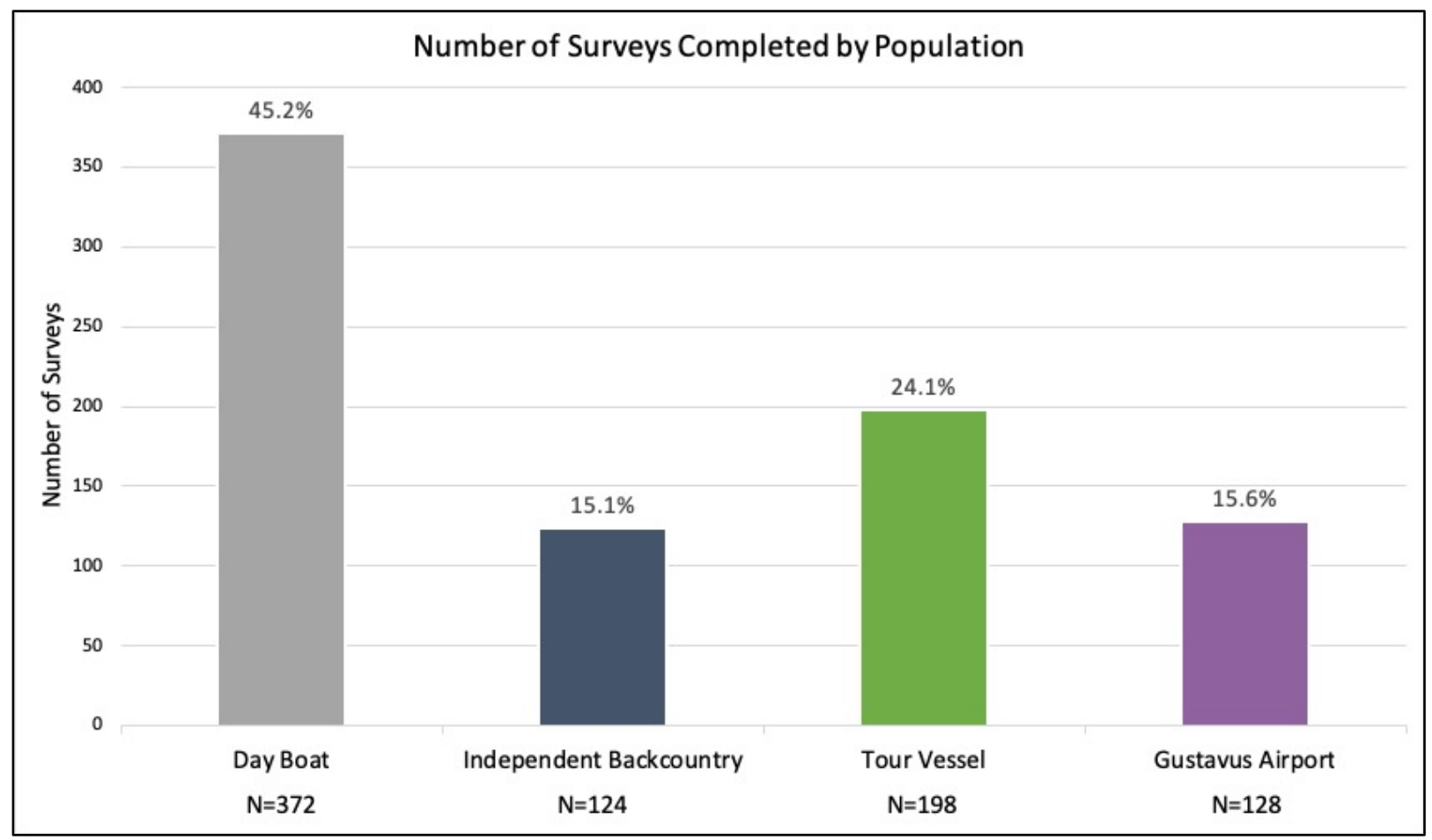

Figure 10. Number of surveys completed for each target population. Percentages illustrate the proportion of visitors sampled per target population to the total number of visitors sampled in 2018.

\section{Demographics}

Demographic information was collected in 2018 for two reasons: 1) to make comparisons between 2017 and 2018 data to see if there were differences in visitors, and 2) to provide information on who was visiting Glacier Bay National Park in that year.

Nearly half (47\%) of visitors traveled in pairs (i.e., two people per group, Table 27). There was a higher proportion of females (59\%) visiting Glacier Bay National Park than males. There was a fairly 
even distribution of visitors between 20 and 49 years old, but a much higher proportion of visitors are above 50 years old $(62 \%$, Table 28$)$.

Table 27. Number of people per group in 2018.

\begin{tabular}{lrr}
\hline Number of People & Frequency & Percent $^{1}$ \\
\hline 1 per group & 55 & 6.95 \\
2 per group & 368 & 46.52 \\
3 per group & 76 & 9.61 \\
4 per group & 130 & 16.43 \\
5 per group & 41 & 5.18 \\
$6+$ per group & 121 & 15.31 \\
\hline
\end{tabular}

$\mathrm{N}=791 ;$ Mean $=4.13 ; \mathrm{SD}=6.449$.

${ }^{1}$ Based on valid data only.

Table 28. Visitor demographics in 2018.

\begin{tabular}{llrr}
\hline Demographic Category & Demographic Group & Frequency & Percent $^{1}$ \\
\hline Gender $^{2}$ & Female & 477 & 58.9 \\
& Male & 333 & 41.1 \\
Age $^{3}$ & Under 18 & 2 & 0.25 \\
& $18-19$ & 18 & 2.24 \\
& $20-29$ & 84 & 10.46 \\
& $30-39$ & 112 & 13.95 \\
& $40-49$ & 92 & 11.46 \\
& $50-59$ & 157 & 19.55 \\
$60-69$ & 231 & 28.77 \\
$70+$ & 107 & 13.32 \\
\hline
\end{tabular}

${ }^{1}$ Based on valid data only.

2 Gender: $\mathrm{N}=810$.

${ }^{3}$ Age: $\mathrm{N}=803$, Mean $=51.96, \mathrm{SD}=16.46$.

In the 2018 post-experience survey, respondents were asked to provide their home ZIP codes, which were analyzed following the same procedure as 2017 data (Figure 11a). About one third (30\%) of Glacier Bay visitors were from the Western United States. The next most common region was the Southern region of the United States (18\%), followed by Midwest visitors (16\%), foreign visitors (14\%), and visitors from the Northeast (12\%). Interestingly, $8.2 \%$ of visitors reported living in Alaska, an increase from 2017. Visitors from specific Alaskan boroughs can be found in Figure 11b. 


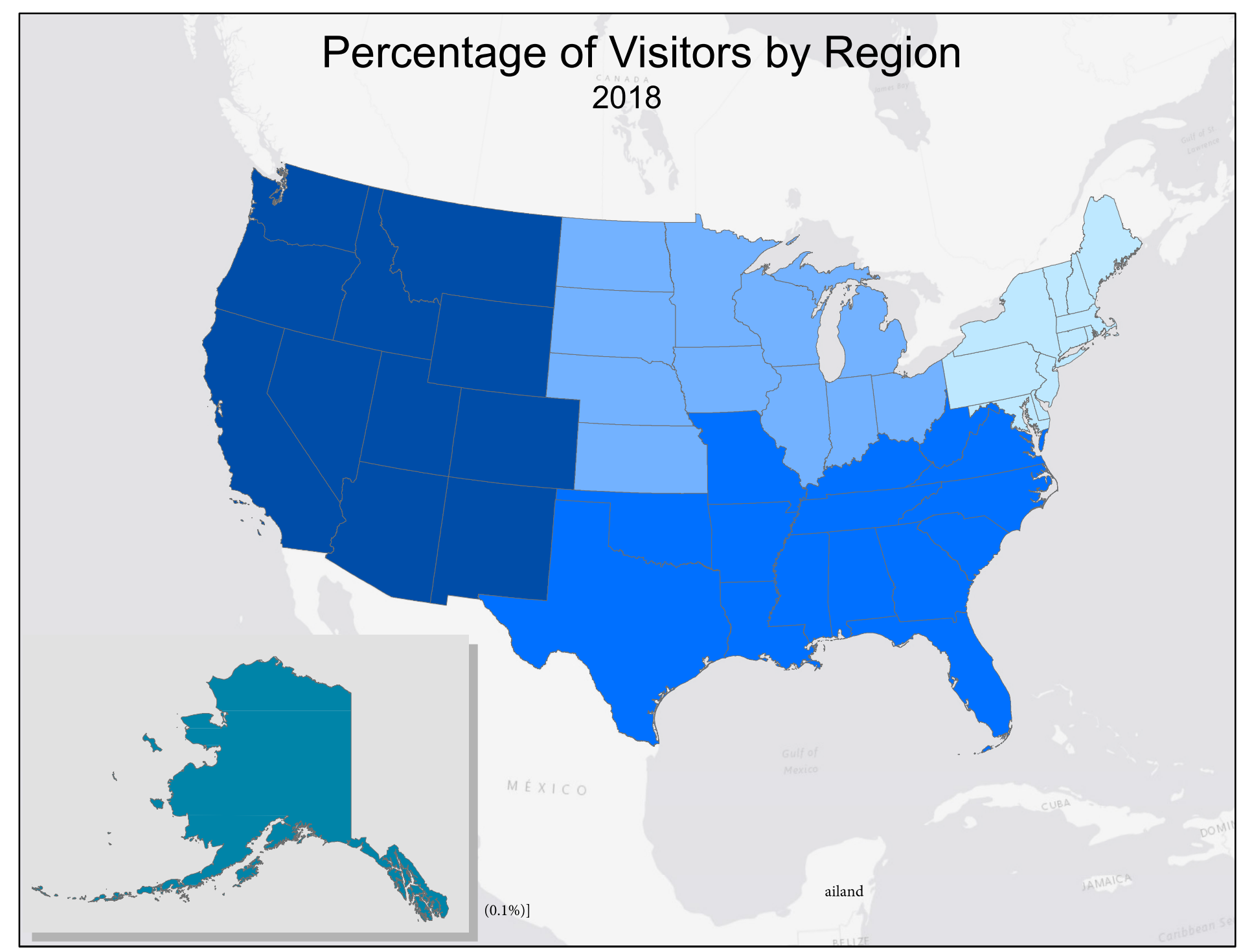

Figure 11a. Percentage of visitors by region for 2018. $\mathrm{N}=718$. 


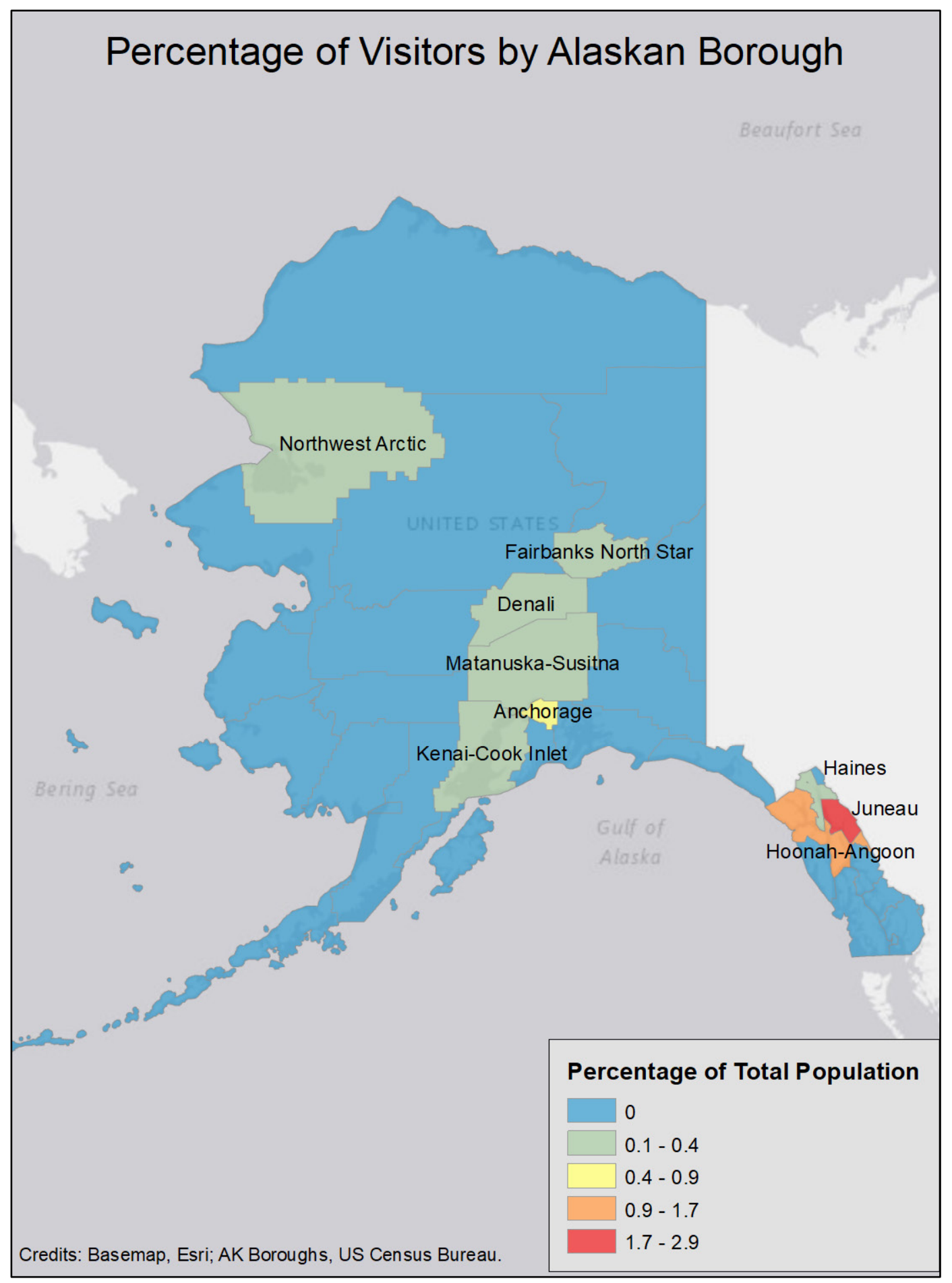

Figure 11b. Percentage of Alaskan visitors by borough for 2018 (8.22\% of total population).

\section{Experience Use History}

To understand how frequently people come to Glacier Bay National Park, visitors were asked how many times they had visited the park in the past five years and how many times they'd visited during their lifetime. GBNP receives very few repeat visitors. Most visitors $(89 \%)$ had only visited once in 
the last five years. For $81 \%$ of visitors this was the first trip of their lifetime. A few people had visited more than 10 times in the past five years. One individual reported visiting 90 times in the past five years, however, this was a park service employee who had worked at GBNP for several years (Table 29).

Table 29. Experience use history of GBNP visitors in 2018.

\begin{tabular}{|c|c|c|c|c|}
\hline \multirow[b]{2}{*}{ Number of Visits } & \multicolumn{2}{|c|}{ Visits in the Past 5 Years } & \multicolumn{2}{|c|}{ Visits in a Lifetime } \\
\hline & Frequency & Percentage & Frequency & Percentage \\
\hline First Visit & 730 & 88.8 & 665 & 80.9 \\
\hline 2 & 42 & 5.1 & 84 & 10.2 \\
\hline 3 & 11 & 1.3 & 10 & 1.2 \\
\hline $4-10$ & 23 & 2.8 & 27 & 3.3 \\
\hline$>10$ & 13 & 1.6 & 33 & 4.0 \\
\hline $11-25$ & 5 & 0.6 & 12 & 1.5 \\
\hline $26-50$ & 2 & 0.2 & 4 & 0.5 \\
\hline$>50$ & 2 & 0.2 & 4 & 0.5 \\
\hline
\end{tabular}

Independent backcountry visitors were asked how many hours or days they spent in the backcountry (Table 30), with the majority visiting frequently (94\%). Those who spent multiple days in the backcountry reported staying an average of just over five days, and those who did not spend multiple days in the backcountry spent around six hours on average. Groups that did not explore backcountry areas of GBNP paddled around Bartlett Cove, which is considered frontcountry.

Table 30. Time independent backcountry visitors spent in GBNP backcountry.

\begin{tabular}{lrrrr}
\hline Time Spent & Frequency $^{1}$ & Percent $^{1}$ & Mean $^{1}$ & SD $^{1}$ \\
\hline$<1$ day & 8 & 6.5 & $6.25^{2}$ & 8.06 \\
$>1$ day & 115 & 93.5 & $5.35^{3}$ & 3.86 \\
\hline N $=123$ & & & \\
$\quad{ }^{1}$ Based on valid data only. & & & \\
${ }^{2}$ Average number of hours. & & & \\
${ }^{3}$ Average number of days. & & & &
\end{tabular}

\section{Overall Trip Quality}

Because this was a post-trip survey, visitor satisfaction and overall trip quality were evaluated. A variety of questions were asked regarding what added and detracted from their visitor experience. Using open-response questions, all sample populations had an opportunity to report what added most 
to their experience. Respondents said wildlife (44\%), learning (27\%) and experiencing glaciers (26\%) added most to their overall trip (Table 31).

Table 31. Factors that added most to the visitor experience for the total sample population.

\begin{tabular}{|c|c|c|}
\hline Experience Factor & Frequency ${ }^{1}$ & Total Response $\%$ \\
\hline Wildlife $^{3}$ & 316 & 44.01 \\
\hline Learning ${ }^{4}$ & 192 & 26.74 \\
\hline Experiencing glaciers & 189 & 26.32 \\
\hline Scenic beauty & 134 & 18.66 \\
\hline Boat tour ${ }^{5}$ & 104 & 14.48 \\
\hline Experience wilderness & 63 & 8.77 \\
\hline Solitude & 62 & 8.64 \\
\hline Experience nature & 49 & 6.82 \\
\hline Weather & 41 & 5.71 \\
\hline Hiking/Walking & 35 & 4.87 \\
\hline Facilities \& services & 27 & 3.76 \\
\hline Natural quiet & 26 & 3.62 \\
\hline Remoteness & 21 & 2.69 \\
\hline Kayaking & 19 & 2.65 \\
\hline \multicolumn{3}{|l|}{$N=781$} \\
\hline \multicolumn{3}{|c|}{${ }^{1}$ Frequencies and percentages exceed $100 \%$ because multiple answers could be given per survey. } \\
\hline \multicolumn{3}{|c|}{${ }^{2}$ Reported percentages refer to concepts that were conveyed by $>2.5 \%$ of the population. } \\
\hline \multicolumn{3}{|c|}{$\begin{array}{l}{ }^{3} \text { Wildlife general category is comprised of viewing wildlife }(42 \%) \text { and positive encounters with wildlife }(2 \%) \text {, } \\
\text { which were solely reported by independent backcountry visitors. }\end{array}$} \\
\hline \multicolumn{3}{|c|}{$\begin{array}{l}{ }^{4} \text { Learning general category refers to mainly NPS interpretive interactions }(23 \%) \text {, including rangers, } \\
\text { presentations, and materials. }\end{array}$} \\
\hline \multicolumn{3}{|c|}{$\begin{array}{l}5 \text { The boat tour general category is comprised of experiences on/with the day boat }(13 \%) \text {, charter vessels } \\
(0.4 \%) \text {, and tour vessels }(1 \%) \text {. }\end{array}$} \\
\hline
\end{tabular}

Responses were separated by independent backcountry and guided, motorized visitors to better understand visitor experiences based on user groups. Both independent backcountry and guided, motorized visitors reported wildlife as the main factor that added most to their experience. There were some differences, however, between the two visitor groups. Independent backcountry visitors reported solitude (29\%), the wilderness experience (18\%) and scenic beauty (15\%) as top elements that added to their experience (Table 32). Guided, motorized visitors, however, reported that learning (29\%), experiencing glaciers (26\%) and scenic beauty (18\%) added most to their experience (Table 33). One independent backcountry visitor reported that learning, specifically regarding the historic artifacts on Lester Island, added to their experience. Non-motorized areas (8\%) and unconfined 
recreation ( $8 \%$ ) were both reported as factors adding to the independent backcountry visitor experience, but neither were reported by guided, motorized visitors. Hiking/walking (5\%) and facilities and services (4\%) were two elements that added to the guided, motorized experience but were not reported by independent backcountry visitors.

Table 32. Factors that added most to independent backcountry visitors' experience.

\begin{tabular}{|c|c|c|}
\hline Experience Factor & Frequency $^{1}$ & Total Response $\% 1,2$ \\
\hline Wildlife $^{3}$ & 76 & 63.87 \\
\hline Solitude & 34 & 28.57 \\
\hline Experience wilderness & 21 & 17.65 \\
\hline Scenic beauty & 18 & 15.13 \\
\hline Experiencing glaciers & 16 & 13.45 \\
\hline Natural quiet & 15 & 12.61 \\
\hline Experience nature & 11 & 9.24 \\
\hline Weather & 10 & 8.40 \\
\hline Non-motorized areas & 10 & 8.40 \\
\hline Unconfined recreation ${ }^{4}$ & 10 & 8.40 \\
\hline Kayaking & 6 & 5.04 \\
\hline Boat tour ${ }^{5}$ & 4 & 3.36 \\
\hline Remoteness & 3 & 2.52 \\
\hline Time with family/friends & 3 & 2.52 \\
\hline
\end{tabular}

$\mathrm{N}=119$

${ }^{1}$ Frequencies and percentages exceed $100 \%$ because multiple answers could be given per survey.

${ }^{2}$ Reported percentages refer to concepts that were conveyed by $>2.5 \%$ of the population.

${ }^{3}$ Wildlife general category is comprised of viewing wildlife (50\%) and positive encounters with wildlife (13\%).

${ }^{4}$ Unconfined recreation general category refers to having a sense of freedom, self-sufficiency and independence.

${ }^{5}$ Boat tour refers solely to kayak transport and drop off/pick up service. 
Table 33. Factors that added most to guided, motorized visitors' experience.

\begin{tabular}{|c|c|c|}
\hline Experience Factor & Frequency $^{1}$ & Total Response $\% 1,2$ \\
\hline Viewing wildlife & 240 & 36.25 \\
\hline Learning $^{3}$ & 192 & 29.00 \\
\hline Experiencing glaciers & 173 & 26.13 \\
\hline Scenic beauty & 116 & 17.52 \\
\hline Boat tour ${ }^{4}$ & 100 & 15.11 \\
\hline Experience wilderness & 42 & 6.34 \\
\hline Experience nature & 38 & 5.74 \\
\hline Hiking/Walking & 35 & 5.29 \\
\hline Weather & 31 & 4.68 \\
\hline Solitude & 28 & 4.23 \\
\hline Facilities \& Services ${ }^{5}$ & 27 & 4.08 \\
\hline Remoteness & 18 & 2.72 \\
\hline \multicolumn{3}{|l|}{$N=662$} \\
\hline \multicolumn{3}{|c|}{${ }^{1}$ Frequencies and percentages exceed $100 \%$ because multiple answers could be given per survey. } \\
\hline \multicolumn{3}{|c|}{${ }^{2}$ Reported percentages refer to concepts that were conveyed by $>2.5 \%$ of the population. } \\
\hline \multicolumn{3}{|c|}{${ }^{3}$ Learning general category refers to mainly NPS interpretive interactions (25\%). } \\
\hline \multicolumn{3}{|c|}{$\begin{array}{l}{ }^{4} \text { Boat tour general category is comprised of experiences on/with the day boat }(13 \%) \text {, charter vessels }(0.5 \%) \text {, } \\
\text { and tour vessels }(1 \%) \text {. }\end{array}$} \\
\hline \multicolumn{3}{|c|}{$\begin{array}{l}{ }^{5} \text { Facilities and services general category refers to lodging }(2 \%) \text {, food availability/quality }(1.5 \%) \text {, and general } \\
\text { services }(0.6 \%) \text {. }\end{array}$} \\
\hline
\end{tabular}

Similarly, it is important to understand what detracted from the visitor experience. Based on openresponse questions, almost half (43\%) of the total population said nothing detracted from their experience in GBNP. For those who did report a negative experience, weather (14\%), cruise ships sightings (12\%), and interactions with other visitors (6\%) were reported (Table 34$)$. The category for other visitors refers to issues of crowding (3\%) and negative encounters with other visitors (3\%). Negative visitor encounters were only reported by visitors participating in guided, motorized experiences, and those encounters most often involved visitors not sharing space on vessels, being too loud, or in one case, climbing on a piece of ice up bay.

Other factors that detracted from overall experiences included sounds from motor boats and aircrafts (mainly reported by independent backcountry users, 4\%), the presence of insects (4\%) and a lack of wildlife viewing opportunities (mainly reported by guided, motorized visitors, $3 \%$ ). Four independent visitors experienced negative interactions with wildlife (i.e., a coastal brown bear charging or spending time at camp), which was more prevalent for this sample population than a lack of wildlife viewing opportunities. Guided, motorized visitors reported a lack of recreational 
opportunities (3\%), including not enough hiking trails, not being able to go ashore from vessels up bay, and not having enough time to explore on land; while $10 \%$ reported how the availability or quality of facilities and services detracted from their experience (i.e., day boat or lodge quality, interpretive experience including availability of the Huna Tribal House, food options, etc.).

Table 34. Factors that detracted most from visitor experience for the total population.

\begin{tabular}{|c|c|c|}
\hline Experience Factor & Frequency $^{1}$ & Total Response $\%^{1,2}$ \\
\hline Nothing detracted & 295 & 42.57 \\
\hline Poor weather & 97 & 14.0 \\
\hline Cruise ship sightings & 82 & 11.83 \\
\hline Facilities \& Services ${ }^{3}$ & 72 & 10.39 \\
\hline Other visitors ${ }^{4}$ & 41 & 5.92 \\
\hline Anthropogenic sounds ${ }^{5}$ & 30 & 4.33 \\
\hline Presence of insects & 25 & 3.61 \\
\hline Wildlife $^{6}$ & 22 & 3.17 \\
\hline $\begin{array}{l}\text { Seeing motorized boats } \\
\text { (other than cruise ships) }\end{array}$ & 20 & 2.89 \\
\hline \multicolumn{3}{|l|}{$N=693$} \\
\hline \multicolumn{3}{|c|}{${ }^{1}$ Frequencies and percentages exceed $100 \%$ because multiple answers could be given per survey. } \\
\hline \multicolumn{3}{|c|}{${ }^{2}$ Reported percentages refer to concepts that were conveyed by $>2.5 \%$ of the population. } \\
\hline \multicolumn{3}{|c|}{$\begin{array}{l}{ }^{3} \text { Facilities and services refer to the lodge }(2.7 \%) \text {, day boat }(1.9 \%) \text { and interpretive experiences (i.e., Tribal } \\
\text { house not being open) }(1.4 \%) \text {, as well as transportation and food options. }\end{array}$} \\
\hline \multicolumn{3}{|c|}{${ }^{4}$ Other visitor general category is comprised of conflict $(3.2 \%)$, crowding $(2.5 \%)$, and other $(0.3 \%)$. } \\
\hline \multicolumn{3}{|c|}{${ }^{5}$ Anthropogenic sound refers to engine noise $(2.3 \%)$, aircrafts $(1.2 \%)$, and PA systems $(0.9 \%)$. } \\
\hline
\end{tabular}

Responses were once again separated between independent backcountry and guided, motorized visitors. Almost half (46\%) of the guided, motorized visitors reported that nothing detracted from their experience, but the weather and available facilities and services were reported (12\% each) as detractions (Table 35). Independent backcountry visitors, however, were much more affected by cruise ships (23\%), anthropogenic sounds (23\%), and motorized boats (11\%) than other visitors; although, "nothing" was also frequently reported, indicating a high level of visitor satisfaction overall (Table 36). 
Table 35. Factors that detracted most from visitor experience specific to guided, motorized visitors.

\begin{tabular}{|c|c|c|}
\hline Experience Factor & Frequency ${ }^{1}$ & Total Response $\%^{1,2}$ \\
\hline Nothing detracted & 268 & 46.37 \\
\hline Poor weather & 73 & 12.63 \\
\hline Facilities \& Services ${ }^{3}$ & 72 & 12.46 \\
\hline Cruise ship sightings & 56 & 9.69 \\
\hline Other visitors ${ }^{4}$ & 36 & 6.23 \\
\hline Accessibility of the park ${ }^{5}$ & 17 & 2.94 \\
\hline Recreational limitations ${ }^{6}$ & 17 & 2.94 \\
\hline Viewing wildlife & 16 & 2.77 \\
\hline
\end{tabular}

$N=578$

${ }^{1}$ Frequencies and percentages exceed $100 \%$ because multiple answers could be given per survey.

${ }^{2}$ Reported percentages refer to concepts that were conveyed by $>2.5 \%$ of the population.

${ }^{3}$ Facilities and services refer to the lodge (2.7\%), day boat $(1.9 \%)$ and interpretive experiences $(1.4 \%)$, as well as transportation and food options.

${ }^{4}$ Other visitor general category is comprised of $3.2 \%$ conflict, $2.5 \%$ crowding, and $0.3 \%$ other.

${ }^{5}$ Accessibility refers to the distance/difficulty of reaching GBNP $(2.1 \%)$, cost $(0.5 \%)$, and private motor boat restrictions $(0.5 \%)$.

${ }^{6}$ Recreational limitation general category refers to not being able to get off the vessel onto shore $(1.9 \%)$ and a lack of hiking trails (1.0\%). 
Table 36. Factors that detracted most from visitor experience specific to independent backcountry visitors.

\begin{tabular}{lcc}
\hline Experience Factor & Frequency $^{1}$ & Total Response ${ }^{1{ }^{1,2}}$ \\
\hline Nothing detracted & 27 & 23.48 \\
Cruise ship sightings & 26 & 22.61 \\
Anthropogenic sound ${ }^{3}$ & 26 & 22.61 \\
Weather & 24 & 20.87 \\
Presence of insects & 15 & 13.04 \\
Seeing motorized boats & 13 & 11.30 \\
$\quad$ (other than cruise ships) & 6 & 5.22 \\
Wildlife & 5 & 4.35 \\
Other visitors & \\
\hline & N $=115$ \\
${ }^{1}$ Frequencies and percentages exceed $100 \%$ because multiple answers could be given per survey. \\
${ }^{2}$ Reported percentages refer to concepts that were conveyed by >2.5\% of the population. \\
${ }^{3}$ Anthropogenic sound refers to engine noise (12\%), aircrafts (6\%), and PA systems (4\%). \\
${ }^{4}$ Wildlife general category is comprised of a lack of wildlife viewing opportunities (1\%) and negative interactions \\
$\quad$ with wildlife (4\%), specifically coastal brown bears. \\
${ }^{5}$ Other visitor general category refers to crowding exclusively.
\end{tabular}

These data indicate that there is very little that detracts from the overall visitor experience in Glacier Bay National Park. In terms of management, however, the number of cruise ship sightings detracted from $12 \%$ of the total sample population's experience and may be worth considering for future management plans. This data also suggests visitors may benefit from receiving additional information to better prepare for their trip, specifically regarding weather, available facilities and services, and the presence of insects.

Respondents were asked to report on their ability to experience adventure using an open-response question. Although $6 \%$ of the total population said they did not experience adventure, the majority reported that the boat tours (24\%), learning (21\%) and opportunities to view wildlife (20\%) all added to their ability to experience adventure (Table 37$)$. Boat tours included the day boat (18\%), tour vessels $(5 \%)$ and charter vessels $(0.7 \%)$ and were reported as adding to adventure by all populations. Interpretive elements (e.g., presentations, interpretation on-board vessels, materials, etc.) accounted for $16 \%$ of the overall learning category $(21 \%)$. Facilities and services, including equipment rentals $(3 \%)$ and day boat drop off and pick up services (3\%), were reported by $10 \%$ of the total population as adding to their ability to experience adventure. 
Table 37. Elements that added most to visitors' ability to experience adventure for the total population.

\begin{tabular}{|c|c|c|}
\hline Experience Element & Frequency $^{1}$ & Total Response \%1,2 \\
\hline Boat tour experience ${ }^{3}$ & 166 & 23.55 \\
\hline Learning & 150 & 21.28 \\
\hline Wildlife ${ }^{4}$ & 142 & 20.14 \\
\hline Facilities \& Services 5 & 69 & 9.79 \\
\hline Experience glaciers & 66 & 9.36 \\
\hline Hiking/Walking & 56 & 7.94 \\
\hline Did not experience adventure & 45 & 6.38 \\
\hline Kayaking & 36 & 5.11 \\
\hline Wilderness & 33 & 4.68 \\
\hline Weather & 25 & 3.55 \\
\hline Limited number of other visitors & 25 & 3.55 \\
\hline Solitude & 24 & 3.40 \\
\hline Experiencing nature & 23 & 3.26 \\
\hline Remoteness & 20 & 2.84 \\
\hline Self-sufficiency & 19 & 2.70 \\
\hline \multicolumn{3}{|l|}{$N=678$} \\
\hline \multicolumn{3}{|c|}{${ }^{1}$ Frequencies and percentages exceed $100 \%$ because multiple answers could be given per survey. } \\
\hline \multicolumn{3}{|c|}{${ }^{2}$ Reported percentages refer to concepts that were conveyed by $>2.5 \%$ of the population. } \\
\hline \multicolumn{3}{|c|}{$\begin{array}{l}{ }^{3} \text { Boat tour experience category refers to the day boat }(18 \%) \text {, tour vessels }(5 \%) \text { and charter vessels obtained } \\
\text { through Gustavus airport sampling }(0.7 \%) \text {. }\end{array}$} \\
\hline \multicolumn{3}{|c|}{${ }^{4}$ Wildlife general category is comprised of opportunities to view wildlife (19\%) and encounters with wildlife (1\%). } \\
\hline \multicolumn{3}{|c|}{$\begin{array}{l}{ }^{5} \text { Facilities and services refer to general services }(2 \%) \text {, equipment rentals }(3 \%) \text { and day boat drop off/pick up } \\
\text { services }(3 \%) \text {. }\end{array}$} \\
\hline
\end{tabular}

There were a few differences in what allowed independent backcountry and guided, motorized visitors to experience adventure. Independent visitors reported that self-sufficiency (17\%), viewing and interacting with wildlife (17\%), and kayaking (14\%) added to their ability to experience adventure (Table 38). Visitors with a guided, motorized experience reported that a boat tour experience (28\%), learning (24\%) and viewing wildlife $(21 \%)$ added most to experiencing adventure (Table 39). Experiencing glaciers, hiking/walking, and the limited number of other visitors in terms of crowding were mentioned more often — or solely_by guided, motorized visitors. Only one independent backcountry visitor said they did not experience adventure, while 44 visitors experiencing a guided, motorized trip said they did not experience adventure (40 visitors) or were not in wilderness because they were restricted to a boat (4 visitors). 
Table 38. Elements that added most to independent backcountry visitors' ability to experience adventure.

\begin{tabular}{|c|c|c|}
\hline Experience Element & Frequency $^{1}$ & Total Response $\%^{1,2}$ \\
\hline Self-sufficiency & 19 & 16.67 \\
\hline Wildlife $^{3}$ & 19 & 16.67 \\
\hline Kayaking & 16 & 14.04 \\
\hline Kayaking equipment rentals & 15 & 13.16 \\
\hline Wilderness & 15 & 13.16 \\
\hline Environmental adaptability ${ }^{4}$ & 14 & 12.28 \\
\hline Solitude & 13 & 11.40 \\
\hline Day boat pickup/drop off & 10 & 8.77 \\
\hline Weather & 7 & 6.14 \\
\hline Unconfined recreation ${ }^{5}$ & 7 & 6.14 \\
\hline Learning & 6 & 5.26 \\
\hline Remoteness & 6 & 5.26 \\
\hline Nature ${ }^{6}$ & 6 & 5.26 \\
\hline Time with family/friends & 5 & 4.39 \\
\hline Accessibility of wilderness & 3 & 2.63 \\
\hline
\end{tabular}

$\mathrm{N}=114$

${ }^{1}$ Frequencies and percentages exceed $100 \%$ because multiple answers could be given per survey.

${ }^{2}$ Reported percentages refer to concepts that were conveyed by $>2.5 \%$ of the population.

${ }^{3}$ Wildlife general category refers to viewing wildlife (17\%) and interactions with wildlife (5\%).

${ }^{4}$ Environmental adaptability refers to personal capabilities (6\%) and environmental challenges (i.e., currents, riptides, glacial mud, $6 \%$ ).

${ }^{5}$ Unconfined recreation refers to freedom to explore and camp.

${ }^{6}$ Nature refers to viewing nature $(4 \%)$ and natural quiet $(2 \%)$. 
Table 39. Elements that added most to guided, motorized visitors' ability to experience adventure.

\begin{tabular}{|c|c|c|}
\hline Experience Element & Frequency $^{1}$ & Total Response $\% 1,2$ \\
\hline Boat tour experience ${ }^{3}$ & 164 & 27.75 \\
\hline Learning ${ }^{4}$ & 144 & 24.37 \\
\hline Viewing wildlife & 123 & 20.81 \\
\hline Experiencing glaciers & 64 & 10.83 \\
\hline Hiking/Walking & 56 & 9.48 \\
\hline Did not experience adventure & 44 & 7.45 \\
\hline Facilities \& Services ${ }^{5}$ & 41 & 6.94 \\
\hline Limited number of other visitors & 25 & 4.23 \\
\hline Kayaking & 20 & 3.38 \\
\hline Nature & 19 & 3.21 \\
\hline Weather & 18 & 3.05 \\
\hline Wilderness & 18 & 3.05 \\
\hline \multicolumn{3}{|l|}{$N=591$} \\
\hline \multicolumn{3}{|c|}{${ }^{1}$ Frequencies and percentages exceed $100 \%$ because multiple answers could be given per survey. } \\
\hline \multicolumn{3}{|c|}{${ }^{2}$ Reported percentages refer to concepts that were conveyed by $>2.5 \%$ of the population } \\
\hline \multicolumn{3}{|c|}{$\begin{array}{l}{ }^{3} \text { Boat tour experience category is comprised of } 21 \% \text { day boat, } 6 \% \text { tour vessel, and } 0.9 \% \text { charter vessel } \\
\text { (obtained through Gustavus airport sampling) visitors. }\end{array}$} \\
\hline \multicolumn{3}{|c|}{$\begin{array}{l}{ }^{4} \text { Learning general category refers to NPS interpretive interactions }(19 \%) \text { and knowledge shared by guides or } \\
\text { staff members }(6 \%) \text {. }\end{array}$} \\
\hline
\end{tabular}

Connecting to nature is an important motivation for visiting national parks. When asked, 95\% of respondents said they were able to connect to nature during their visit to Glacier Bay National Park (Table 40). As a follow up, respondents were then asked to identify specific elements of their visit that allowed them to connect to nature and to have a sense of renewal. Based on the total population, viewing wildlife (29\%), scenic beauty (16\%), wilderness (13\%) and experiencing glaciers (11\%) were a few of the most common responses (Table 41). Five visitors reported that they may have connected with nature, but their experience did not result in a sense of renewal. 
Table 40. Frequency of visitors who felt a connection to nature.

\begin{tabular}{|c|c|c|}
\hline Connection to Nature & Frequency & Percent $^{1}$ \\
\hline Yes & 755 & 95.1 \\
\hline No & 39 & 4.9 \\
\hline
\end{tabular}

Table 41. Total population responses from open-ended questions as to how visitors experienced a connection to nature.

\begin{tabular}{|c|c|c|}
\hline Connection Element & Frequency $^{1}$ & Total Response $\%^{1,2}$ \\
\hline Viewing wildlife & 178 & 28.62 \\
\hline Scenic beauty & 99 & 15.92 \\
\hline Wilderness $^{3}$ & 82 & 13.18 \\
\hline Experiencing glaciers & 74 & 11.90 \\
\hline Hiking/Walking & 58 & 9.32 \\
\hline Natural quiet & 54 & 8.68 \\
\hline Tranquility & 54 & 8.68 \\
\hline Nature immersion & 50 & 8.04 \\
\hline Overall experience & 43 & 6.91 \\
\hline Solitude & 40 & 6.43 \\
\hline Escape $^{4}$ & 39 & 6.27 \\
\hline Learning $^{5}$ & 39 & 6.27 \\
\hline Natural soundscape & 31 & 4.98 \\
\hline Observing & 22 & 3.54 \\
\hline Kayaking & 21 & 3.38 \\
\hline
\end{tabular}

$\mathrm{N}=622$

${ }^{1}$ Frequencies and percentages exceed $100 \%$ because multiple answers could be given per survey.

${ }^{2}$ Reported percentages refer to concepts that were conveyed by $>2.5 \%$ of the population.

${ }^{3}$ Wilderness general category refers to the vastness of the landscape $(4 \%)$ and minimal human impact $(3 \%)$.

${ }^{4}$ Escape general category consists of $3 \%$ escape from technology, $\mathrm{Wi}-\mathrm{Fi}$, or cell service specifically.

${ }^{5}$ Learning general category refers to interpretive materials or presentations $(3 \%)$ and cultural connections made $(1 \%)$.

Of those who said they were not able to connect to nature (5\%), the most common reason mentioned was because they were restricted to a motorized experience (30\%, Table 42). Only one independent backcountry visitor reported they did not connect with nature, and their response was related to 
safety concerns throughout their experience. The important takeaway is that only 33 respondents said they were unable to connect to nature, which - compared to the total sample of 822 -is a very small proportion of visitors, indicating that the vast majority of visitors were able to connect to nature during their visit.

Table 42. Total population responses as to why visitors did not experience a connection to nature.

\begin{tabular}{lcr}
\hline Reason for Lack of Connection & Frequency $^{1}$ & Total Response ${ }^{1}{ }^{1}$ \\
\hline Restricted to a motorized & 10 & 30.30 \\
experience & 7 & 21.21 \\
Too many people & 4 & 12.12 \\
Not during this trip & 3 & 9.09 \\
Limited wildlife sightings & 3 & 9.09 \\
Disbelief in connection to nature & 2 & 6.06 \\
Connection elsewhere & 2 & 6.06 \\
Not enough time & 1 & 3.03 \\
Safety concerns ${ }^{2}$ & 1 & 3.03 \\
Distance from shore & 1 & 3.03 \\
Cruise ship blocking view of glacier & 1 & 3.03 \\
Already connected to nature & & \\
\hline$\quad \mathrm{N}=33$ & &
\end{tabular}

A one-way ANOVA was conducted to better understand where statistical differences exist between each visitor group and the quality of their experience. Table 43 presents mean scores from the 2018 survey question asking participants to rate the quality of their experience for each construct (derived from 2017 factor analysis) on a scale from 5, "very good" to 1, "very poor." The quality of experiencing glaciers was not different between any visitor group, and was the highest scored construct for day boat, tour vessel and Gustavus airport visitors. Independent backcountry visitors scored highest for quality of viewing wildlife and opportunities for adventure and are statistically significantly different $(\mathrm{p}<.000)$ from day boat passengers for all items. Gustavus Airport visitors are statistically different $(\mathrm{p}<.000)$ from all other populations when it comes to quality of opportunities for adventure, with scores between the independent backcountry visitors (higher) and day boat/tour vessel visitors (lower). Day boat, tour vessel and Gustavus Airport visitors are not statistically different for any construct, except the quality of adventure opportunities. The lowest score was for the quality of adventure opportunities. 
Table 43. A comparison of mean experience quality by visitor type.

\begin{tabular}{lrrrrrrr}
\hline & \multicolumn{9}{c}{ Visitor Group $^{1}$} & & & \\
\cline { 2 - 6 } Constructs $^{2}$ & $\begin{array}{r}\text { Independent } \\
\text { Backcountry }\end{array}$ & Day Boat & $\begin{array}{r}\text { Tour } \\
\text { Vessel }\end{array}$ & $\begin{array}{r}\text { Gustavus } \\
\text { Airport }\end{array}$ & $\begin{array}{r}\text { F- } \\
\text { ratio }\end{array}$ & $\begin{array}{r}\mathbf{p} \\
\text { value }\end{array}$ \\
\hline Alaskan Wilderness Experience $^{\text {Solitude \& Natural Sounds }}{ }^{3}$ & - & - & - & - & - & - \\
$\quad$ Natural Connection \& Renewal & & $4.61^{\mathrm{a}}$ & $4.20^{\mathrm{b}}$ & $4.34^{\mathrm{ab}}$ & $4.40^{\mathrm{ab}}$ & 4.79 & .000 \\
Opportunities for Adventure $^{3}$ & $4.69^{\mathrm{a}}$ & $4.37^{\mathrm{b}}$ & $4.46^{\mathrm{b}}$ & $4.45^{\mathrm{b}}$ & 5.81 & .000 \\
Experience Glaciers $^{4}$ & $4.83^{\mathrm{a}}$ & $3.83^{\mathrm{c}}$ & $3.73^{\mathrm{c}}$ & $4.16^{\mathrm{b}}$ & 22.26 & .000 \\
Opportunities to View Wildlife $^{3}$ & 4.74 & 4.77 & 4.80 & 4.80 & 3.23 & .777 \\
\hline
\end{tabular}

1 Values are means.

2 Constructs are derived from 2017 survey data and are coded on a 5-point scale identical to that of the variables: "Very Good" = 5, "Good" = 4, "Average" = 3, "Poor" = 2, "Very Poor" = 1.

${ }^{3}$ Means followed by the same letter are not statistically significantly different with the Hochberg procedure at $\mathrm{p}<.05$.

${ }^{4}$ Means followed by the same letter are not statistically significantly different with the Games-Howell procedure at $p<.05$.

Most visitors who had guided, motorized experiences reported a moderate amount of interaction with GBNP wilderness. Of these populations, tour vessels and people at the Gustavus Airport reported the highest levels of interaction (Table 44).

Table 44. Visitor interactions with wilderness by user group.

\begin{tabular}{lrrr}
\hline User Group & Mean $^{1}$ & SD & Frequency $^{2}$ \\
\hline Tour Vessel & 3.50 & .94 & 195 \\
Gustavus Airport & 3.48 & .97 & 128 \\
Day Boat & 3.18 & 1.01 & 362 \\
\hline
\end{tabular}

${ }^{1}$ Means are based on a 5-point scale: "A great deal" = 5, "Quite a bit" = 4, "Moderate" = 3, "Very little" = 2, "None at all" $=1$.

2 Based on valid data only.

Guided, motorized visitors were asked how they interacted with GBNP wilderness, and the most common response was through observations (76\%). When possible, specific observations were categorized resulting in observations via boat tours (33\%), viewing wildlife (28\%), experiencing glaciers $(8 \%)$, observing from a distance $(7 \%)$, listening to the natural soundscape (4\%), and viewing scenery (4\%). Hiking/walking (31\%), kayaking (10\%), photography (9\%), and nature immersion (3\%) were the next most common responses. A small percentage of visitors $(3 \%)$ reported they either 
had a minimal interaction with wilderness $(2 \%)$, usually because they were limited by the confines of a boat, while $1.3 \%$ of visitors reported there was no interaction with wilderness (Table 45 ).

Table 45. Guided, motorized visitor responses from open-ended questions as to how they interacted with wilderness.

\begin{tabular}{lrr}
\hline Wilderness Experience & Frequency $^{1}$ & Total Response $^{\text {\% }^{1,2}}$ \\
\hline Observations $^{3}$ & 424 & 75.58 \\
$\quad$ Via boat tour & 184 & 32.80 \\
$\quad$ Viewing wildlife & 159 & 28.34 \\
Experiencing glaciers & 46 & 8.20 \\
From a distance & 37 & 6.60 \\
Listening & 23 & 4.10 \\
Scenery/Nature & 23 & 4.10 \\
Hiking/Walking & 175 & 31.19 \\
Kayaking & 56 & 9.98 \\
Photography & 51 & 9.09 \\
Minimal interaction with wilderness ${ }^{4}$ & 19 & 3.39 \\
Nature Immersion & 15 & 2.67 \\
\hline
\end{tabular}

$\mathrm{N}=561$

${ }^{1}$ Frequencies and percentages exceed $100 \%$ because multiple answers could be given per survey.

${ }^{2}$ Reported percentages refer to concepts that were conveyed by $>2.5 \%$ of the population. Based on valid data only.

${ }^{3}$ Observations general category consists of basic observations, as well as more specific classifications presented in the table as sub-categories.

${ }^{4}$ Minimal interaction general category refers to minimal interaction with wilderness $(2 \%)$ and no interaction with wilderness $(1 \%)$.

\section{Place Attachment}

The two most common forms of place attachment were place identity and place dependence. Place identity is defined as an emotional attachment to a place, and place dependence is defined as a utilitarian attachment, meaning the "place" provides the best opportunities for a certain activity or experience (Manning, 2011). Visitors' levels of both place identity and place dependence were measured (Table 46). Visitors scored very high in place identity, which indicates that visitors have a stronger emotional attachment to Glacier Bay. One common trait of place identity is that it is developed over time and after frequent interaction with a place; however, the vast majority - over $80 \%$ - of visitors were visiting for the first time. This would suggest that visitors are having powerful interactions with Glacier Bay and are quickly developing strong emotional attachments with the park. Independent backcountry visitors were also the user group that exhibited the highest degree of place 
identity, which makes sense given the intimate nature of their interaction with Glacier Bay's backcountry. Place dependence, on the other hand, relates to how well a place accommodates visitor objectives, goals and activities. Park visitors exhibited lower levels of place dependence, most falling just above the "neutral" category. Independent backcountry visitors demonstrated a slightly stronger degree of place dependence than other populations, which may be due to their engagement in specialized activities that cannot be achieved in just any environment. Overall, data suggests that visitors do not feel dependent on Glacier Bay for wilderness and/or recreation experiences.

A one-way ANOVA was conducted to see if different populations expressed different levels of place attachment. When comparing all groups with place identity and place dependence scores, independent backcountry visitors were statistically significantly different from the guided, motorized visitors. Independent backcountry visitors showed the highest levels of place identity and place dependence, while the other three populations - day boat, tour vessel, and those at the Gustavus Airport—had similar levels of place identity and place dependence. 
Table 46. A comparison of mean place attachment by visitor type.

\begin{tabular}{|c|c|c|c|c|c|c|c|}
\hline \multirow[b]{2}{*}{ Scale Items ${ }^{2}$} & \multicolumn{4}{|c|}{ Type of User ${ }^{1}$} & \multirow[b]{2}{*}{ F-ratio } & \multirow[b]{2}{*}{$p$ value } & \multirow[b]{2}{*}{$\begin{array}{l}\alpha \text { if item } \\
\text { deletec }\end{array}$} \\
\hline & $\begin{array}{l}\text { Independent } \\
\text { Backcountry }\end{array}$ & Day Boat & $\begin{array}{r}\text { Tour } \\
\text { Vessel }\end{array}$ & $\begin{array}{r}\text { Gustavus } \\
\text { Airport }\end{array}$ & & & \\
\hline Place Identity ${ }^{3}$ & $4.32^{\mathrm{a}}$ & $3.82^{b}$ & $3.75^{b}$ & $3.94^{b}$ & 19.11 & .000 & - \\
\hline GBNP means a lot to me. & 4.78 & 4.37 & 4.35 & 4.38 & - & - & .782 \\
\hline I identify strongly with GBNP. & 3.95 & 3.44 & 3.40 & 3.66 & - & - & .715 \\
\hline I am very attached to GBNP. & 4.23 & 3.64 & 3.48 & 3.77 & - & - & .677 \\
\hline Overall alpha $=.806^{5}$ & - & - & - & - & - & - & - \\
\hline Place Dependence ${ }^{4}$ & $3.59^{a}$ & $3.04^{b}$ & $3.02^{\mathrm{b}}$ & $3.12^{b}$ & 21.04 & .000 & - \\
\hline $\begin{array}{l}\text { I wouldn't substitute any other park or wilderness area for what I } \\
\text { do in GBNP. }\end{array}$ & 3.74 & 3.06 & 3.03 & 3.07 & - & - & .828 \\
\hline I enjoy recreation in GBNP more than in any other park. & 3.73 & 3.18 & 3.09 & 3.31 & - & - & .846 \\
\hline $\begin{array}{l}\text { I get more satisfaction out of visiting GBNP that from visiting any } \\
\text { other wilderness area. }\end{array}$ & 3.47 & 2.87 & 2.89 & 2.98 & - & - & .810 \\
\hline $\begin{array}{l}\text { A wilderness experience in GBNP is more important than a } \\
\text { wilderness experience in any other place. }\end{array}$ & 3.13 & 2.81 & 2.75 & 2.91 & - & - & .816 \\
\hline No other place can compare to GBNP. & 3.83 & 3.30 & 3.33 & 3.35 & - & - & .870 \\
\hline Overall alpha $=.871^{5}$ & - & - & - & - & - & - & - \\
\hline
\end{tabular}

1 Values are means.

2 Scale items are based on Place Attachment theoretical constructs coded on a 5-point scale: "Strongly Agree" = 5, "Agree" = 4, "Neutral" = 3, "Disagree" = 2, "Strongly Disagree" = 1.

${ }^{3}$ Means followed by the same letter are not significantly different with the Hochberg procedure at $p<.05$.

${ }^{4}$ Means followed by the same letter are not significantly different with the Games-Howell procedure at $p<.05$.

${ }^{5}$ Cronbach's alpha based on standardized items. 


\section{Thresholds}

There are many facets that make up a visitor's experience. One of those is understanding if/how frequently visitors encounter things in parks and protected areas that bother them, ultimately detracting from their experience. Respondents were asked a series of questions to better understand what they experienced during their trip, and how experiencing these things affected their visit. In addition, hypothetical scenarios in the form of simulated images displaying a range of conditions were used to determine visitor thresholds of acceptance for crowding and coastal resource conditions. Visitors were handed a random series of images that depicted varying levels of an indicator (i.e., tents/kayaks on a beach, and tent rocks with a fire ring), and they were then asked to indicate the level of acceptability for each image. Using these data, managers can determine when levels of use and resource impacts become less than acceptable to visitors.

First, visitors were given a list of items they may have encountered in GBNP (Table 47), including litter, cruise ships, human waste, etc. Visitors were asked if and how often they encountered these items, and how much the encounter bothered them. Day boat, tour vessel and Gustavus Airport visitors were most bothered by litter, but very few visitors encountered litter-only 6\%. Most visitors who were on guided, motorized trips encountered cruise ships - about two on average - and they reported that seeing cruise ships bothered them "slightly." Overall, levels of "bother" reported by these visitors were very low, indicating that the frequency of encountering the items on the list was quite low, and has not yet reached a point of concern.

Independent backcountry visitors also expressed low levels of "bother" when referring to many items on the list. The element that bothered backcountry visitors the most was cruise ships, which they saw an average of six during their visit. The vast majority of backcountry visitors saw cruise ships; however, the level of bother was between "slight" and "moderate," indicating that backcountry encounters with cruise ships was not a huge concern. Backcountry visitors were also asked about additional things they may have encountered in the backcountry, such as campfire rings, human waste, and campsite impacts. Backcountry visitors reported a low frequency of encountering these things, and of those who did encounter them, levels of "bother" were very low-between "not at all" and "slightly." Therefore, it seems that conditions experienced by all visitors are quite acceptable and have not yet reached or surpassed the point where they are diminishing the visitor experience. 
Table 47. Anthropogenic encounters and the effect on the visitor experience.

\begin{tabular}{|c|c|c|c|c|c|}
\hline \multirow[b]{2}{*}{ Visitor Category } & \multirow[b]{2}{*}{ Anthropogenic Encounter } & \multirow{2}{*}{$\begin{array}{r}\text { How much visitors } \\
\text { were bothered by } \\
\text { seeing (mean) }\end{array}$} & \multirow{2}{*}{$\begin{array}{r}\text { Average \# of } \\
\text { Sightings }\end{array}$} & \multicolumn{2}{|c|}{ Frequency Seen ${ }^{4}$} \\
\hline & & & & Yes & No \\
\hline \multirow[t]{9}{*}{ Guided, Motorized Visitors ${ }^{1}$} & Litter & 3.22 & 2.40 & 36 & 627 \\
\hline & Cruise ship & 2.16 & 2.09 & 601 & 72 \\
\hline & Propeller-driven aircraft & 1.36 & 2.48 & 137 & 523 \\
\hline & Motorized boats (other than cruise ships) & 1.33 & 4.24 & 578 & 89 \\
\hline & Groups you saw who were on the water & 1.21 & 2.99 & 319 & 339 \\
\hline & Tents on the beach & 1.13 & 2.72 & 160 & 502 \\
\hline & People on the beach & 1.11 & 6.70 & 345 & 320 \\
\hline & Groups you saw who were on land & 1.11 & 2.45 & 316 & 344 \\
\hline & Kayaks & 1.05 & 6.81 & 535 & 132 \\
\hline \multirow[t]{9}{*}{ Independent Backcountry Visitors ${ }^{2}$} & Cruise ship & 2.71 & 6.51 & 106 & 11 \\
\hline & Litter & 2.31 & 1.62 & 35 & 83 \\
\hline & Propeller-driven aircraft & 2.03 & 3.30 & 71 & 45 \\
\hline & Motorized boats (other than cruise ships) & 2.01 & 7.74 & 102 & 16 \\
\hline & People on the beach & 1.32 & 6.06 & 80 & 38 \\
\hline & Groups you saw who were on land & 1.31 & 2.03 & 73 & 45 \\
\hline & Tents on the beach & 1.30 & 4.20 & 72 & 46 \\
\hline & Kayaks & 1.18 & 6.81 & 111 & 7 \\
\hline & Groups you saw who were on the water & 1.16 & 2.64 & 86 & 32 \\
\hline
\end{tabular}

\footnotetext{
${ }^{1}$ Guided, motorized visitor $\mathrm{N}=698$

2 Independent backcountry visitor $\mathrm{N}=124$

${ }^{3}$ Means are based on a 5-point scale: "Extremely" = 5, "Very" = 4, "Moderately" = 3, "Slightly" = 2, "Not at all" = 1 .

${ }^{4}$ Values may not equal total $\mathrm{N}$ due to missing values.
} 
Table 47 (continued). Anthropogenic encounters and the effect on the visitor experience.

\begin{tabular}{|c|c|c|c|c|c|}
\hline \multirow[b]{2}{*}{ Visitor Category } & \multirow[b]{2}{*}{ Anthropogenic Encounter } & \multirow{2}{*}{$\begin{array}{r}\text { How much visitors } \\
\text { were bothered by } \\
\text { seeing (mean) }\end{array}$} & \multirow{2}{*}{$\begin{array}{r}\text { Average \# of } \\
\text { Sightings }\end{array}$} & \multicolumn{2}{|c|}{ Frequency Seen ${ }^{4}$} \\
\hline & & & & Yes & No \\
\hline \multirow[t]{6}{*}{ Backcountry Specific Items ${ }^{2}$} & Campfire rings & 1.76 & 1.17 & 26 & 92 \\
\hline & Human waste & 1.75 & 1.17 & 12 & 106 \\
\hline & $\begin{array}{l}\text { Hiker-made campsites (e.g., soil compaction, } \\
\text { vegetation trampling due to tends, tent rocks) }\end{array}$ & 1.35 & 2.55 & 45 & 73 \\
\hline & Hiker-made trails & 1.30 & 1.42 & 24 & 94 \\
\hline & Cut bushes and tress & 1.17 & 3.00 & 6 & 112 \\
\hline & $\begin{array}{l}\text { NPS backcountry staff (such as law } \\
\text { enforcement and researchers) }\end{array}$ & 1.11 & 2.17 & 27 & 91 \\
\hline
\end{tabular}

\footnotetext{
${ }^{1}$ Guided, motorized visitor $\mathrm{N}=698$

2 Independent backcountry visitor $\mathrm{N}=124$

${ }^{3}$ Means are based on a 5-point scale: "Extremely" = 5, "Very" = 4, "Moderately" = 3, "Slightly" = 2, "Not at all" = 1.

${ }^{4}$ Values may not equal total $\mathrm{N}$ due to missing values.
} 
An objective of this question was to understand differences in the effect each item had on the overall visitor experience between populations. A one-way ANOVA was conducted using mean scores (Table 48). There were no differences for levels of bother for tents on the beach, people on the beach, litter, or groups seen on land. Following the trend, independent backcountry visitors were statistically significantly different $(\mathrm{p}<.000)$ for cruise ships, motorized boats, groups seen on land and propellerdriven aircrafts. Visitors with a guided, motorized experience did not differ amongst themselves for any item and the respective level of bother. Day boat passengers and those at the Gustavus Airport reported the highest levels of bother at 3.43 and 3.23, respectively. This may be attributed to the additional time spent around developed areas (Bartlett Cove and Gustavus) compared to backcountry or tour vessel visitors.

Table 48. A comparison of anthropogenic encounters and the effect on the visitor experience by population.

\begin{tabular}{|c|c|c|c|c|c|c|}
\hline \multirow[b]{2}{*}{$\begin{array}{l}\text { How much visitors were } \\
\text { bothered by seeing: }{ }^{2}\end{array}$} & \multicolumn{4}{|c|}{ Type of User ${ }^{1}$} & \multirow[b]{2}{*}{ F-ratio } & \multirow[b]{2}{*}{$p$ value } \\
\hline & $\begin{array}{l}\text { Independent } \\
\text { Backcountry }\end{array}$ & Day Boat & $\begin{array}{l}\text { Tour } \\
\text { Vessel }\end{array}$ & $\begin{array}{r}\text { Gustavus } \\
\text { Airport }\end{array}$ & & \\
\hline Cruise ship 3 & $2.70^{\mathrm{a}}$ & $2.16^{b}$ & $2.12^{\mathrm{b}}$ & $2.21^{\mathrm{b}}$ & 6.43 & .000 \\
\hline Kayaks $^{4}$ & $1.18^{a}$ & $1.06^{a b}$ & $1.06^{a b}$ & $1.02^{\mathrm{b}}$ & 5.46 & .001 \\
\hline Tents on the beach ${ }^{4}$ & 1.30 & 1.12 & 1.17 & 1.11 & 1.40 & .251 \\
\hline Motorized boats ${ }^{4}$ & $2.01^{\mathrm{a}}$ & $1.32^{\mathrm{b}}$ & $1.31^{\mathrm{b}}$ & $1.41^{\mathrm{b}}$ & 14.87 & .000 \\
\hline People on the beach ${ }^{4}$ & 1.32 & 1.10 & 1.22 & 1.09 & 3.06 & .031 \\
\hline Litter $^{3}$ & 2.31 & 3.43 & 2.89 & 3.23 & 2.78 & .048 \\
\hline $\begin{array}{l}\text { Groups you saw who were on } \\
\text { land } 4\end{array}$ & $1.31^{\mathrm{a}}$ & $1.06^{b}$ & $1.19^{a b}$ & $1.15^{\mathrm{ab}}$ & 3.62 & .015 \\
\hline $\begin{array}{l}\text { Groups you saw who were on the } \\
\text { water }^{4}\end{array}$ & 1.16 & 1.16 & 1.29 & 1.18 & .853 & .467 \\
\hline Propeller-driven aircraft ${ }^{4}$ & $2.03^{a}$ & $1.36^{\mathrm{b}}$ & $1.48^{\mathrm{b}}$ & $1.25^{\mathrm{b}}$ & 6.80 & .000 \\
\hline \multicolumn{7}{|l|}{${ }^{1}$ Values are scale means. } \\
\hline $\begin{array}{l}{ }^{2} \text { Concepts are derived from fa } \\
\text { of the variables: "Extremely" }\end{array}$ & $\begin{array}{l}\text { analysis of al } \\
\text { "Very" = 4, "N }\end{array}$ & $\begin{array}{l}\text { questions a } \\
\text { rately" = } 3\end{array}$ & $\begin{array}{l}\text { are code } \\
\text { lightly" = }\end{array}$ & $\begin{array}{l}\text { on a 5-poin } \\
\text { "Not at All" }\end{array}$ & $\begin{array}{l}\text { scale ide } \\
1 .\end{array}$ & ical to that \\
\hline
\end{tabular}

Table 49 presents data showing how much the backcountry experience was affected by a variety of anthropogenic encounters, such as other groups, national park law enforcement, etc. The scale used to measure this effect ranged from 5 "added greatly" to 1 "detracted greatly." On average, visitors did not say that encountering any of the listed items added to their backcountry experience. The only element that seemed to detract from the visitor experience were seeing/hearing cruise ships, hearing other motor boats, and vessel wakes. Ultimately, it seems that experiencing motorized use was the 
only thing that visitors reported detracting from the backcountry experience; however, visitors indicated that it only "slightly detracted" from their backcountry experience, on average.

Table 49. How anthropogenic visitor encounters affected the quality of independent backcountry visitor experience.

\begin{tabular}{|c|c|c|c|}
\hline Anthropogenic Encounter & Mean $^{1}$ & SD & Frequency $^{2}$ \\
\hline Kayaking groups encountered & 3.11 & 0.74 & 102 \\
\hline NPS backcountry staff (law enforcement, researchers) & 3.05 & 0.68 & 44 \\
\hline Scientific research signs, including people and equipment & 3.04 & 0.80 & 45 \\
\hline Tents on the beaches & 2.91 & 0.59 & 80 \\
\hline Vessel wakes you saw, heard or felt & 2.37 & 0.78 & 103 \\
\hline Motorized boats you heard (other than cruise ships) & 2.18 & 0.71 & 106 \\
\hline Cruise ships you saw and/or heard & 2.01 & 0.82 & 108 \\
\hline
\end{tabular}

Visitors were asked if the actions of others interfered with their experience (Table 50). Twelve percent of visitors said yes, the actions of others interfered with their experience, while the majority $(88 \%)$ said they did not. When asked to clarify their response, the two most common causes of interference were other visitors (59\%) ranging from impeding views to climbing on an iceberg (Table 51). It is important to note that the three reports of others climbing on an iceberg were observed from a single tour vessel and was part of one occurrence. Cruise ships (33\%) were the second most reported element interfering with the visitor experience.

Table 50. Interfering actions of others.

\begin{tabular}{lrr}
\hline Interference & Frequency & Total Response \% ${ }^{1}$ \\
\hline Yes & 94 & 11.7 \\
No & 708 & 88.3 \\
\hline \multicolumn{1}{c}{$\mathrm{N}=802$} & & \\
$\quad{ }^{1}$ Based on valid data only. & &
\end{tabular}


Table 51. How other groups interfered with visitor's experience.

\begin{tabular}{|c|c|c|}
\hline Group Type & Frequency $^{1}$ & Total Response $\%{ }^{1,2}$ \\
\hline Other visitors ${ }^{3}$ & 53 & 58.89 \\
\hline Impeding views & 10 & 11.11 \\
\hline Backcountry visitors ${ }^{4}$ & 8 & 8.89 \\
\hline Children's behavior & 7 & 7.78 \\
\hline Speaking loudly & 7 & 7.78 \\
\hline Unwanted conversation & 3 & 3.33 \\
\hline Competing for space ${ }^{5}$ & 3 & 3.33 \\
\hline Climbing on iceberg ${ }^{6}$ & 3 & 3.33 \\
\hline Other ${ }^{7}$ & 12 & 13.34 \\
\hline Cruise ships $^{8}$ & 27 & 30.00 \\
\hline Anthropogenic sounds & 7 & 7.78 \\
\hline Kayaker drop off/pick up & 3 & 3.33 \\
\hline NPS staff interaction ${ }^{9}$ & 3 & 3.33 \\
\hline \multicolumn{3}{|l|}{$N=90$} \\
\hline \multicolumn{3}{|c|}{${ }^{1}$ Frequencies and percentages exceed $100 \%$ because multiple answers could be given per survey. } \\
\hline \multicolumn{3}{|c|}{${ }^{2}$ Reported percentages refer to concepts that were conveyed by $>2.5 \%$ of the population. } \\
\hline \multicolumn{3}{|c|}{$\begin{array}{l}{ }^{3} \text { Other visitor general category refers to a variety of interactions with more specific classifications presented in } \\
\text { the table as sub-categories. }\end{array}$} \\
\hline \multicolumn{3}{|c|}{$\begin{array}{l}{ }^{4} \text { Backcountry visitor category refers to backcountry visitors interacting with other backcountry users }(7 \%) \text { and } \\
\text { day boat passengers watching kayakers interact too closely with bears on the shore }(2 \%) \text {. }\end{array}$} \\
\hline \multicolumn{3}{|c|}{${ }^{5}$ Specific to the day boat experience. } \\
\hline \multicolumn{3}{|c|}{${ }^{6}$ All reports occurred on the same day and were specific to a tour vessel experience. } \\
\hline \multicolumn{3}{|c|}{${ }^{7}$ Other miscellaneous responses associated to "other visitors" that were reported by $<2.5 \%$ of the population. } \\
\hline \multicolumn{3}{|c|}{$\begin{array}{l}{ }^{8} \text { Cruise ship general category refers to seeing cruise ships }(12 \%) \text {, placement of cruise ships impeding view of } \\
\text { glaciers }(9 \%) \text {, feeling the wake }(3 \%) \text {, and other miscellaneous responses that were reported by }<2.5 \% \text { of the } \\
\text { population }(6 \%) \text {. }\end{array}$} \\
\hline
\end{tabular}

In addition to asking independent backcountry visitors what they saw, they were also asked to report what they heard and how much each of those sounds bothered them (Table 52). Backcountry visitors were most bothered by public addresses aboard commercial vessels; however, only $34 \%$ of visitors reported hearing these addresses, and the level of bother only reached "moderate." Many more visitors (79\%) heard motor boats while in the backcountry, but the level of bother from these sounds was only between "slight" and "moderate." Overall, anthropogenic sounds in the backcountry of Glacier Bay did detract from visitors' experiences, but not to a level that would be of great concern. 
Table 52. Anthropogenic sounds heard by independent backcountry visitors.

\begin{tabular}{|c|c|c|c|c|}
\hline \multirow[b]{2}{*}{ Sound Type } & \multirow{2}{*}{$\begin{array}{r}\text { How much visitors } \\
\text { were bothered by } \\
\text { the sighting }(M)^{1}\end{array}$} & \multicolumn{2}{|c|}{ Frequency Heard ${ }^{2}$} & \multirow[b]{2}{*}{ Percent (Yes) } \\
\hline & & Yes & No & \\
\hline $\begin{array}{l}\text { Public address system aboard } \\
\text { commercial vessels }\end{array}$ & 2.98 & 42 & 77 & 33.9 \\
\hline Boat motors & 2.39 & 98 & 21 & 79.0 \\
\hline Sounds of generators & 2.17 & 18 & 102 & 14.5 \\
\hline Aircraft & 2.04 & 93 & 26 & 75.0 \\
\hline Other & 2.00 & 8 & 8 & 6.5 \\
\hline Vessel wake crashing on the beach & 1.96 & 75 & 45 & 60.5 \\
\hline People shouting or speaking loudly & 1.82 & 22 & 97 & 17.7 \\
\hline Loud music & 1.20 & 5 & 114 & 4.0 \\
\hline \multicolumn{5}{|l|}{$N=124$} \\
\hline $\begin{array}{l}{ }^{1} \text { Means are based on a } 5 \text {-point } \\
\text { "Not at All" }=1 .\end{array}$ & ely" = 5, "Very" = 4 & oderately & tll & 2 \\
\hline
\end{tabular}

Visitors were presented with a list of hypothetical scenarios and developments within GBNP that may add or detract from the wilderness experience (Table 53). Visitors leaned toward requiring bear cans for all backcountry users, saying that would add somewhat to the experience. Visitors said the presence of floating cabins or rafts, outhouses, or developed facilitates would detract from the wilderness experience.

Table 53. Effect on visitor wilderness experience based on possible future management facilities.

\begin{tabular}{lrrr}
\hline Scenario & Mean $^{1}$ & SD & Frequency $^{2}$ \\
\hline Being required to use bear cans & 3.59 & .95 & 122 \\
Encountering NPS backcountry staff & 3.12 & .87 & 120 \\
Presence of developed trails & 2.48 & 1.23 & 120 \\
Presence of designated campsites & 2.01 & .96 & 119 \\
Presence of developed facilities (e.g., rain shelters, bridges over rivers) & 1.79 & 1.02 & 117 \\
Presence of outhouses & 1.77 & .99 & 119 \\
Presence of floating cabins or rafts & 1.60 & .89 & 118 \\
\hline
\end{tabular}

$\mathrm{N}=124$

${ }^{1}$ Means are based on a 5-point scale: "Add Greatly" = 5, "Add Somewhat" = 4, "No effect" = 3, "Detract Somewhat" = 2, "Detract Greatly" = 1.

2 Based on valid data only. 
Visitor thresholds of acceptance for crowding were studied using simulated photos showing different numbers of tents and kayaks on a beach in Glacier Bay National Park (see Appendix A). The measurement scale made available to visitors ranged from 3 "highly acceptable" to -3 "highly unacceptable." The highest mean, or preferred condition, was 2.53 with 0 tents and kayaks combined on the beach. The lowest mean, or displacement condition, was -2.22 with 20 tents and kayaks combined on the beach. Using the point-slope line equation, the minimum acceptable condition was 6.2 tents and kayaks. This suggests that visitors feel that any more than 6.2 tents and kayaks (i.e., a group size of 6 or less) is less than preferred. The norm curve based on this data can be found in Figure 12.

The Potential for Conflict Index (PCI) ranged from .04 (much agreement) to .36 (agreement), suggesting respondents were predominately in agreement regarding crowding thresholds.

Respondents agreed most on the third image with four tents and four kayaks on the beach as being unacceptable. Respondents disagreed most on the first image with no tents or kayaks on the beach. Although there was some disagreement that no tents or kayaks was highly acceptable, there was more agreement than disagreement. This may suggest that some independent backcountry visitors feel that any level of use on a beach becomes less than preferred.

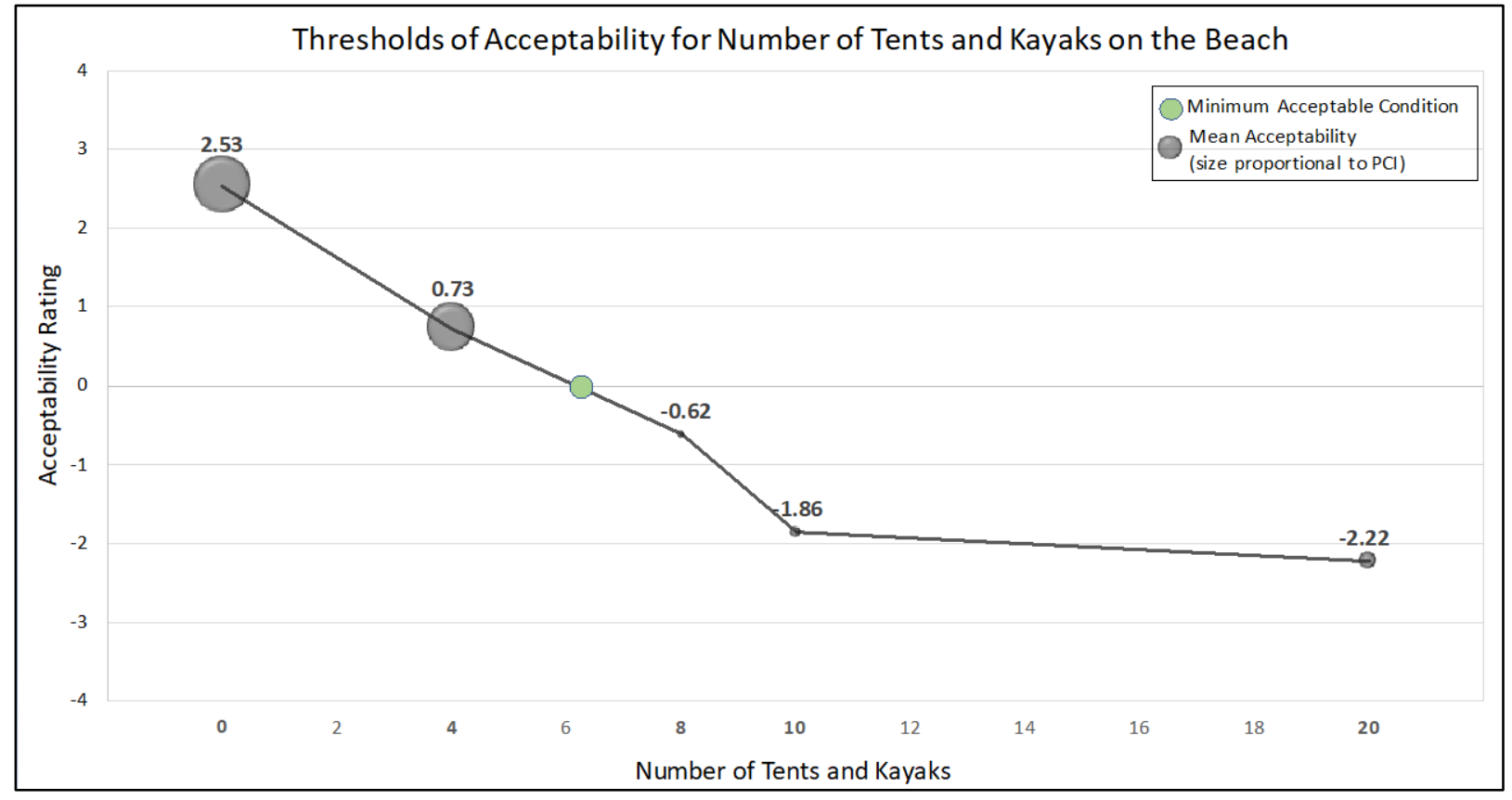

Figure 12. Social norm curve for crowding conditions in Glacier Bay National Park. The minimum acceptable condition is 6.2 tents and kayaks. Larger bubbles indicate less agreement. Smaller bubbles indicate more agreement. Respondent agreement is based on $\mathrm{PCl}$ scores.

Thresholds of acceptance for coastal resource conditions were measured using the presence of tent rocks on a beach (see Appendix A). For the photo with the highest number of tent rocks, a fire ring was also included. Similar to the other photo series, the measurement scale made available to visitors ranged from 3 "highly acceptable" to -3 "highly unacceptable." The highest mean, or preferred 
condition, was 1.8 with 0 tent rocks present. The lowest mean, or displacement condition, was -1.49 with 20 tent rocks and a fire ring present. Using the point-slope line equation, the minimum acceptable condition was 8.5 tent rocks, with the assumption of no fire ring. This suggests that visitors feel that any more than 8.5 tent rocks are unacceptable. The norm curve based on this data can be found in Figure 13.

The PCI ranged from .11 (agreement) to .55 (some disagreement), suggesting respondents were in some agreement regarding coastal resource condition thresholds. Respondents agreed most on the second image with five tent rocks present as being acceptable. Respondents disagreed most on the third image with 10 tent rocks present.

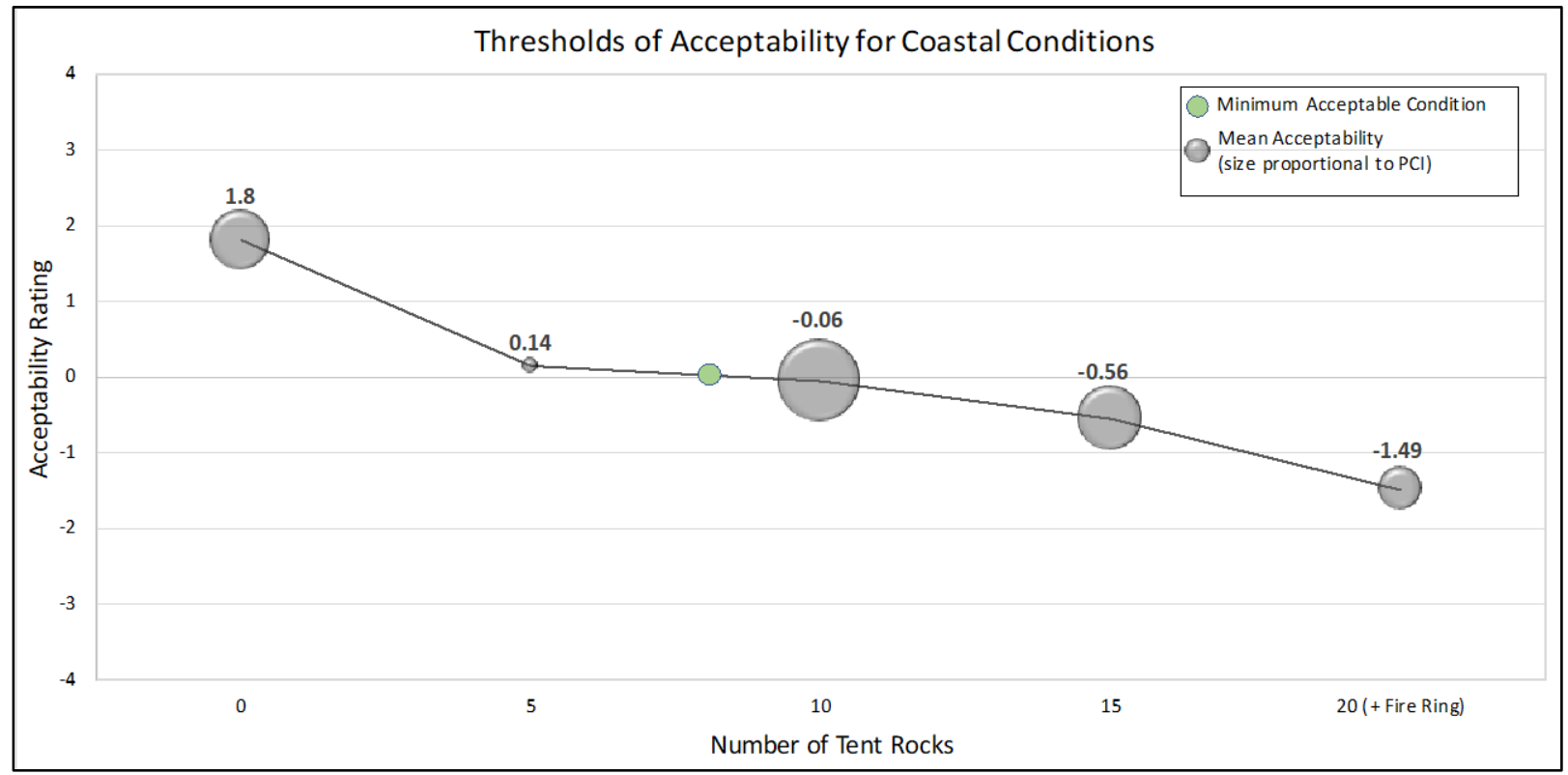

Figure 13. Social norm curve for coastal resource conditions in Glacier Bay National Park. The minimum acceptable condition is 8.5 tent rocks. Larger bubbles indicate less agreement. Smaller bubbles indicate more agreement. Respondent agreement is based on PCl scores.

\section{Leave-No-Trace Knowledge and Use}

Visitors were asked about their current "Leave-No-Trace" (LNT) knowledge. Means were compared to better understand differences among levels of knowledge in relation to experience use history and between visitor groups. There was no difference of LNT knowledge based on the number of visits to GBNP in the past five years (Table 54). Considering the number of visitors to GBNP within a lifetime, there was a statistically significant difference $(\mathrm{p}<.05)$ between only visiting once and visiting more than 10 times (Table 55). Independent backcountry visitors reported having the most knowledge of Leave-No-Trace and were statistically significantly different $(p<.000)$ than all other populations. People riding the day boat reported having the least knowledge, but still ranked themselves "above average" (Table 56). 
Table 54. A comparison of mean Leave No Trace knowledge by past five-year experience use history.

\begin{tabular}{|c|c|c|c|c|c|c|c|}
\hline \multirow[b]{2}{*}{ Knowledge } & \multicolumn{5}{|c|}{ Experience Use in Past 5 Years ${ }^{1}$} & \multirow[b]{2}{*}{ F-ratio } & \multirow[b]{2}{*}{$p$ value } \\
\hline & Once & 2 & 3 & $4-10$ & $>10$ & & \\
\hline $\begin{array}{l}\text { Current "Leave No Trace" } \\
\text { Knowledge }\end{array}$ & 4.99 & 5.17 & 5.73 & 5.36 & 5.54 & 3.23 & .012 \\
\hline
\end{tabular}

1 Values are means.

${ }^{2}$ LNT knowledge is based on a 6-point scale: "Extensive" = 5, "Above Average" = 4, "Fair" = 3, "Limited" = 2, "Very Limited" = 1, "No Knowledge" = 0.

${ }^{3}$ Means are not statistically significantly different based on the Hochberg procedure at $p<.05$.

Table 55. A comparison of mean Leave No Trace knowledge by lifetime experience use history.

\begin{tabular}{llllllll}
\hline & \multicolumn{5}{c}{ Experience Use for Lifetime } & & \\
\cline { 2 - 6 } Knowledge & Once & $\mathbf{2}$ & $\mathbf{3}$ & $\mathbf{4 - 1 0}$ & $\mathbf{> 1 0}$ & F-ratio & p value \\
\hline $\begin{array}{l}\text { Current "Leave No Trace" } \\
\text { Knowledge } 2,3\end{array}$ & $4.96^{\mathrm{b}}$ & $5.24^{\mathrm{ab}}$ & $5.50^{\mathrm{ab}}$ & $5.17^{\mathrm{ab}}$ & $5.58^{\mathrm{a}}$ & 4.79 & .001 \\
\hline
\end{tabular}

${ }^{1}$ Values are means.

2 LNT knowledge is based on a 6-point scale: "Extensive" = 5, "Above Average" = 4, "Fair" = 3, "Limited" = 2, "Very Limited" = 1, "No Knowledge" = 0.

${ }^{3}$ Means followed by the same letter are not statistically significantly different with the Hochberg procedure at $p<.05$.

Table 56. A comparison of mean Leave No Trace knowledge by visitor type.

\begin{tabular}{|c|c|c|c|c|c|c|}
\hline \multirow[b]{2}{*}{ Knowledge } & \multicolumn{4}{|c|}{ Type of User ${ }^{1}$} & \multirow[b]{2}{*}{ F-ratio } & \multirow[b]{2}{*}{$p$ value } \\
\hline & $\begin{array}{l}\text { Independent } \\
\text { Backcountry }\end{array}$ & Day Boat & $\begin{array}{r}\text { Tour } \\
\text { Vessel }\end{array}$ & $\begin{array}{r}\text { Gustavus } \\
\text { Airport }\end{array}$ & & \\
\hline $\begin{array}{l}\text { Current "Leave No Trace" } \\
\text { Knowledge } 2,3\end{array}$ & $5.48^{a}$ & $4.91^{\mathrm{b}}$ & $4.95^{\mathrm{b}}$ & $5.04^{b}$ & 21.51 & .000 \\
\hline \multicolumn{7}{|l|}{${ }^{1}$ Values are means. } \\
\hline \multicolumn{7}{|c|}{$\begin{array}{l}2 \text { Knowledge is based on a 6-point scale: "Extensive" = 5, "Above Average" = 4, "Fair" = 3, "Limited" = 2, "Very } \\
\text { Limited" = } 1 \text {, "No Knowledge" }=0 .\end{array}$} \\
\hline
\end{tabular}

In an open answer format, visitors were asked to report anything that prevented them from following Leave-No-Trace practices (Table 57). Most visitors (73\%) said "nothing" prevented them, while others said that camping, weather, personal challenges, and walking prevented them from following LNT practices. A few others expressed that using the bathroom, sometimes due to other visitors, and cooking, due to tides, were also cause for not following LNT practices. 
Table 57. Independent backcountry visitor reports of what prevented them from following LNT practices.

\begin{tabular}{|c|c|c|}
\hline Reason & Frequency $^{1}$ & Total Response $\%^{1}$ \\
\hline Nothing prevented LNT practices & 69 & 73.40 \\
\hline Camping ${ }^{2}$ & 10 & 10.64 \\
\hline Weather & 5 & 5.32 \\
\hline Personal challenges ${ }^{3}$ & 5 & 5.32 \\
\hline Walking leaving footprints behind & 4 & 4.26 \\
\hline Human waste disposal ${ }^{4}$ & 3 & 3.19 \\
\hline Cooking & 2 & 2.13 \\
\hline
\end{tabular}

$\mathrm{N}=94$

${ }^{1}$ Frequencies and percentages exceed $100 \%$ because multiple answers could be given per survey.

${ }^{2}$ Camping category refers to camping directly on vegetation (5\%) and camping in general (5\%).

${ }^{3}$ Personal challenges category refers to being considerate to others, being too tired, or losing an item in the backcountry.

${ }^{4}$ Human waste disposal issues due to other visitors being present $(2 \%)$.

\section{Orientation Video}

There was interest in exploring how effective the backcountry orientation video was at preparing people for their backcountry experience in GBNP. Visitors were asked how the backcountry orientation video added to or detracted from their experience (Table 58). Respondents reported that the orientation video added most in preparing them for bears, food storage and dealing with human waste, while it added least in terms of selecting routes and campsites. Visitors ranked all items in the list relatively high, and all mean scores were near or above "added somewhat." Therefore, it seems that visitors felt the backcountry orientation was adequately preparing them for their backcountry experience; however, more information could be provided regarding selecting sites and routes in GBNP backcountry. 
Table 58. Effect of VIS backcountry orientation video on visitor wilderness experience.

\begin{tabular}{llll}
\hline Video Topic & Mean & SD & Frequency $^{2}$ \\
\hline Bears / food storage & 4.22 & .79 & 113 \\
Human waste & 4.19 & .81 & 113 \\
NPS regulations on what you can do & 4.06 & .77 & 112 \\
Tides & 4.03 & .84 & 112 \\
Importance of self-reliance & 4.03 & .80 & 112 \\
NPS regulations on where you can go & 4.01 & .82 & 112 \\
Potential challenges & 3.93 & .76 & 113 \\
Day boat transportation & 3.88 & .91 & 113 \\
Selecting campsites & 3.81 & .77 & 113 \\
Routes & 3.71 & .81 & 112 \\
\hline $\begin{array}{l}\text { N = 124 } \\
1 \text { Means are based on a 5-point scale: "Added Greatly (the right amount of information)" = 5, }\end{array}$
\end{tabular}

To further understand the depth of the orientation video, backcountry visitors were asked if there were any gaps in information provided during the backcountry orientation, with $51 \%$ reporting yes. A follow up open-ended question was asked to see where those gaps were with varied results. Out of those that responded yes to orientation video gaps (51\%), 19\% suggested more information regarding tides (e.g., reading tide charts, what to do in tidal rips, etc.), 10\% asked for more on bear safety, and 9\% wanted to know more about day boat related information (e.g., pick up and drop off locations, preparation, missing pick-up time, etc.). Other suggestions ( $<9 \%$ each) included more information on wildlife encounters (i.e., what to do if a seal approaches the kayak; whales; etc.), water sources, campsite selection (e.g., tidal considerations, vegetation, and more appropriate places to camp for larger kayaking groups), and weather forecasts and changes. One visitor asked for a more technical suggestion to add more subtitle languages.

\section{Spatial Element}

In 2017, visitors were asked to report where they planned to travel throughout GBNP during their trip (Table 14). In 2018, independent backcountry visitors were asked to report where they actually traveled throughout GBNP (Table 59). Most visitors reported traveling within non-motorized waters (56\%) and the West Arm in Glacier Bay (56\%), with fewer individuals traveling through the Beardslee Islands (43\%), Mid Bay (27\%) and East Arm (24\%). The least traveled areas include inland areas of the park, the Icy Strait, outer coast and other locations. Many groups traveled through multiple areas during their trip, which is why percentages are more than $100 \%$. 
Table 59. Areas visited by backcountry users.

\begin{tabular}{|c|c|c|c|c|c|c|}
\hline \multirow[b]{2}{*}{ Area } & \multicolumn{2}{|c|}{ Yes } & \multicolumn{2}{|c|}{ No } & \multicolumn{2}{|c|}{ Not Sure } \\
\hline & Frequency & Percent $^{1}$ & Frequency & Percent ${ }^{1}$ & Frequency & Percent $^{1}$ \\
\hline $\begin{array}{l}\text { Non-motorized waters of Glacier } \\
\text { Bay }\end{array}$ & 69 & 55.6 & 28 & 22.6 & 1 & 0.8 \\
\hline $\begin{array}{l}\text { West Arm Glacier Bay } \\
\text { (Northwest of Tlingit Point) }\end{array}$ & 69 & 55.6 & 26 & 21.0 & 1 & 0.8 \\
\hline Beardslee Islands & 53 & 42.7 & 43 & 34.7 & - & - \\
\hline $\begin{array}{l}\text { Mid Bay (Willoughby Island North } \\
\text { of Tlingit Point and Muir Point) }\end{array}$ & 33 & 26.6 & 50 & 40.3 & 1 & 0.8 \\
\hline $\begin{array}{l}\text { East Arm Glacier Bay (North of } \\
\text { Muir Point) }\end{array}$ & 30 & 24.2 & 57 & 46.0 & - & - \\
\hline $\begin{array}{l}\text { Lower Bay (North of Pt. } \\
\text { Gustavus, South of Willoughby } \\
\text { Island, and excluding the } \\
\text { Beardslee Islands) }\end{array}$ & 22 & 17.7 & 56 & 45.2 & 2 & 1.6 \\
\hline $\begin{array}{l}\text { Inland areas of the park (more } \\
\text { than on mile inland from the } \\
\text { shoreline) }\end{array}$ & 13 & 10.5 & 66 & 53.2 & 2 & 1.6 \\
\hline $\begin{array}{l}\text { Icy Strait / Cross Sound (Dundas } \\
\text { Bay, Taylor Bay/Fern Harbor) }\end{array}$ & 5 & 4.0 & 71 & 57.3 & 2 & 1.6 \\
\hline Other Location(s) & 4 & 3.2 & 6 & 4.8 & - & - \\
\hline Outer Coast & 1 & 0.8 & 74 & 59.7 & - & - \\
\hline
\end{tabular}

$\mathrm{N}=124$

${ }^{1}$ Based on valid data only, invalid or missing data ranged per location.

Independent backcountry visitors were asked if they had difficulty finding a place to camp and/or anchor during their trip, with only $2 \%$ of visitors reporting yes (Table 60 ). There was space on the survey to provide clarification. The difficulties resulted from camping space limitations at Chocolate Falls in Johns Hopkins Inlet and around Lamplugh Glacier. Marine weather conditions were also mentioned as making it more difficult to find places to camp/anchor.

Table 60. Difficulty finding a place to camp/anchor for backcountry users.

\begin{tabular}{lrr}
\hline Difficulty & Frequency & Total Response \% \\
\hline Yes $^{1}$ & 2 & 1.8 \\
No & 112 & 98.2 \\
\hline
\end{tabular}

$\mathrm{N}=114$

${ }^{1}$ Reported locations where visitors had difficulty finding camp sites include Chocolate Falls and Lamplugh Glacier, in addition to marine weather conditions. 
All 2018 GPS tracks that were successfully collected are represented in Figure 14. In total, there are 124 backcountry visitors who completed a survey, 54 that agreed to take a GPS unit, and 45 tracks that were successfully paired with a completed survey. Out of the 54 tracks, only eight GPS units died before the trip was complete.

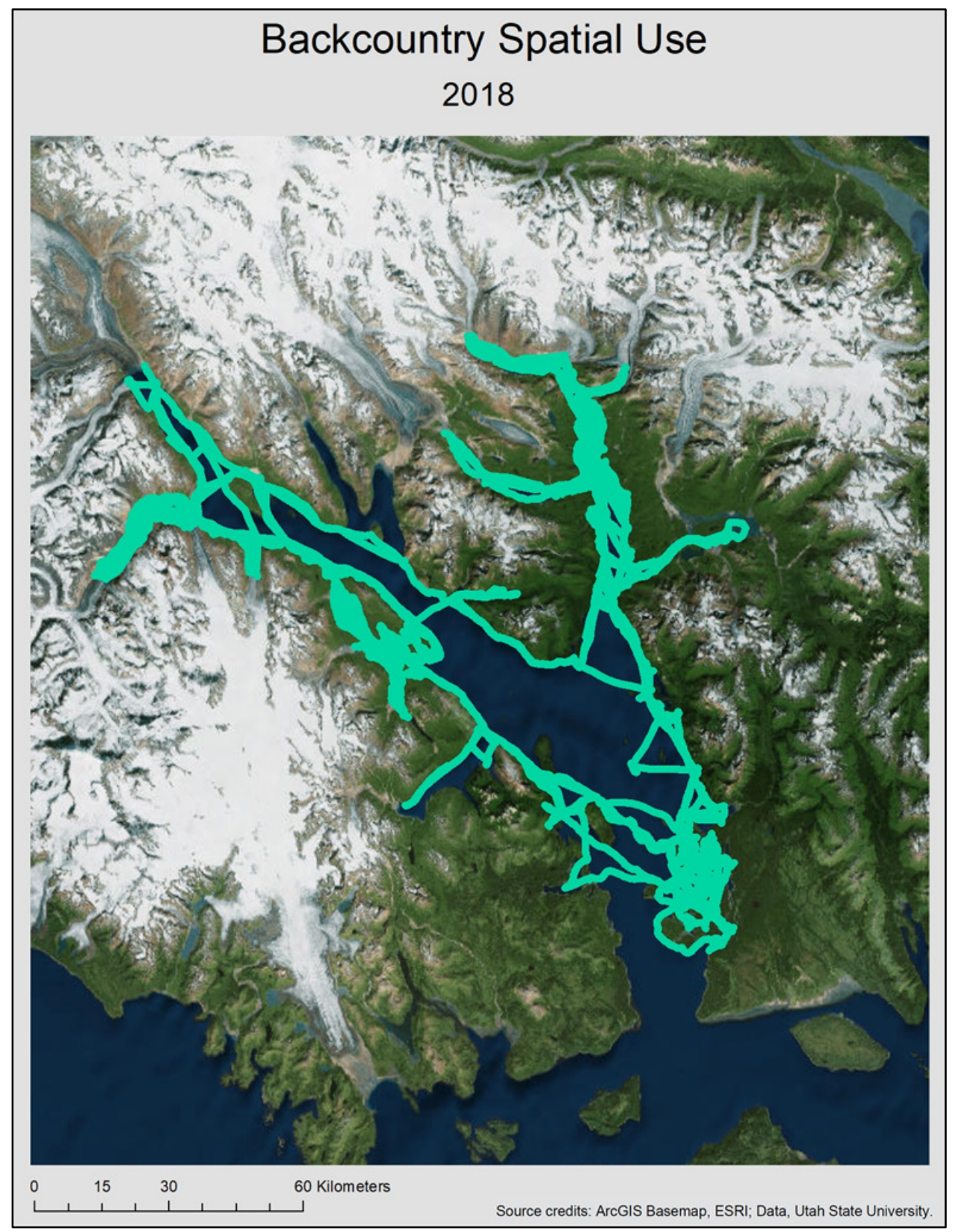

Figure 14. A total of 45 GPS tracks representing 2018 backcountry visitor spatial use in Glacier Bay National Park. Not all tracks were paired to valid survey data.

Using Kernel Density analysis, Figure 15 represents the level of use for all 2018 GPS tracks. Similar to 2017 use, there were high use centers in the West Arm (the base of Johns Hopkins Glacier and around Reid Inlet), but there were additional high use areas located central to Scidmore, Sundew and 
Ptarmigan drop off locations. Additionally, in the East Arm, there was high use at the base of McBride Glacier. There was moderate to low use in the Beardslee Islands, East Arm (at the base of Muir Glacier, Adams Inlet entrance, and at Mt. Wright drop off), and West Arm (patches throughout) Johns Hopkins Inlet and at the base of Johns Hopkins Glacier, base of Lamplugh Glacier, the entrance to Reid Inlet around towards Scidmore drop off, and areas around Gilbert Peninsula). There was low to very low use in the outer limits of the Beardslee Islands, Berg Bay, Geikie Inlet, West Arm (Tarr Inlet, Tidal Inlet, Charpentier Inlet, and the Northeast side of the West Arm split) and parts of the East arm (Sturgess Island, patches throughout Muir Inlet, Adams Inlet, Wachusett Inlet and the base of Riggs Glacier). Most areas within the bay were visited to some extent, except for Rendu and Queen Inlets.

To better understand use in high-density areas, each high-density area was reclassified, polygons were formed using the Raster to Polygon tool, and all points were selected using the Intercept tool. This allowed all points specifically in high use areas to be analyzed independent from the whole track. Descriptive measurements for these high-density areas are presented in Table 61. 
Table 61. Attributes of tracks within high-density areas in 2018.

\begin{tabular}{|c|c|c|c|c|c|c|c|c|c|}
\hline Region & Area & $\begin{array}{r}\text { \# of } \\
\text { Tracks } \\
\text { Included }\end{array}$ & $\begin{array}{r}\text { Passing } \\
\text { Through }^{1}\end{array}$ & $\begin{array}{r}\text { Day } \\
\text { Use }^{2}\end{array}$ & $\begin{array}{l}\text { Overnight } \\
\text { Camping }^{3}\end{array}$ & $\begin{array}{c}\text { Average \# } \\
\text { of Nights } \\
\text { Camped }^{4}\end{array}$ & $\begin{array}{r}\text { Average Time } \\
\text { in Area } \\
(\mathrm{hh}: \mathrm{mm}: \mathrm{ss})\end{array}$ & $\begin{array}{r}\text { Median Time } \\
\text { in Area } \\
\text { (hh:mm:ss) }\end{array}$ & $\begin{array}{r}\text { Range of Time in } \\
\text { Area } \\
\text { (hh:mm:ss) }\end{array}$ \\
\hline East Arm & Base McBride Glacier & 5 & 1 & 3 & 5 & 2.5 & $20: 56: 08$ & 02:00:20 & 00:09:12-64:15:01 \\
\hline \multirow[t]{5}{*}{ West Arm } & Johns Hopkins Glacier & 15 & 1 & 4 & 14 & 1.3 & 21:05:09 & 18:19:12 & 00:30:24-74:00:55 \\
\hline & Base of Mt. Parker & 18 & 5 & 15 & 7 & 1.2 & 09:11:25 & $02: 45: 25$ & $00: 04: 35-38: 02: 23$ \\
\hline & NW of Scidmore Bay & 18 & 11 & 6 & 4 & 1.3 & $03: 52: 23$ & $05: 27: 47$ & 00:00:14-19:23:28 \\
\hline & Rendu Inlet, Ibach Point & 22 & 11 & 6 & 15 & 1.4 & $13: 20: 35$ & $07: 59: 49$ & $00: 03: 28-85: 43: 00$ \\
\hline & Sundew Cove & 25 & 26 & 6 & 17 & 2.1 & $13: 10: 15$ & $00: 23: 50$ & 00:01:04-94:10:21 \\
\hline
\end{tabular}

$\mathrm{N}=45$

${ }^{1}$ Passing through refers to tracks that did not stop $(0 \mathrm{mph})$ for a consecutive 5 -minute increment.

2 Day use refers to tracks that did stop $(0 \mathrm{mph})$ for at least one consecutive 5 -minute increment and did not continue into the next day.

${ }^{3}$ Overnight camping refers to tracks that were stopped $(0 \mathrm{mph})$ for more than 6 hours and occurred over night (12 AM).

${ }^{4}$ Average number of nights camped includes only overnight tracks.

${ }^{5}$ Average and median time in each area was calculated using all tracks.

${ }^{6}$ Range of time in each area includes tracks that were just passing through to those that stayed multiple nights in a single high-density area. 


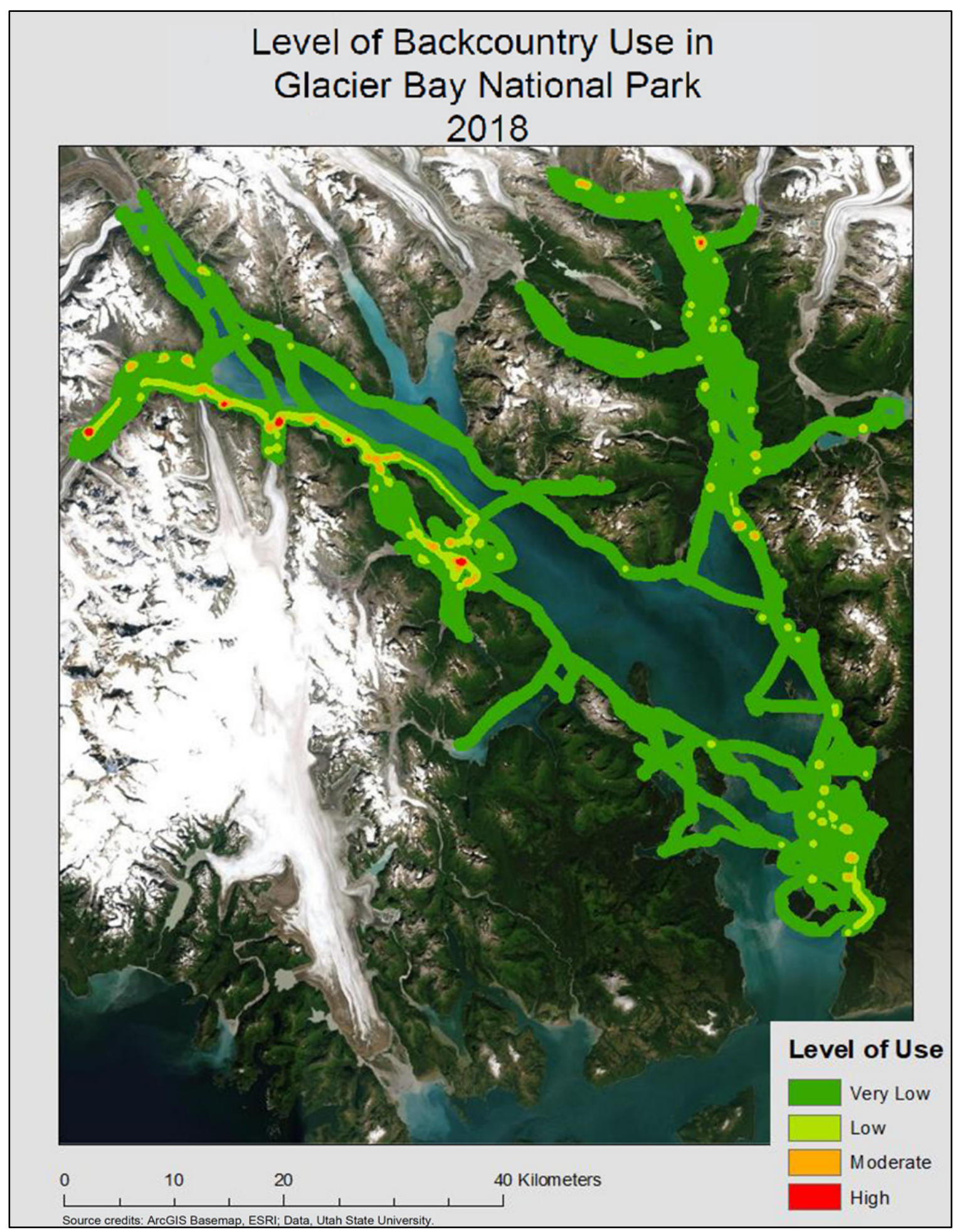

Figure 15. Kernel density map representing overall densities of total 2018 backcountry visitor spatial use in Glacier Bay National Park. Areas of high density are colored red. 


\section{Relevant Historic Data}

Salvi and Johnson (1985) compared socio-economic characteristics between surveyed backcountry campers in 1978 and 1984. More males (57\%) visited GBNP in 1978, increasing to 58.6\% in 1984, and the average age of campers stayed relatively stable between the two sampling periods: 30.8 and 31.8 years old. There was little difference between the average education level of visitors (16.7 and 16.6 respectively), translating to 16 years of education (e.g., bachelor's degree, trade-school, etc.). Annual (i.e., family) income was included on the 1978 survey, resulting in a majority making less than $\$ 19,999$ [ $\$ 9,999$ or less $(26.8 \%)$, and $\$ 10,000-\$ 19,999(34.2 \%)$ ]. Race was not included in the survey.

Comparisons of these socio-economic characteristics between historic and current independent backcountry visitors suggests slight shifts over time (Table 62). Female visitation has increased from an average of $42.2 \%$ in $1978 / 84$ to $50.7 \%$ in $2017 / 18$. The average age range has increased from 31.8 years of age in 1984 to 40.2 in 2018, and the number of years of education has also increased with a majority reporting a four-year degree in 1978 (28.4\%) to a Master's or other graduate degree in 2017 (39.7\%). When comparing annual household income, changes to income distribution must be considered with a 275\% increase from 1978 to 2017 (Bureau of Labor Statistics, n.d.). In 1978, for example, $34.2 \%$ of visitors had incomes ranging from $\$ 10,000$ to $\$ 19,999$ - translating to about $\$ 37,000$ to $\$ 74,999$ in 2017 . Of visitors responding in $2017,33.3 \%$ fit within this range. Forty-six percent reached beyond $\$ 75,000$ in 2017, and 38.7\% reached beyond \$19,999 in 1978 .

Table 62. A comparison of socio-economic characteristics of independent backcountry visitors from 1978, 1984,2017 , and 2018.

\begin{tabular}{|c|c|c|c|c|}
\hline Demographic & 1978 & 1984 & 2017 & 2018 \\
\hline Female $^{1}$ & $43.0 \%$ & $41.4 \%$ & $49.2 \%$ & $52.1 \%$ \\
\hline Age $(\text { years) })^{2}$ & 30.8 & 31.8 & - & 40.2 \\
\hline Number of Years of Education ${ }^{3}$ & 16.5 & 16.4 & 18.0 & - \\
\hline Annual Household Income $>\$ 75,000^{4}$ & $39 \%$ & - & $46 \%$ & - \\
\hline
\end{tabular}

Adapted from Johnson (1979) and Salvi and Johnson (1985).

${ }^{1}$ Percentage of population that self-identified as female.

2 Mean years of age. In 2017, data was collected using binned categories and, therefore, the data is not conducive for comparisons across historic and current years.

${ }^{3}$ Median scores used to compare number of years of education among populations: 16 would be equivalent to a 4-year degree and 18 would be equivalent to a Master's or other graduate degree. Median score from 2017 was adapted to match 1978/84 binned categories. In 2018, visitors were not asked for their education level.

${ }^{4}$ Percentage of population that reported $>\$ 75,000$ in annual household income in 2017 , translating to $>\$ 20,000$ in 1978.

Experience use history was assessed for both historic sampling periods. Most backcountry campers were visiting GBNP for the first time, with $95 \%$ in 1978 and $90 \%$ in 1984 . Three percent of campers 
in 1978 had visited one other time in a previous year, while this increased to $7 \%$ in 1984 . In 1978 , the average number of nights spent in the backcountry was 4.9, increasing to an average of 5.9 in 1984.

Salvi \& Johnson (1985) measured motivations by asking visitors to rank the "importance of selected factors relative to enjoyment of the backcountry." Ten constructs were addressed: views of glaciers, seeing wildlife, physical challenge, solitude, fishing, avoiding certain wildlife, fellowship with party members, observing wildflowers and other vegetation, wildness, and seeing other parties. The majority of constructs were comparable between 1978 and 1984, except fishing and avoiding certain wildlife. For both years, viewing glaciers, wildness, seeing wildlife and solitude were ranked as the more important factors, while seeing other parties ranked as the least important factor.

As discussed in Furr (2019), there were a few assumptions made in order to compare historic and current data. The motivations measured in 1978 and 1984, for example, mirror many of the current motivational constructs from the 2017 analysis (Table 63). Viewing glaciers, solitude, and fishing were three constructs that directly compared. Others were compared relative to scale items found within the current constructs, pairings include: "seeing wildlife" as "guided wilderness experience;" "physical challenge" as "adventure," "observing wildflowers and other vegetation" as "learning;" "wildness" as "natural connection and renewal;" and "seeing other parties" as "safety." A construct included in the 1984 survey that may be comparable to pair with "safety" would be "avoiding certain wildlife," but this was only measured one year opposed to both and was therefore excluded.

Table 63. Motivations for visiting the backcountry: Comparison of 1978, 1984, and 2017 Glacier Bay studies.

\begin{tabular}{lrrrl}
\hline Historical Constructs & $\begin{array}{r}1978 \\
\text { Mean }\end{array}$ & $\begin{array}{r}1984 \\
\text { Mean }^{2}\end{array}$ & $\begin{array}{r}2017 \\
\text { Mean }^{2}\end{array}$ & Current Constructs \\
\hline Views of glaciers & $1.5^{(3)}$ & $4.3^{(3)}$ & $4.35^{(3)}$ & Experience Glaciers \\
Seeing wildlife & $1.9^{(3)}$ & $4.2^{(3)}$ & 3.71 & Guided Wilderness Experience \\
Physical challenge & 2.9 & 3.1 & 3.61 Adventure \\
Solitude & $1.9^{(3)}$ & 3.9 & $4.35^{(3)}$ & Solitude \\
Fishing & $\mathrm{NA}$ & 1.5 & 1.48 Fishing \\
Observing wildflowers \& other vegetation & 2.2 & 3.4 & 3.17 Learning \\
Wildness & $1.4^{(3)}$ & $4.3^{(3)}$ & $3.90^{(3)}$ & Natural Connection/Renewal \\
Seeing other parties & 4.7 & 1.4 & 2.53 Safety \\
\hline
\end{tabular}

Adapted from Johnson (1979) and Salvi and Johnson (1985).

${ }^{1}$ Means are based on a 5-point scale: "Very Important" = 1, 2, "Somewhat Important" = 3, 4, "Not Important" = 5.

2 Means are based on a 5-point scale: "Extremely Important" = 5, "Very Important" = 4, "Moderately Important" = 3, "Somewhat Important" = 2, "Not Important" = 1.

${ }^{3}$ Numbers highlighted in gray signify means that suggest higher importance for the corresponding motivational construct. Changes in mean values across survey years can be interpreted as potential shifts in visitor motivations. 
Two components used to evaluate the visitor experience were appropriate for historical comparisons (Furr, 2019): 1) evidence of human use seen in the backcountry and the effect it had one their experience, and 2) sightings of other parties and crafts in relation to preferences. The effects of anthropogenic sightings were measured using a four-point scale ranging from (1) "did not see" to (4) "yes-very bothered" (Salvi \& Johnson, 1985). The sight of litter increased very slightly (1.4\%) between the two studies but was rated as the most bothersome for both years (mean of 1.7). There was an increase in sightings for hiker-made trails and campsites from 1978 to 1984; however, the majority of visitors that saw them reported that they were not bothered (Table 64).

Table 64. Evidence of human use seen in the backcountry: Comparison of 1978, 1984, and 2018 Glacier Bay studies.

\begin{tabular}{|c|c|c|c|c|c|c|}
\hline \multirow[b]{2}{*}{ Evidence of Use } & \multirow[b]{2}{*}{ Year } & \multicolumn{4}{|c|}{ Percent } & \multirow[b]{2}{*}{$\begin{array}{r}\text { Mean } \\
\text { Response }^{1,2}\end{array}$} \\
\hline & & $\begin{array}{r}\text { Did not } \\
\text { see }\end{array}$ & $\begin{array}{l}\text { Yes-Not } \\
\text { Bothered }\end{array}$ & $\begin{array}{r}\text { Yes - Somewhat } \\
\text { Bothered }\end{array}$ & $\begin{array}{r}\text { Yes - Very } \\
\text { Bothered }\end{array}$ & \\
\hline \multirow[t]{3}{*}{ Human waste } & 1978 & 94.2 & 1.3 & 1.9 & 2.6 & 1.1 \\
\hline & 1984 & 92.7 & 2.1 & 3.1 & 2.1 & 1.1 \\
\hline & 2018 & - & - & - & - & 1.75 \\
\hline \multirow[t]{3}{*}{ Campfire rings } & 1978 & 71.1 & 15.2 & 10.5 & 3.2 & 1.5 \\
\hline & 1984 & 72.5 & 13.4 & 9.9 & 4.2 & 1.5 \\
\hline & 2018 & - & - & - & - & 1.76 \\
\hline \multirow[t]{3}{*}{ Litter } & 1978 & 67.4 & 7.2 & 10.7 & 14.7 & 1.7 \\
\hline & 1984 & 68.8 & 3.1 & 14.5 & 13.6 & 1.7 \\
\hline & 2018 & - & - & - & - & 2.31 \\
\hline \multirow[t]{3}{*}{ Cut bushes or trees } & 1978 & 91.0 & 5.1 & 2.6 & 1.3 & 1.1 \\
\hline & 1984 & 90.1 & 4.5 & 4.0 & 1.4 & 1.2 \\
\hline & 2018 & - & - & - & - & 1.17 \\
\hline \multirow[t]{3}{*}{ Hiker-made trails } & 1978 & 59.9 & 28.5 & 10.6 & 1.0 & 1.5 \\
\hline & 1984 & 51.8 & 35.2 & 11.8 & 1.2 & 1.6 \\
\hline & 2018 & - & - & - & - & 1.30 \\
\hline \multirow[t]{3}{*}{ Hiker-made campsites } & 1978 & 61.4 & 25.7 & 11.6 & 1.3 & 1.5 \\
\hline & 1984 & 53.1 & 31.9 & 12.1 & 2.9 & 1.6 \\
\hline & 2018 & - & - & - & - & 1.35 \\
\hline
\end{tabular}

Adapted from Johnson (1979) and Salvi and Johnson (1985).

${ }^{1}$ Means for 1978 and 1984 are based on a 4-point scale ranging from (1) "did not see" to (4) "yes-very bothered."

2 Means for 2018 are based on a 5-point scale ranging from (1) "not at all bothered" to (5) "extremely bothered." 
Visitors reported the number of anthropogenic encounters during their trip, in addition to their resulting preferences (Table 65). For the purpose of this review, there were four anthropogenic encounters reported that are comparable to the current study: parties on land, parties on water, cruise ships, and propeller-driven aircrafts (Furr, 2019). Over the two study years, the number of sightings for each encounter reported at "about right" decreased, while encounters that visitors reported as "preferred less" increased. The majority of visitors reported that they preferred seeing less or no cruise ships and propeller-driven aircrafts.

Table 65. Campers' reactions to sightings of other parties and crafts: Comparison of 1978 and 1984 Glacier Bay studies.

\begin{tabular}{|c|c|c|c|c|c|c|c|c|}
\hline \multirow[b]{2}{*}{ Type of Sighting } & \multirow[b]{2}{*}{ Year } & \multicolumn{6}{|c|}{ Percent } & \multirow[b]{2}{*}{$\mathbf{N}$} \\
\hline & & $\begin{array}{r}\text { Preferred } \\
\text { None }\end{array}$ & $\begin{array}{r}\text { Preferred } \\
\text { Less }\end{array}$ & $\begin{array}{l}\text { About } \\
\text { Right }\end{array}$ & $\begin{array}{l}\text { Preferred } \\
\text { Few More }\end{array}$ & $\begin{array}{r}\text { Preferred } \\
\text { Many More }\end{array}$ & $\begin{array}{r}\text { Did Not } \\
\text { Matter }\end{array}$ & \\
\hline \multirow[t]{2}{*}{ Parties on land } & 1978 & 11.4 & 8.8 & 66.5 & 2.6 & 0.3 & 10.4 & 308 \\
\hline & 1984 & 6.4 & 10.5 & 64.2 & 1.7 & 1.0 & 16.2 & 419 \\
\hline \multirow[t]{2}{*}{ Parties on water } & 1978 & 7.6 & 3.3 & 66.4 & 6.0 & 0.4 & 16.3 & 301 \\
\hline & 1984 & 3.8 & 8.9 & 60.8 & 3.8 & 1.3 & 21.4 & 416 \\
\hline \multirow[t]{2}{*}{ Cruise ships } & 1978 & 28.5 & 17.2 & 42.3 & 1.0 & 0.0 & 11.0 & 309 \\
\hline & 1984 & 28.4 & 23.9 & 36.1 & 0.0 & 0.0 & 11.6 & 415 \\
\hline \multirow{2}{*}{$\begin{array}{l}\text { Propeller-driven } \\
\text { aircrafts }\end{array}$} & 1978 & 33.6 & 29.7 & 28.3 & 0.7 & 0.0 & 7.7 & 300 \\
\hline & 1984 & 30.5 & 39.9 & 20.0 & 0.2 & 0.2 & 9.2 & 416 \\
\hline
\end{tabular}

Adapted from Johnson (1979) and Salvi and Johnson (1985). 


\section{Conclusions}

This study was conducted over a two-year period that consisted of two separate data collection efforts. Data collected in 2017-the pre-experience survey - was focused on visitors' pre-trip planning, expectations, and motivations for visiting Glacier Bay National Park. Data collected in 2018 - the post-experience survey - was more evaluative and was focused on the quality of their visit. In both 2017 and 2018, spatial use data were collected from independent, non-motorized backcountry visitors, including mainly sea kayakers with a few backpackers. These data show how independent visitors travel throughout the park.

Distinct populations were targeted within the park for this study. These populations included people riding the day boat, independent backcountry visitors (kayakers and a few backpackers), independent boaters, passengers on charter vessels, passengers on tour vessels, Gustavus residents, and those who visited Glacier Bay National Park preparing to leave from the Gustavus Airport. Main findings of this study are highlighted below.

\section{Visitor demographics and characteristics}

Overall, Glacier Bay National Park visitors were generally older (median age range is 50-59 years old), white, highly educated, and high earning individuals. Nearly half of the people who visit Glacier Bay traveled from the western United States. GBNP is also a place that most people only visited once in their lifetime, with approximately $78 \%$ only making one visit. The majority of visitors planned on spending an average of five days in the park. The main activities planned for their visit included viewing tidewater glaciers and observing nature and wildlife.

\section{Motivations and constructs}

In the pre-experience survey, visitors explained the overall purpose of their trip, with the most common answers including viewing wildlife, experiencing glaciers, and exploration. The less common responses included hiking/walking, relaxation and photography. When asked what experiences visitors were seeking, many answered viewing wildlife and experiencing glaciers once again, but also wilderness, solitude, and scenic beauty.

Based on responses to a 29-item scale based on the recreation experience preference scale (Driver et al., 1983), visitors traveling to Glacier Bay National Park were motivated by an Alaskan wilderness experience (i.e., solitude and natural sounds, natural connection and renewal), adventure, learning, opportunities to experience glaciers, fishing, a guided wildlife viewing experience, and safety. All visitors were highly motivated by experiencing glaciers. Independent backcountry visitors were more motivated by solitude and natural sounds, natural connection and renewal, and adventure. Those riding the day boat were motivated by having a guided, wilderness experience. Residents were mostly motivated by solitude and natural sounds, even more so than experiencing glaciers. Tour vessel visitors were motivated by learning, while those visiting via charter vessel and independent boaters were motivated by solitude and natural sounds.

Based on the seven motivational constructs, there were three different types of visitors determined: (1) Glacier Experience, (2) Guided Wilderness Experience, and (3) Remote Wilderness Experience. 
Most visitors fit into two groups: a remote wilderness experience (148) and a guided wilderness experience (147). Fewer visitors fit into cluster 3, glacier experience (58), but each population except for charter vessels visitors were represented in some capacity. This suggests that experiencing glaciers are important across all visitor groups, which is supported by the ANOVA results as well. The majority of day boat passengers fit into the guided wilderness experience (cluster 2), while the majority of independent backcountry visitors fit into the remote wilderness experience (cluster 3). This suggests that those traveling via day boat were seeking a controlled, safe experience, while those traveling in an independent backcountry setting were more interested in solitude, natural connection, adventure, and learning as motives for their experience.

\section{Overall trip quality}

In the post-experience survey, a variety of questions were asked that evaluated the quality of the visitor experience in Glacier Bay National Park. Viewing wildlife (44\%), learning (27\%), and experiencing glaciers (26\%) were the elements that added most to the visitor experience. When asked what detracted from their experience, nearly half of visitors said "nothing," mostly derived from the guided, motorized visitor populations. Some visitors (14\%) said the weather was a detraction, while $12 \%$ said seeing cruise ships detracted from their experience. Cruise ships and anthropogenic sounds, however, had the greatest effect on independent backcountry visitors, largely consisting of kayakers.

Visitors said that being part of a boat tour experience (24\%), learning (21\%), and viewing wildlife $(20 \%)$ added most to their ability to experience adventure. Looking at the differences in users, however, independent backcountry visitors said that self-sufficiency (17\%), viewing wildlife (17\%) and kayaking (14\%) added to their sense of adventure. Guided, motorized populations (i.e., people riding the day boat or tour vessels) said that being part of a boat tour $(28 \%)$, learning $(24 \%)$, viewing wildlife (21\%), and experiencing glaciers (11\%) added most to their sense of adventure. Additionally, visitors were asked if they felt a connection to nature while in GBNP, and 95\% of visitors said they felt connected to nature during their visit. Visitors were able to connect to nature by viewing wildlife (29\%), scenic beauty (16\%), experiencing wilderness (13\%) and experiencing glaciers (12\%). Only 5\% said they were unable to connect to nature during their visit, with the most common responses including feeling restricted on a motorized experience (30\%) and too many other people (21\%). The vast majority of people who said they were unable to connect to nature were on a motorized, guided tour of the park.

\section{Place attachment}

Visitor levels of both place identity and place dependence were measured. Visitors scored very high in place identity, which indicates that visitors had a strong emotional attachment to GBNP. One common trait of place identity is that it is developed over time and after frequent interaction with a place; however, the vast majority - around $80 \%$ — of visitors were visiting for the first time. This would suggest that visitors are having powerful interactions with GBNP and quickly developing high levels of emotional attachment with the park. Independent backcountry visitors were the user group that exhibited the highest degree of place identity, which makes sense given the intimate nature of their interaction with GBNP backcountry. Visitors exhibited lower levels of place dependence, most

falling just above the "neutral" category. This indicates that visitors are less dependent on GBNP for 
wilderness and recreation experiences. Place dependence, on the other hand, relates to how well a place accommodates visitor objectives, goals and activities. Park visitors exhibited lower levels of place dependence, most falling just above the "neutral" category. Independent backcountry visitors demonstrated a slightly stronger degree of place dependence than other populations, which may be due to their engagement in specialized activities that cannot be achieved in just any environment. Overall, data suggests that visitors do not feel dependent on Glacier Bay for wilderness and/or recreation experiences.

To identify different levels of place attachment among visitor groups, the overall scores for both identity and dependence were compared. Independent backcountry visitors were statistically significantly different $(\mathrm{p}<.00)$ from the three guided, motorized visitor groups. Independent backcountry visitors showed the highest levels of place identity and place dependence, while the other three populations - day boat, tour vessel, and those at the Gustavus airport - had similar levels of place identity and place dependence to each other.

\section{Thresholds}

Visitors were given a list of possible items they could have possibly encountered in GBNP, including litter, cruise ships, human waste, etc. Visitors reported if and how often they encountered them, and how much each affected their experience. Day boat, tour vessel and Gustavus Airport visitors were most bothered by litter, but very few visitors encountered litter-only $6 \%$. The majority $(86 \%)$ of visitors who experienced a guided, motorized trip encountered cruise ships - about two ships/trip on average - and they reported that seeing these cruise ships only bothered them "slightly." Overall, visitors reported any negative effects as very low, which indicates that the frequency of encountering the items in the list was quite low and has likely not yet reached a point of concern.

Independent backcountry visitors also expressed being only slightly affected when referring to many items on the list. The element that bothered backcountry visitors the most was cruise ships, which they saw an average of six during their visit. The vast majority of backcountry visitors saw cruise ships; however, the overall effect was between "slight" and "moderate," indicating that backcountry encounters with cruise ships at current levels is not a main concern. Backcountry visitors were also asked about additional things they may encounter in the backcountry, such as campfire rings, human waste, and campsite impacts. Backcountry visitors reported a low frequency of encountering these things, and of those who did encounter them, the overall effect on their experience was very lowbetween "not at all" and "slightly." Therefore, it seems that conditions experienced by visitors are quite acceptable and have not yet reached or surpassed the point where they are diminishing the visitor experience.

Independent backcountry visitors were asked if encountering anthropogenic elements (e.g., kayaking groups encountered, vessel wakes, etc.) positively affected the quality of their experience. On average, visitors did not say that encountering any of the listed items added to their backcountry experience. Some elements seemed to detract from the visitor experience, however, including seeing/hearing cruise ships, hearing other motor boats, and vessel wakes. Ultimately, it seems that experiencing others' motorized use was the only thing that visitors reported as detracting from their 
backcountry experience. This suggests that visitors are searching for a very remote, purist experience.

Independent backcountry visitors were asked what they heard and how much each of those sounds bothered them. Backcountry visitors were most bothered by public addresses from commercial vessels; however, only $34 \%$ of visitors reported hearing these addresses, and the level of bother only reached "moderate." Many more visitors (79\%) heard motor boats while in the backcountry, but the level of bother from these sounds was only between "slight" and "moderate." Overall, anthropogenic sounds in the backcountry of Glacier Bay detracted from visitors" experiences, but not to a level that are of great concern.

When asked if encountering other groups interfered with the visitor experience, only $12 \%$ of respondents said that other groups interfered. The two most common "groups" mentioned were other visitors and the presence of cruise ships.

A normative approach was used to better understand visitor thresholds of acceptance for both crowding and coastal resource conditions. Visitors were asked to rate the acceptability for different simulated conditions using a series of photos presented to them during the post-experience survey. Crowding conditions were represented using different numbers of tents and kayaks present on a beach, ranging from 0 ( 0 tents, 0 kayaks) to 20 (10 tents, 10 kayaks). For crowding conditions, the maximum acceptable condition was 6.2 (three tents and three kayaks) on a beach at one time. The Potential for Conflict Index (PCI) ranged from .04 (high agreement) to .36 (agreement), suggesting respondents were predominately in agreement surrounding crowding thresholds. Coastal resource conditions were represented by the presence of tent rocks on a beach ideal for camping in Glacier Bay, ranging from 0 to 20 (with the additional of a fire ring). The maximum acceptable condition for coastal resource impacts was 8.5 tent rocks at one time, not including a fire ring. The PCI ranged from .11 (agreement) to .55 (some agreement), suggesting respondents were somewhat in agreement surrounding coastal resource condition thresholds.

\section{Spatial Distribution of Use}

In 2017, 68 backcountry visitors were sampled and 40 agreed to take a GPS unit. There was use throughout the Beardslee Islands, East Arm and West Arm. Use was concentrated in the Beardslee Islands, West Arm near glaciers, and the East Arm within the main inlet. In 2018, 124 backcountry visitors were sampled and 54 agreed to take a GPS unit. The range of spatial data was much greater for this sample population, as the GPS units lasted longer and because there was a larger sample size. Spatial use reached throughout GBNP, from the Beardslee Islands to Berg Bay and Willoughby Passage, and then throughout both West and East Arms. Use was concentrated in the West Arm near day boat drop off and pick up locations, as well as near Johns Hopkins Glacier. 


\section{Historical Trends}

Comparisons between historic and current data are limited to independent backcountry visitors as this was the sampling foci for both 1978 and 1984 surveys (Furr, 2019). Socio-economic characteristics have shifted slightly over time, including more female visitors and an overall increase in average age, years of education, and annual household income.

A trend that is easily identifiable within visitors 40 years ago to the present are the top motivations for visiting: opportunities to experience glaciers, natural connection and renewal, and solitude (Furr, 2019). Solitude has become a stronger motivation over the years, which suggests visitors may be seeking dispersed wilderness settings more often, possibly due to the increase in visitation to PPAs or the increasing stresses of everyday life. Adventure is another motivation that has become stronger over the years, which supports claims made by Cordell (2012) regarding increasing activity trends. Between years, fishing and safety were both rated as less important motivations for independent backcountry visitors.

Assessing trends of anthropogenic encounters and the effect they have on the visitor experience may provide clarity to managers regarding potentially problematic interactions between backcountry campers and other visitor-related factors (Furr, 2019). Campers from 1978 and 1984 reported that their encounters with litter had the greatest negative effect on their experience. Although the mean for both studies was 1.7 (did not see - yes, not bothered), the majority of visitors that encountered litter reported that they were very to somewhat bothered by it than not. This mirrors the current trend in which backcountry users reported that their experience was slightly to moderately affected after seeing litter. Although the historical studies measured the effect of encountering cruise ships and propeller-driven aircrafts using preferences, the results suggest similar conclusions. More than half of visitors within the 1978 and 1984 studies reported that they would prefer seeing less to no propellerdriven aircrafts and cruise ships. Visitors in 2018 ranked cruise ship encounters as having the greatest negative effect on their trip (slight to moderate effect), and those that saw propeller-driven aircrafts said it slightly affected their experience. To give perspective to just how many encounters visitors were basing their evaluations on, in 1978, visitors saw an average of 2.6 cruise ships and 5.2 propeller-driven aircrafts during their trip, an average of 3 cruise ships and 8.9 propeller-driven aircrafts in 1984, and 6.51 cruise ships and 3.3 propeller-driven aircrafts in 2018.

In regards to independent backcountry visitors, there are five strong suggestions supported by these comparisons: 1) visitor socio-demographics are slightly shifting to older, highly educated, wealthy individuals; 2) visitors continue to be highly motivated by experiencing glaciers and natural connection and renewal; 3) solitude and adventure have become more important motivators for these visitors; 4) encounters with litter, cruise ships and propeller-driven aircrafts continue to detract from the visitor experience; and 5) there has been an increase in cruise ship and a decrease in propellerdriven aircraft sightings over the years (Furr, 2019). 


\section{Management Implications}

The analyses presented throughout this report highlight several managerially important elements specific to Glacier Bay National Park. By thoroughly understanding GBNP visitors (e.g., motivations, the quality of experiences, place attachment, thresholds of acceptability for both crowding and resource impacts), managers can better develop and implement strategies in order to protect resources while simultaneously providing meaningful visitor experiences. It is important to acknowledge that certain challenges in data collection resulted in some populations being more represented than others. The data presented in this report are valuable, but it is important for managers to consider which perspectives are in fact represented when using these data to support decisions.

In GBNP, there are a hand-full of activity-based recreationists and they differ subtly based on their motivations for visiting. Although there are subtle statistical differences, there are no definitive motivational patterns or differences across populations.

All data suggest that visitors are having very high-quality experiences in Glacier Bay National Park. Some visitors were slightly bothered when they encountered litter, cruise ships, propeller-driven aircrafts and other motorized vessels; however, the overall effects were quite low which suggests that current management strategies are effective at producing high quality experiences. In addition, the current zoning with the presence of non-motorized waters provides opportunities for solitude and natural connection and renewal. Even though visitors are experiencing high levels of satisfaction, it is important for managers to know that some anthropogenic encounters (i.e., litter, cruise ships, and propeller-driven aircrafts) have the potential to reduce visitor experiences if use levels change from their current state.

Investigating visitor thresholds of acceptance for both crowding and coastal resource conditions provides important managerial insight into social influences on the visitor experience. For crowding, visitors responded with the maximum acceptable condition as 6.2 (i.e., three tents and three kayaks) on a beach at one time. This suggests that backcountry visitors view other group sizes of about 6 as the maximum acceptable condition. It is important to acknowledge, then, that the current backcountry policy has a maximum of 12 individuals per group, which reaches beyond the reported threshold. The maximum acceptable condition for coastal resource impacts was 8.5 tent rocks at one time, not including a fire ring. Tent rocks were chosen as an indicator for resource conditions, but there is some conjecture that visitors may have considered tent rocks as amenities, which is why the norm curve was not as pronounced. Sixty-two percent of backcountry campers were first-time visitors, suggesting that the majority of visitors may have a different understanding of common GBNP wilderness conditions/practices. With this information, managers can make more informed decisions for crowding and resource impacts. For example, management can continue to limit the number of people permitted in one group or limit the number of permits allotted for large groups. Managers may also encourage Leave-No-Trace principles for backcountry visitors specifically, in terms of dispersing any natural materials used for camping purposes. 
Finally, the spatial data collected allow us to understand where and how visitors are moving across the landscape throughout Glacier Bay National Park. To some extent, visitors are exploring the majority of inlets and islands while hugging the coastline. Higher use areas (see Kernel Density maps), however, may guide management towards specific areas exposed to heavier visitor use. Based on these data, management should consider both social and ecological impacts around the base of Johns Hopkins, Lamplugh, and Reid Glaciers, at the day boat drop off locations and McBride Glacier in the East Arm. 


\section{Literature Cited}

Arrowsmith, C., \& Chhetri, P. (2003). Port Campbell National Park: Patterns of Use. A report for the development of a visitor typology as input to a generic model of visitor movements and patterns of use. Melbourne.

Baldassare, M. (1978). Human Spatial Behavior. Annual Review of Sociology, 4, 29-56.

Beeco, J. A., Hallo, J. C., \& Brownlee, M. T. J. (2014). GPS Visitor Tracking and Recreation Suitability Mapping: Tools for understanding and managing visitor use. Landscape and Urban Planning, 127 (Supplement C), 136-145.

Bell, C. M., Needham, M. D., \& Szuster, B. W. (2011). Congruence among encounters, norms, crowding, and management in a marine protected area. Environmental Management, 48(3), 499513.

Cole, D. N. (1981). Vegetational changes associated with recreational use and fire suppression in the Eagle Cap Wilderness, Oregon: Some management implications. Biological Conservation, 20(4), $247-270$.

Cole, D. N. (1991). Changes on trails in the Selway-Bitterroot Wilderness, Montana, 1978-89. Res. Pap. INT-450. Ogden, UT: U.S. Department of Agriculture, Forest Service, Intermountain Research Station. 5 P, 450.

Cole, D. N., \& Hall, T. E. (1992). Trends in campsite condition: Eagle Cap Wilderness, Bob Marshall Wilderness, and Grand Canyon National Park (No. INT-RP-453). Ogden, UT: U.S. Department of Agriculture, Forest Service, Intermountain Research Station.

Crompton, J. L. (1979). Motivations for pleasure vacation. Annals of Tourism Research, 6(4), 408424.

Dann, G. S. (1977). Anomie, ego-enhancement and tourism. Annals of Tourism Research, 4(4), 184194.

Dann, G. S. (1981). Tourist motivation an appraisal. Annals of Tourism Research, 8(2), 187-219.

D’Antonio, A., Monz, C., Lawson, S., Newman, P., Pettebone, D., \& Courtemanch, A. (2010). GPSBased Measurements of Backcountry Visitors in Parks and Protected Areas: Examples of Methods and Applications from Three Case Studies. Journal of Park and Recreation Administration; Urbana, 28(3).

Devesa, M., Laguna, M., \& Palacios, A. (2010). The role of motivation in visitor satisfaction: Empirical evidence in rural tourism. Tourism Management, 31(4), 547-552.

Driver, B. L. (1983). Master list of items for Recreation Experience Preference scale and domains. Ft. Collins, CO: USDA Forest Service Rocky Mountain Forest and Range Experiment Station. 
Field, A. (2013). Discovering statistics using IBM SPSS statistics: and sex and drugs and rock " $n$ " roll (4th edition). In MobileStudy (4th edition). Los Angeles London New Delhi Singapore Washington DC: Sage.

Furr, G. R. (2019). Current and historic visitor experiences in coastal Alaskan wilderness: Visitor motivations and experience quality in Glacier Bay National Park and Preserve (Publication No. 7695) [Master's thesis, Utah State University]. USU Digital Commons.

Glacier Bay Wilderness Management. (2020, November 27). National Park Service. Retrieved from https://www.nps.gov/glba/learn/management/wilderness.htm

Goonan, K. C., Monz, C., Bruno, B., \& Lewis, T. (2014). Recreation Impact Monitoring Analysis and Protocol Development, Glacier Bay National Park.

Hallo, J. C., Beeco, J. A., Goetcheus, C., McGee, J., McGehee, N. G., \& Norman, W. C. (2012). GPS as a Method for Assessing Spatial and Temporal Use Distributions of Nature-Based Tourists. Journal of Travel Research, 51(5), 591-606.

Hallo, J. C., Manning, R., Valliere, W., \& Budruck, M. (2005). A case study comparison of visitor self-reported and GPS recorded travel routes. In Proceedings of the 2004 Northeastern Recreation Research Symposium, (Gen. Tech. Rep. NE-326), U.S. Department of Agriculture, Forest Service, Northeastern Research Stations, Newtown Square, PA.

Hammitt, W. E., Cole, D. N., \& Monz, C. A. (2015). Wildland Recreation: Ecology and Management (Third). John Wiley \& Sons.

Heberlein, T., \& Vaske, J. (1977). Crowding and visitor conflict on the Bois Brule River. Technical Report WIS WRC 77-04: Water Resources Center, University of Wisconsin, Madison.

Hendee, J. C., Clark, R. N., Dailey, T. E., Pacific Northwest Forest Experiment Station (Portland, OR), \& United States Forest Service. (1977). Fishing and other recreation behavior at highmountain lakes in Washington State. Portland, OR: Dept. of Agriculture, Forest Service, Pacific Northwest Forest and Range Experiment Station.

Heywood, J. L., Manning, R. E., \& Vaske, J. J. (2002). Normative research in outdoor recreation: progress and prospects for continued development and applications. Leisure Sciences, 24(3/4), 251-253.

Hollenhorst, S. J., Whisman, S. A., \& Ewert, A. W. (1992). Monitoring visitor use in backcountry and wilderness: a review of methods (No. PSW-GTR-134). Albany, CA: U.S. Department of Agriculture, Forest Service, Pacific Southwest Research Station. 
Hollenhorst, S., \& Stull-Gardner, L. (1992). The Indicator Performance Estimate (IPE) Approach to Defining Acceptable Conditions in Wilderness. In: Chavez, Deborah J., Technical Coordinator. 1992. Proceedings of the Symposium on Social Aspects and Recreation Research, February 1922, 1992, Ontario, California. Gen. Tech. Rep. PSW-GTR-132. Albany, CA: Pacific Southwest Research Station, Forest Service, U.S. Department of Agriculture; p. 48-49, 132.

Hunt, K. S., Scott, D., \& Richardson, S. (2003). Positioning public recreation and park offerings using importance-performance analysis. Journal of Park and Recreation Administration, 21(3), $1-21$.

Iso-Ahola, S. E. (1982). Toward a social psychological theory of tourism motivation: A rejoinder. Annals of Tourism Research, 9(2), 256-262.

Johnson, D. R. (1979). A Statistical Summary of Selected Data from the 1978 Backcountry Users Survey, Glacier Bay National Monument. National Park Service.

Jolliffe, I. T. (2002). Principal component analysis (2nd ed.). New York, NY: Springer-Verlag.

Kanfer, R. (1990). Motivation Theory and Industrial and Organizational Psychology (Vol. 1). Palo Alto, CA: Consulting Psychologists Press.

Kidd, A. M., D’Antonio, A., Monz, C., Heaslip, K., Taff, D., \& Newman, P. (2018). A GPS-Based Classification of Visitors' Vehicular Behavior in a Protected Area Setting. Journal of Park \& Recreation Administration, 36(1), 69-89.

Kim, S. O., \& Shelby, B. (1998). Norms for Behavior and Conditions in Two National Park Campgrounds in Korea. Environmental Management, 22(2), 277-285.

LaPage, W. F. (1967). Some observations on campground trampling \& ground cover response. Res. Pap. NE-68. Upper Darby, PA: US Department of Agriculture, Forest Service, Northeastern Forest Experiment Station. 11 pp., 68.

Leatherberry, E. C., \& Lime, D. W. (1981). Unstaffed trail registration compliance in a backcountry recreation area, 14.

Machlis, G. E., \& Tichnell, D. L. (2019). The state of the world's parks: An international assessment for resource management, policy, and research. Routledge.

Manfredo, M., Driver, B., \& Tarrant, M. (1996). Measuring Leisure Motivation: A Meta-Analysis of the Recreation Experience Preference Scales. Journal of Leisure Research, 28(3), 188-213.

Manfredo, M., Vaske, J., \& Teel, T. (2003). The potential for conflict index: A graphic approach to practical significance of human dimensions research. Human Dimensions of Wildlife, 8(3), 219228.

Manning, R. E. (1997). Social carrying capacity of parks and outdoor recreation areas. Parks \& Recreation (Ashburn), 32(10), 32-38. 
Manning, R. E. (1999). Crowding and carrying capacity in outdoor recreation: from normative standards to standards of quality. State College, PA: Venture Publishing.

Manning, R. E. (2007). Parks and Carrying Capacity: Commons Without Tragedy (2 edition). Washington, DC: Island Press.

Manning, R. E. (2011). Studies in Outdoor Recreation, 3rd ed.: Search and Research for Satisfaction (3 edition). Corvallis: Oregon State University Press.

Manning, R. E., \& Krymkowski, D. H. (2010). Standards of Quality for Parks and Protected Areas: Applying Normative Theory and Methods in U.S. National Parks, 40(International Journal of Sociology).

Manning, R. E., Leung, Y.-F., \& Budruk, M. (2005). Research to Support Management of Visitor Carrying Capacity of Boston Harbor Islands. Northeastern Naturalist, 12(sp3), 201-220.

Manning, R. E., \& Lime, D. W. (2000). Defining and managing the quality of wilderness recreation experiences. Defining and Managing the Quality of Wilderness Recreation Experiences., (No. RMRS-P-15(Vol. 4)), 13-52.

Manning, R. E., Lime, D. W., Hof, M., \& Freimund, W. A. (1995). The Visitor Experience and Resource Protection (VERP) Process: The Application of Carrying Capacity to Arches National Park. The George Wright Forum, 12(3), 41-55.

Manning, R. E., Valliere, W., Minteer, B., Wang, B., \& Jacobi, C. (2000). Crowding in Parks and Outdoor Recreation: A Theoretical, Empirical, and Managerial Analysis. Journal of Park \& Recreation Administration, 18(4), 57-72.

Marion, J. L. (1985). Ecological Changes Resulting from Recreational Use: A Study of Backcountry Campsites in the Boundary Waters Canoe Area Wilderness, Minnesota. Ph.D. dissertation, University of Minnesota, St. Paul.

Monz, C., D’Antonio, A., \& Heaslip, K. (2014). Moose-Wilson Road use levels, types, patterns and impacts in Grand Teton National Park. Environment and Society Faculty Publications, 125.

National Park Service (NPS). (2015). Programmatic Clearance for NPS-Sponsored Public Surveys. Pool of Known Questions. National Park Service. Washington, District of Columbia.

National Park Service (NPS). (2017). Southeast Alaskan Wilderness [National Park Service: Glacier Bay National Park \& Preserve]. Retrieved from https://www.nps.gov/glba/index.htm

National Park Service (NPS). (2018). Glacier Bay Inset Detail Map. Retrieved March 23, 2019, from https://www.nps.gov/images/Glacier-Bay-Inset-Detail-Map.jpg

Newman, P., Taff, B., Newton, J., \& Abbott, L. (2015). Informing visitor use management strategies for the Moose-Wilson Corridor, Grand Teton National Park. Pennsylvania State University, Protected Areas Research Cooperative, University Park, PA. 
Orellana, D., Bregt, A. K., Ligtenberg, A., \& Wachowicz, M. (2012). Exploring visitor movement patterns in natural recreational areas. Tourism Management, 33(3), 672-682.

Pilcher, E. J., Newman, P., \& Manning, R. E. (2009). Understanding and Managing Experiential Aspects of Soundscapes at Muir Woods National Monument. Environmental Management, $43(3), 425$.

Salvi, W. C., \& Johnson, D. R. (1985). Glacier Bay Backcountry User Study 1984: Statistical Abstract. National Park Service.

Shelby, B., Brown, T. C., \& Baumgartner, R. (1992). Effects of stream flows on river trips on the Colorado River in Grand Canyon, Arizona. Rivers, 3(3), 191-201.

Shelby, B., \& Shindler, B. (1992). Interest group standards for ecological impacts at wilderness campsites. Leisure Sciences, 14(1), 17-27.

Shelby, B., \& Whittaker, D. (1995). Flows and recreation quality on the Dolores River: Integrating overall and specific evaluations. Rivers, 5(2), 121-132.

Shelby, B., Vaske, J., \& Harris, R. (1988). User standards for ecological impacts at wilderness campsites. Journal of Leisure Research, 20(3), 245-256.

Shoval, N., \& Isaacson, M. (2007). Tracking tourists in the digital age. Annals of Tourism Research, $34(1), 141-159$.

Stamberger, L., van Riper, C. J., Keller, R., Brownlee, M. T. J., \& Rose, J. (2018). A GPS tracking study of recreationists in an Alaskan protected area.

State of Alaska Department of Commerce, Community, and Economic Development: Division of Community and Regional Affairs. (2008). City of Gustavus: Three-Year Anniversary Review, 146. Retrieved from https://www.commerce.alaska.gov/web/Portals/4/Gustavus 3 yr$\underline{\text { Review.pdf }}$

Towler, W. L. (1977). Hiker perception of wilderness. A study of the social carrying capacity of Grand Canyon. Arizona Review, 26(8/9), 1-10.

United States Department of Transportation (n.d.). Bureau of Transportation Statistics. Retrieved from https://www.transtats.bts.gov/airports.asp?pn=1

Utah State University and National Park Service (USU and NPS). 2021a. Pre-experience Glacier Bay National Park backcountry visitor survey (2017). Available at: https://irma.nps.gov/DataStore/Reference/Profile/2287162

Utah State University and National Park Service (USU and NPS). 2021b. Post-experience Glacier Bay National Park visitor survey (2018). Available at: https://irma.nps.gov/DataStore/Reference/Profile/2287168 
Utah State University and National Park Service (USU and NPS). 2021c. Post-experience Glacier Bay National Park backcountry visitor survey (2018). Available at: https://irma.nps.gov/DataStore/Reference/Profile/2287161

Vaske, J. (2008). Survey Research and Analysis: Applications in Parks, Recreation and Human Dimensions. State College, Pa: Venture Publishing, Inc.

Vaske, J., Donnelly, M. P., \& Petruzzi, J. P. (1996). Country of origin, encounter norms, and crowding in a frontcountry setting. Leisure Sciences, 18(2), 161-176.

Vaske, J., Needham, M. D., Newman, P., Manfredo, M. J., \& Petchenik, J. (2006). Potential for conflict index: Hunters' responses to chronic wasting disease. Wildlife Society Bulletin, 34(1), $44-50$.

Vaske, J., \& Whittaker, D. (2004). Normative approaches to natural resources. In Society and natural resources: A summary of knowledge (pp. 283-294).

Wilson, D. B. (2009). Systematic coding. In H. Cooper, L. V. Hedges, \& J. C. Valentine (Eds.), The handbook of research synthesis and meta-analysis (pp. 159-176). Russell Sage Foundation. 


\section{Appendix A. Supplemental Tables \& Figures}

Supplemental information to the 2017 and 2018 surveys are presented in Tables A1 and A2 and Figures A1-A8.

Table A1. Proportion of visitors surveyed in 2017 relative to total visitation for sampled populations.

\begin{tabular}{|c|c|c|c|}
\hline Sample Population & Total \# of visitor groups ${ }^{1}$ & \# of groups surveyed & Percentage \\
\hline Independent Backcountry & 293 & 68 & 23.2 \\
\hline Day Boat & 2132 & 254 & 11.9 \\
\hline Resident & 500 & 34 & 6.8 \\
\hline Independent Boaters ${ }^{2}$ & 358 & 18 & 5.0 \\
\hline Tour Vessels & 3713 & 93 & 2.5 \\
\hline Charter Vessels & 405 & 5 & 1.2 \\
\hline
\end{tabular}

${ }^{1}$ Per sampling protocol, one individual from each group was surveyed. For 2017, the average group size was three. Therefore, the total number of visitors (per sample population) recorded was divided by three to calculate the proportion of individuals surveyed. The 2017 sampling period ranged from June - August.

2 Independent boaters were recorded based on boater permits. The number of visitors per private boat varies. The total number of private boaters was used in full to calculate the proportion of individuals surveyed.

Table A2. Proportion of visitors surveyed in 2018 relative to total visitation for sampled populations.

\begin{tabular}{lcrr}
\hline Sample Population $^{1}$ & Total \# of visitor groups $^{2}$ & \# of groups surveyed $^{\text {Percentage }}$ \\
\hline Independent Backcountry & 206 & 124 & 60.2 \\
Day Boat & 1681 & 372 & 22.2 \\
Tour Vessels & 2024 & 198 & 9.8 \\
\hline
\end{tabular}

1 The proportion of visitors surveyed at the Gustavus Airport was not calculated as this survey location captured from multiple populations.

2 Per sampling protocol, one individual from each group was surveyed. For 2018, the average group size was four. Therefore, the total number of visitors (per sample population) recorded was divided by four to calculate the proportion of individuals surveyed. The 2018 sampling period ranged from June - mid-September. 


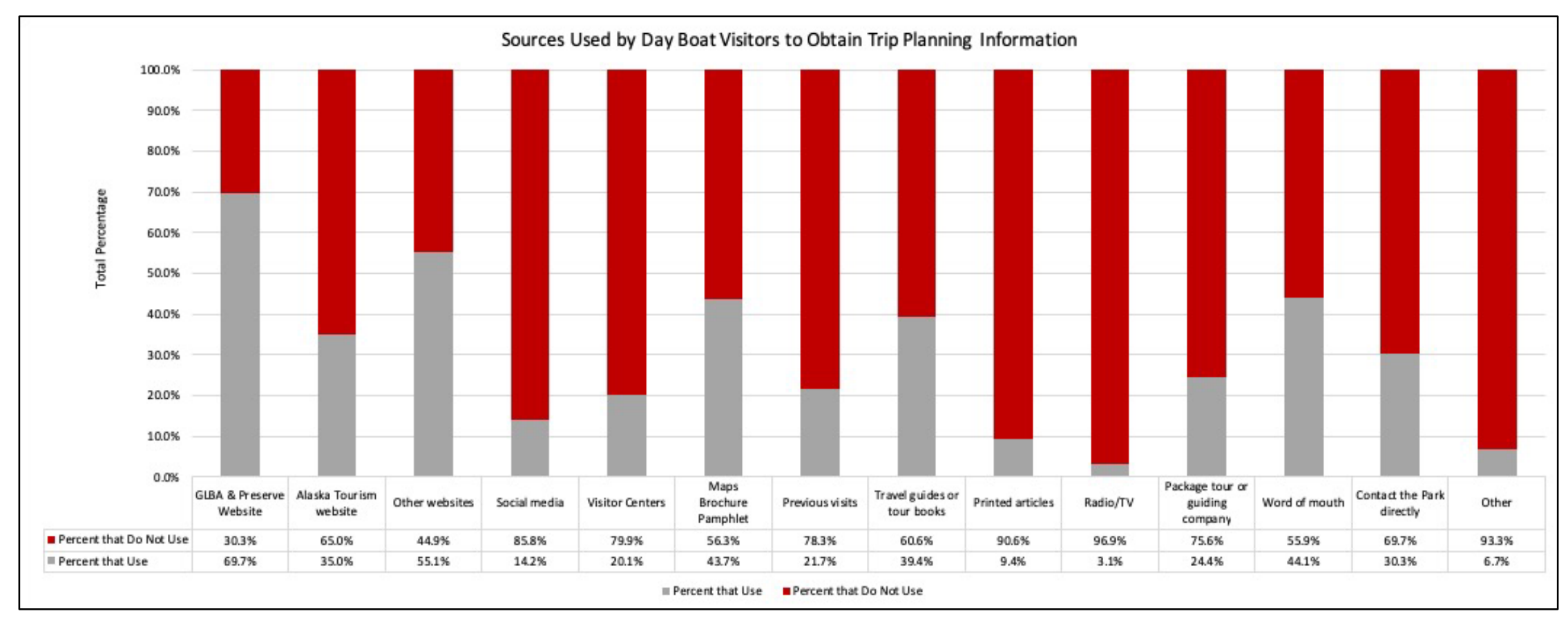

Figure A1. Percentage of sources used versus not used by day boater visitors ( $N=254)$. 


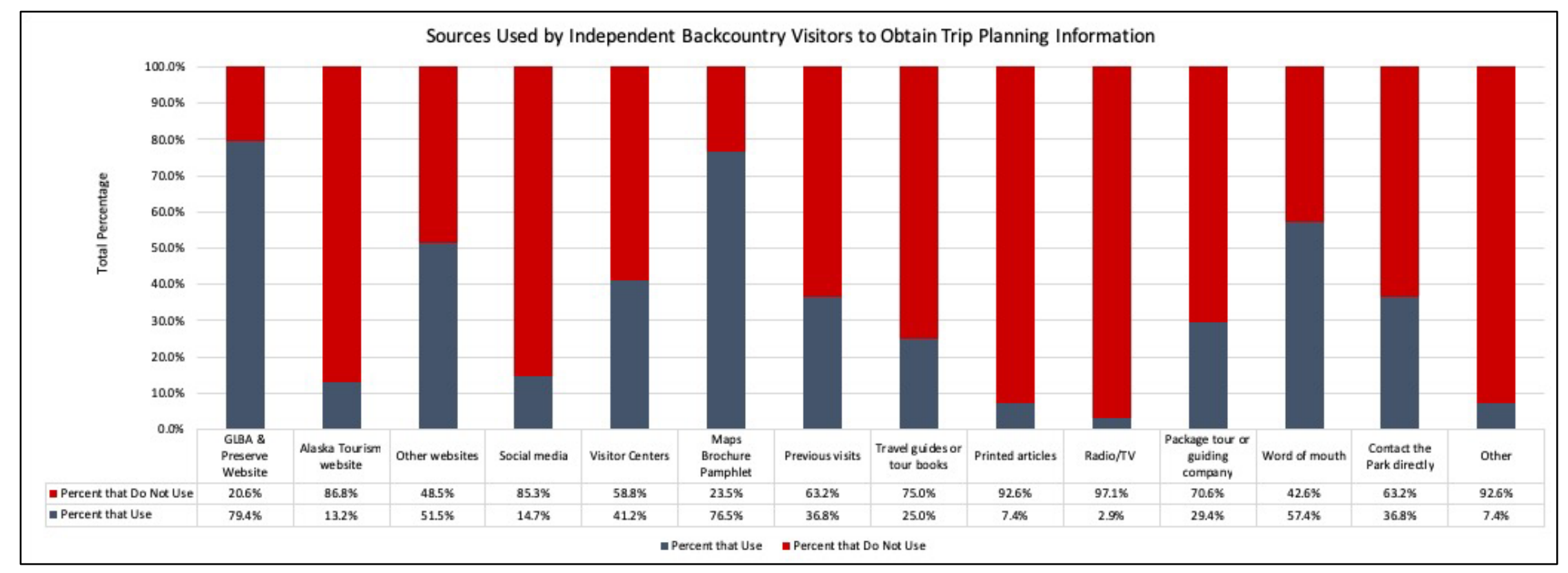

Figure A2. Percentage of sources used versus not used by independent backcountry visitors $(N=68)$. 


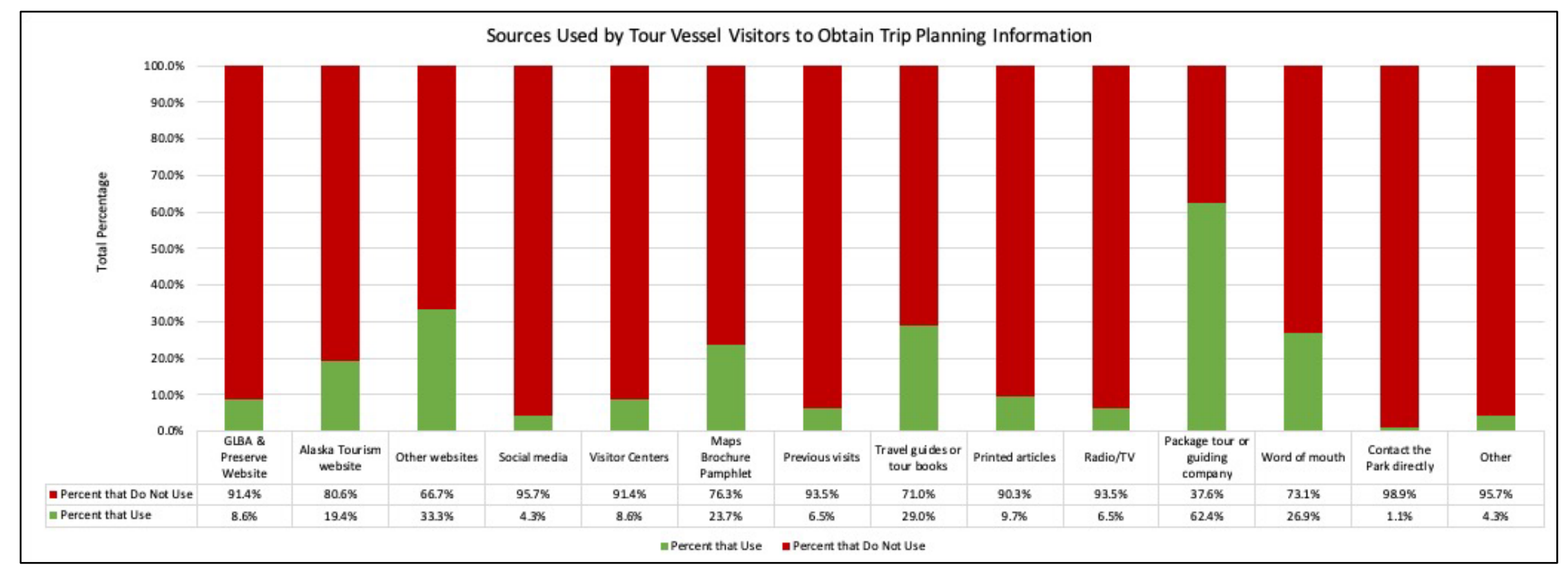

Figure A3. Percentage of sources used versus not used by tour vessel visitors $(N=93)$. 


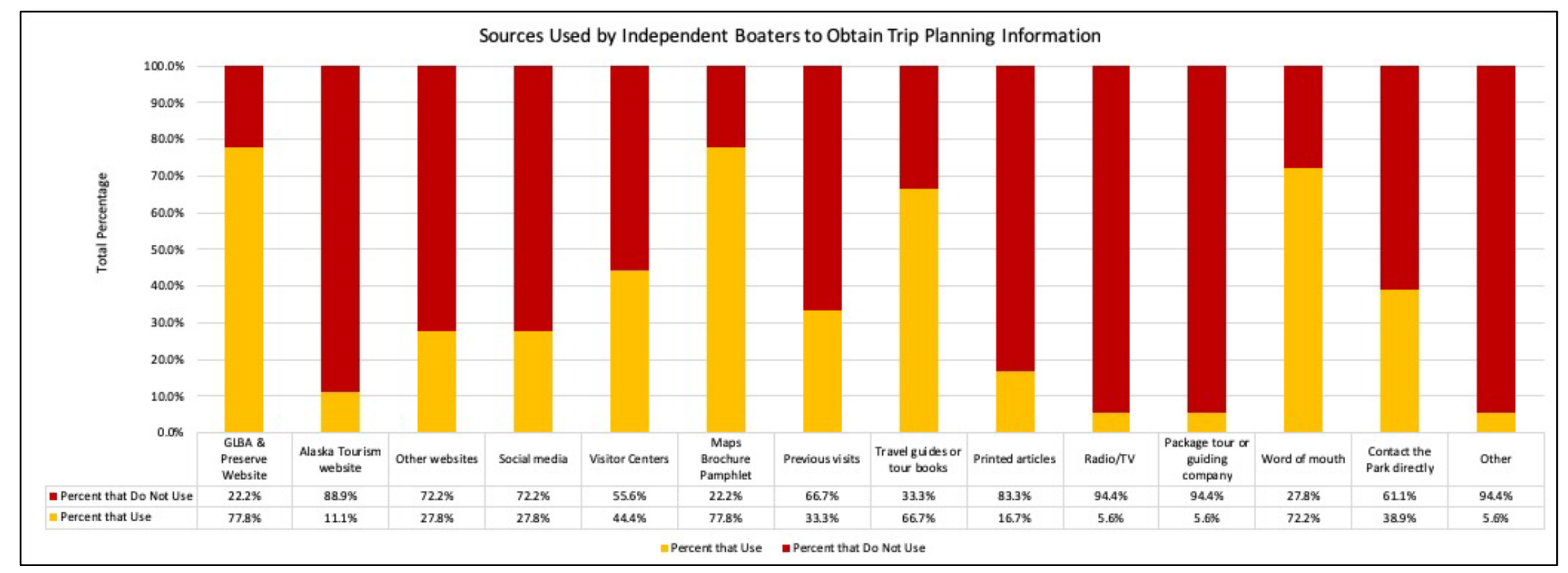

Figure A4. Percentage of sources used versus not used by independent boaters $(\mathrm{N}=18)$. 


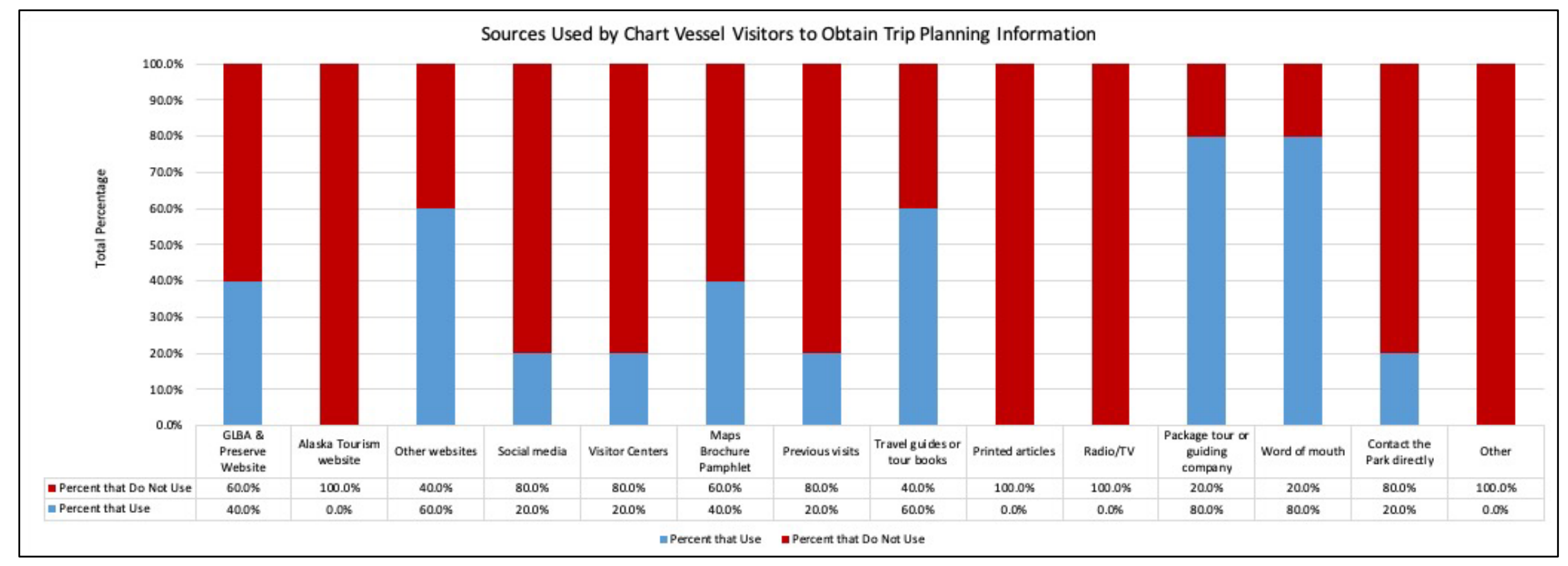

Figure A5. Percentage of sources used versus not used by charter boat visitors $(\mathrm{N}=5)$. 


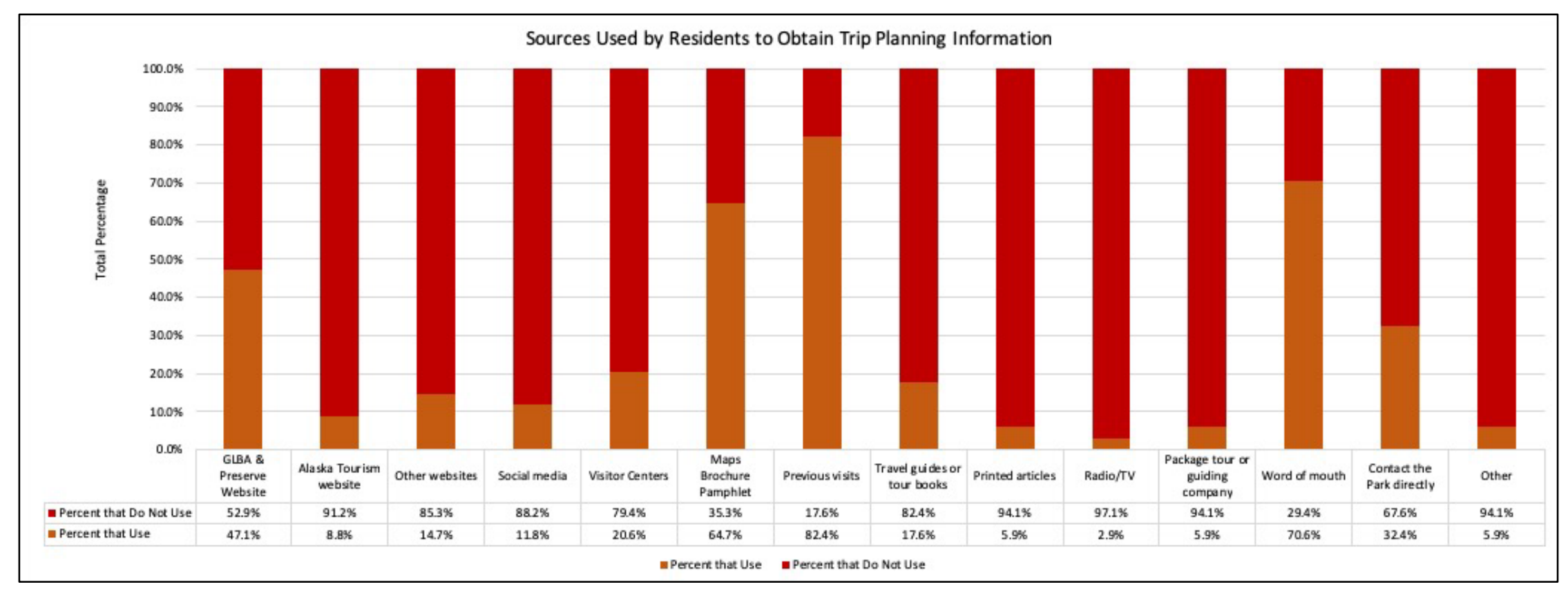

Figure A6. Percentage of sources used versus not used by residents $(\mathrm{N}=34)$. 


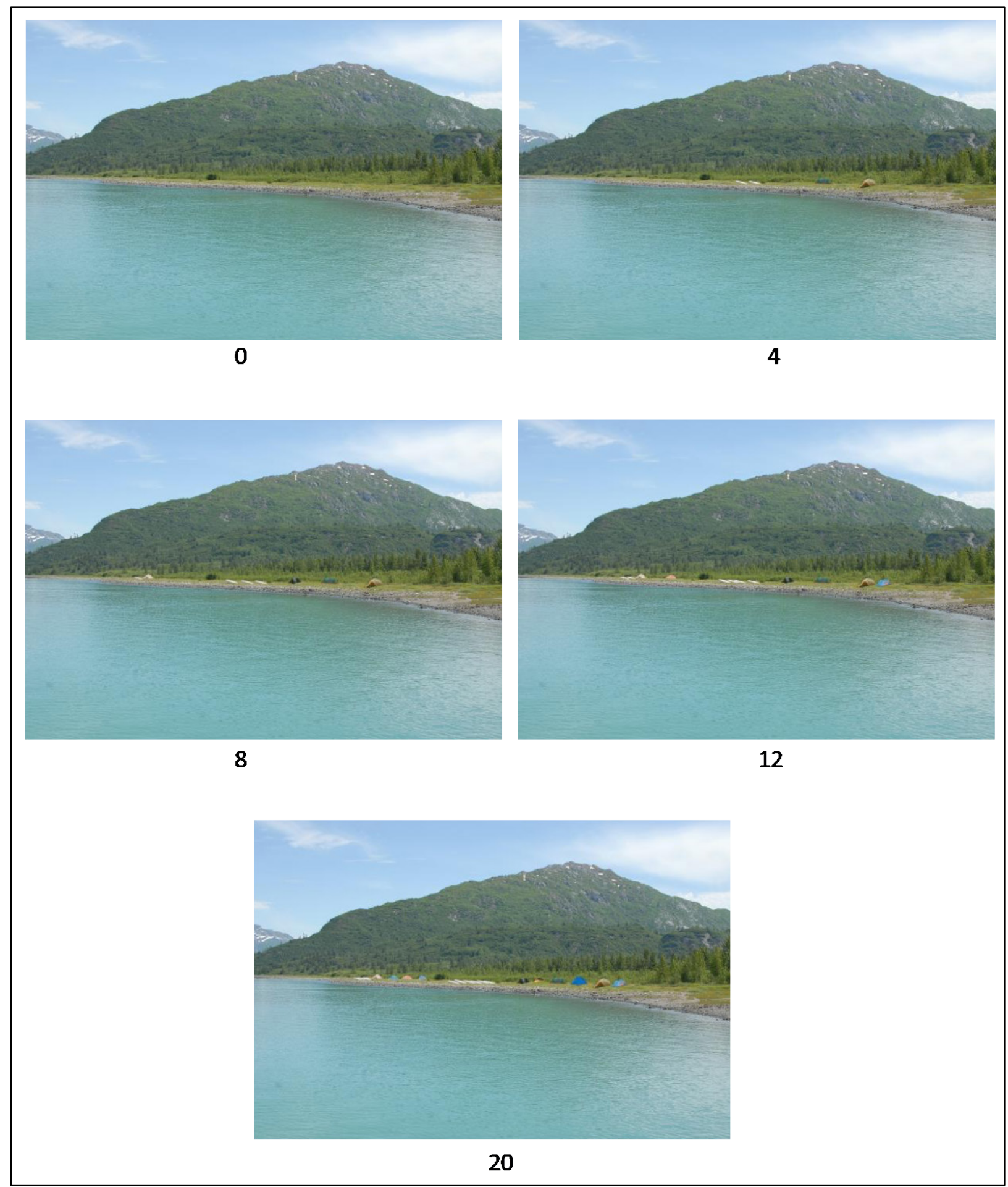

Figure A7. Photo series used to represent crowding in GBNP for post-experience independent backcountry survey. Available response scale ranged from highly unacceptable (-3) to highly acceptable $(+3)$. Respective labels represent the number of tents and kayaks on a beach within each photo. 


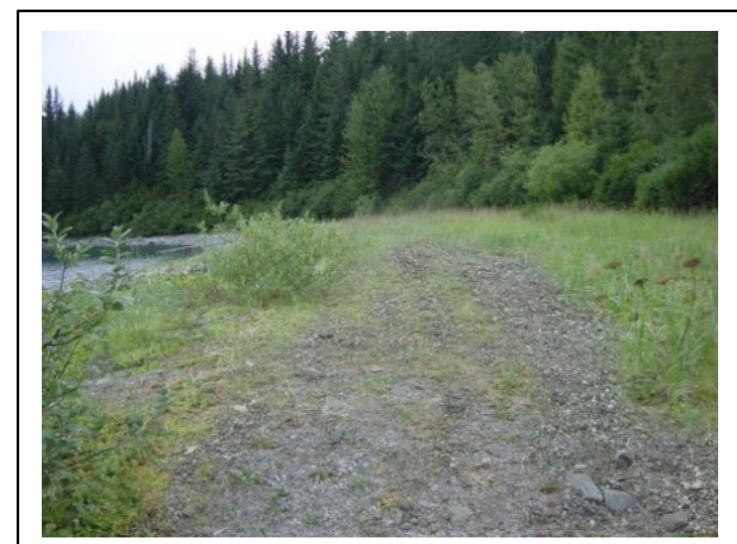

0

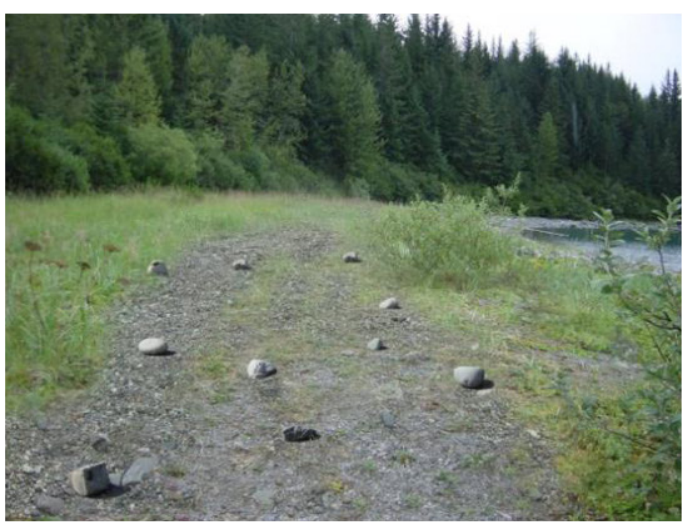

10

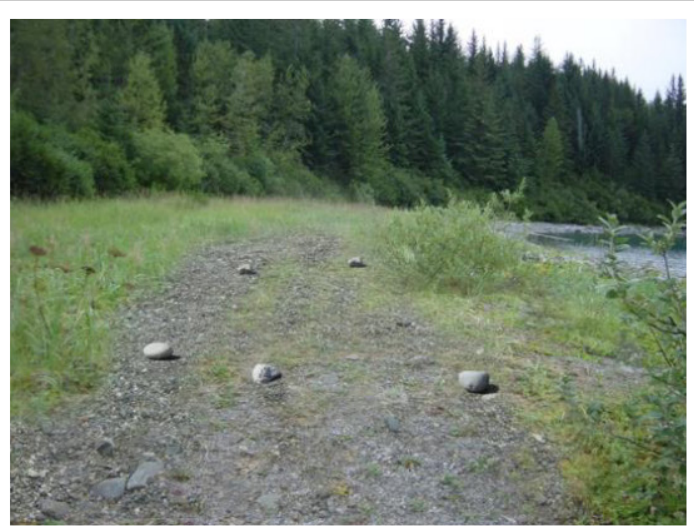

5

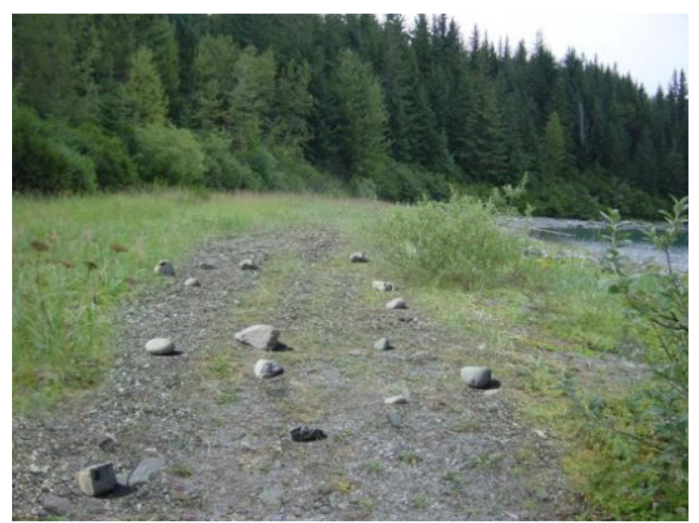

15

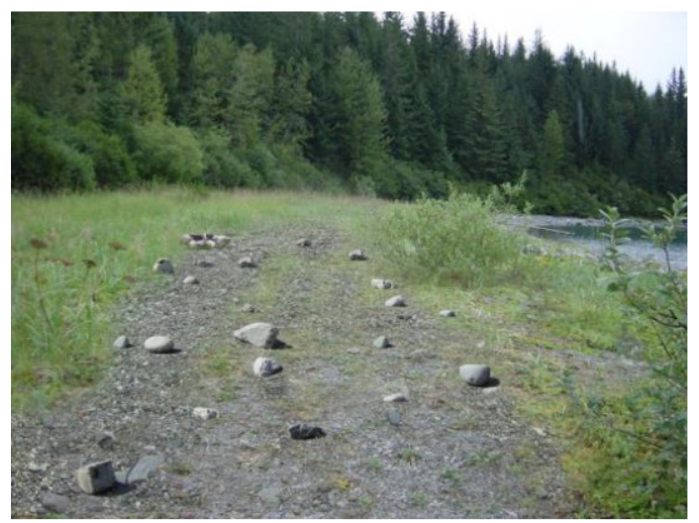

$20+$ Fire Ring

Figure A8. Photo series used to represent coastal conditions in GBNP for post-experience independent backcountry survey. Available response scale ranged from highly unacceptable $(-3)$ to highly acceptable $(+3)$. Respective labels represent the number of tent rocks on a beach within each photo. 


\section{Appendix B. Method Details}

With the purpose of guiding study replication, addition details regarding methodological approaches, including sampling plans and survey implementation are outlined below.

\section{Sampling Plan, Instrument Administration, \& Expected Response Rate}

The total number of visitor contacts was estimated for each population for the 2017 sampling period (Table B1). The response rate from all direct contacts (on-site and guided tours) was estimated to be at least 74\% (Table B2). This number is based upon recent research by Newman, Taff, Newton, \& Abbott (2015) who also used paired survey and GPS-tracking techniques. Additionally, research conducted in Glacier Bay in 2016, where all backcountry camping groups were asked to take maps, mark locations where they camped, and return the maps resulted in a $74 \%$ return rate $(\mathrm{T}$. Lewis, personal communication, 2017). Sampling procedures are described below for each of the targeted populations.

Table B1. Estimated number of visitor contacts ${ }^{1}$ during 2017 sampling period.

\begin{tabular}{|c|c|c|c|c|}
\hline \multirow[b]{2}{*}{ Respondent Group } & \multicolumn{4}{|c|}{ Estimated Number of Visitor Contacts } \\
\hline & June & July & August & Total \\
\hline On-site survey and GPS tracker & 88 & 135 & 68 & 291 \\
\hline Guided tour survey & 282 & 432 & 226 & 940 \\
\hline Community survey & 264 & $\mathrm{~N} / \mathrm{A}$ & N/A & 264 \\
\hline Total & 634 & 567 & 294 & 1,495 \\
\hline
\end{tabular}

Table B2. Expected response rates based on total estimated visitor contacts for 2017.

\begin{tabular}{lrrrrr}
\hline Respondent Group & $\begin{array}{r}\text { Initial } \\
\text { Contacts }\end{array}$ & $\begin{array}{r}\text { Completed } \\
\text { Responses }\left(\%^{1}\right)\end{array}$ & $\begin{array}{r}\text { All Refusals } \\
\left(\%^{1}\right)\end{array}$ & $\begin{array}{r}\text { Non-response } \\
\text { Survey }\left(\%^{1}\right)\end{array}$ & $\begin{array}{r}\text { Hard Refusals } \\
\left(\%^{1}\right)\end{array}$ \\
\hline $\begin{array}{l}\text { On-site survey and GPS } \\
\text { tracker }\end{array}$ & 291 & $215(74)$ & $76(26)$ & $26(35)$ & $50(65)$ \\
Guided tour survey & 940 & $696(74)$ & $244(26)$ & $85(35)$ & $159(65)$ \\
Community survey & 264 & $132(50)$ & $132(50)$ & $46(35)$ & $86(65)$ \\
Total & 1495 & 1043 & 452 & 157 & 295 \\
\hline
\end{tabular}

${ }^{1}$ Percentages (shown in parentheses) are based on previous research (Newman et al., 2015) and personal communication (S. Doyle, 2016). 


\section{Non-motorized Backcountry Survey and GPS Tracker}

There were 291 total non-motorized backcountry groups that received backcountry permits from the Visitor Information Station (VIS) between June 1, 2016 and September 1, 2016 (T. Lewis, personal communication, 2017). Based on these statistics, we attempted to interview one person from each backcountry visitor group to maximize the sample size. As such, this collection was a census, rather than a stratified sample. All backcountry groups were intercepted through direct personal contact by a USU student researcher after visitors picked up their backcountry permit inside the VIS or after completing the backcountry orientation presentation. USU researchers were present and surveying visitors on site every day from 8 am to $5 \mathrm{pm}$ during the sampling period. NPS staff were trained in all aspects of survey administration and helped when necessary. The primary put-in for backcountry kayakers visiting GBNP is proximate to the VIS.

Every independent non-motorized backcountry group exiting the VIS during the sampling period was asked to participate in the study. Only one member per group was contacted to complete the on-site survey and carry a GPS tracking device with them during their time in the backcountry. If multiple members of the group were over the age of 18 , the person with the closest, upcoming birthday was selected for participation to minimize the potential for leader bias. If the group declined to participate, the group member who we engaged with was asked to complete several quick nonresponse bias questions. Visitors were approached inside the VIS after they received their backcountry permit or after the orientation session had ended. After completion of the survey, the respondent was given instructions for placing a small GPS unit in their kayak for the duration of their trip. These respondents were also given instructions for returning the unit to the VIS upon completion of their trip. In the event that the visitor mistakenly left the park before returning the GPS unit, each unit was equipped with instructions for mail-back return.

Note: Independent private boaters were surveyed similarly to non-motorized backcountry visitors, but only for a two-week period. Boaters were intercepted at the VIS after an orientation session for permitting was complete. Surveys were administered to private boaters, but they were not asked to carry a GPS unit. Surveying this population ceased the second week of data collection as it was determined that the population fell outside the scope and approval of the study. Therefore, the sample size for this population is quite small.

Survey administration and non-response procedures were as follows:

Visitors selected for participating in the survey were read the following script:

"Hello, my name is [Jane Researcher]. I am conducting a survey for the National Park Service to understand more about your experiences in the park today. The answers you provide based on your perception of the park will help inform future management actions. Would you be willing to answer a few questions? Your participation is voluntary and all responses will be kept anonymous.

- If they refused, they were asked the non-response questions.

- If the non-response questions were refused, they were thanked for their time and contact ended. 
- If they accepted, they were then asked, "have you (or - has any member of your group) been asked to participate in this survey before?"

If "YES" (already asked to participate) then, "Thank you for agreeing to participate in this study. Have a great day."

- If "NO" (had not been previously asked to participate) then, "Thank you for agreeing to participate. Are you at least 18 years old (or - who in your group is at least 18 years old and has the next birthday)?

- Proceed with survey.

\section{Guided, motorized survey}

The "day boat" is a chartered catamaran vessel that carries visitors from Bartlett Cove to up bay areas of the park one time each operating day (June 1-September 1). An average of 75 visitors (S. Doyle, personal communication, 2016) use the dayboat each operating day (75 visitors $\mathrm{x} 90$ operating days $=$ 6,750 visitors). Sampling took place daily where one person from each group was selected to complete a survey (approximately 5-15 groups boarded the day boat each morning). The targeted sample was 540. Surveys, or non-response bias survey questions, were distributed to visitors just prior to the boat leaving the dock at 0730 .

Tour vessels are chartered vessels that may arrive at GBNP from Skagway, Juneau or other ports. Roughly 20 of these vessels enter the park each season, carrying an average of 100 people (but up to 200 people) to up bay areas of the park, totaling roughly 2,000 visitors per season. A park interpreter is present onboard for the entirety of the trip within GBNP boundaries. Packets of blank surveys were provided to park interpreters, which were then handed out to each group onboard the tour vessel. A census of all groups was completed (targeted sample was 400). Interpreters were instructed to give one survey per group, distributing survey instruments (or non-response bias surveys) to visitors as the boat left the dock, after safety announcements were made and before the interpretive program began.

Note: Charter vessels are private boats that are chartered by one to several groups at a time and are often up bay for a week or longer. Unlike other guided, motorized tours, charter vessels travel into limited-motorized areas within the East Arm. The Sea Wolf is the most common charter vessel to operate within GBNP. A packet of blank surveys was given to the operator of the Sea Wolf at the Bartlett Cove dock to distribute to one person within each group aboard the vessel. Surveying this population ceased after the first round of surveys were distributed because it was determined that the population fell outside the scope and approval of the study. Therefore, the sample size for this population is small.

\section{Community survey}

The town of Gustavus has roughly 264 residents, and all mail is delivered to households and/or individuals through P.O. Boxes at the local post office. We mailed a postcard to each P.O. Box at the Gustavus post office. Each post card had an online link with a unique access code and instructions explaining how to access the survey. If residents did not have access to a computer, they were instructed to go to the VIS to exchange the postcard for a paper survey through the USU researcher 
or NPS staff. A reminder postcard was placed in all P.O. Boxes two weeks after the initial postcards were sent out. These also include non-response bias questions in a mail-back format.

We estimated that $50 \%(n=132)$ of residents who were mailed a postcard with a link to the online survey would be willing to complete the survey. This response rate is based on the work of Vaske (2008), who suggests response rates for online surveys should be between 25-50\%. We expected response rates to the online survey for local residents to be on the higher end of this range (50\%) due to the small local population and the productive relationship between the national park and Gustavus residents.

\section{Sampling Plan, Instrument Administration, \& Expected Response Rate}

A total of 791 visitor contacts was estimated for all sample populations for the 2018 sampling period (Table B3). Based on yearly park visitor estimates and data collected during the 2017 pre-experience surveys, we calculated the target numbers required for each sample population (Table B4). We estimated that $91 \%$ of all visitors contacted on-site at the VIS and at the airport and $98 \%$ of visitors on guided tours (dayboat, tour vessels) would be willing to complete the survey upon intercept at various sampling locations. The results of these surveys should not be used to generalize beyond the specific populations participating in this study during this sampling period. Sampling plans and procedures are described below for each of the targeted populations.

Table B3. Estimated number of visitor contacts ${ }^{1}$ during 2018 sampling period.

\begin{tabular}{lcrrr}
\hline & \multicolumn{4}{c}{ Estimated Number of Visitor Contacts } \\
\cline { 2 - 5 } Respondent Group & June & July & August & Total \\
\hline Independent Backcountry & 37 & 56 & 29 & 122 \\
Day Boat & 80 & 116 & 49 & 245 \\
Tour Vessel & 88 & 88 & 44 & 220 \\
Gustavus Airport & 67 & 69 & 68 & 204 \\
Total & 272 & 329 & 190 & 791 \\
\hline
\end{tabular}

${ }^{1}$ Monthly estimates for all backcountry user groups are based on 2016 monthly visitation rates for independent visitors: (June $=30 \%$ of all visitors, July $=46 \%$ of all visitors, August $=24 \%$ of all visitors). These data are derived from visitor use data collected by park staff (S. Doyle, personal communication, 2017). While proportion of visitor use by month is derived from 2016 use date, the numbers of estimated visitor contacts are derived from response rates and calculated from 2017 survey efforts. Day boat, tour vessel, and Gustavus Airport expected numbers of contacts by month are derived from the proportion of sampling dates that fall in each month. 
Table B4. Expected response rates based on total estimated visitor contacts for 2018.

\begin{tabular}{lrrrrr}
\hline Respondent Group & $\begin{array}{r}\text { Initial } \\
\text { Contacts }\end{array}$ & $\begin{array}{r}\text { Completed } \\
\text { Responses }\left(\%^{1}\right)\end{array}$ & $\begin{array}{r}\text { All Refusals } \\
\left(\%^{1}\right)\end{array}$ & $\begin{array}{r}\text { Non-response } \\
\text { Survey }\left(\%^{1}\right)\end{array}$ & $\begin{array}{r}\text { Hard Refusals } \\
\left(\%^{1}\right)\end{array}$ \\
\hline Independent Backcountry & 122 & $111(91)$ & $11(9)$ & $4(35)$ & $7(65)$ \\
Gustavus Airport & 204 & $186(91)$ & $18(9)$ & $6(35)$ & $12(65)$ \\
Day Boat & 245 & $240(98)$ & $5(2)$ & $2(35)$ & $3(65)$ \\
Tour Vessel & 220 & $216(98)$ & $4(2)$ & $1(35)$ & $3(65)$ \\
Total & 791 & 753 & 38 & 13 & 25 \\
\hline
\end{tabular}

${ }^{1}$ Percentages (shown in parentheses) are based on 2017 survey response rates: on-site contact (91\%) and guided tour contact (98\%).

\section{Non-motorized Backcountry Survey and GPS Tracker}

The 2017 census sampling effort yielded 82 completed visitor surveys for non-motorized backcountry visitors. Based upon this, the graduate student on the project once again attempted to intercept all backcountry visitor groups to maximize sample size. As such, this collection was a census, rather than a stratified sample (targeted sample size was 111). Based on last season's research where we had a response rate of $91 \%$ for backcountry users at the VIS, we anticipated making 122 contacts in order to reach the target sample size (Table B3). All backcountry visitor groups were intercepted and asked to carry a GPS tracking unit after picking up their backcountry permit or after completing the backcountry orientation presentation inside the VIS. Surveys were administered post experience when visitors returned their GPS tracker, at three possible locations for post trip intercepts: (1) VIS, (2) dock in Bartlett Cove, and (3) on the Day Boat during their return trip. If the group declined to participate, the group member originally contacted was asked to complete several quick non-response bias questions.

\section{Day Boat Guided Tour Survey}

The "day boat" is a chartered catamaran vessel that carries visitors from Bartlett Cove to up bay areas of the park one time each operating day (June 1-September 15). A park interpreter is present on this boat during each trip and provides interpretation to the visitors beginning about 15 minutes after the boat departs. An average of 75 visitors (S. Doyle, personal communication, 2017) use the day boat each operating day (75 visitors $x 90$ operating days $=6,750$ visitors). Visitors using the day boat travel 130 miles through Glacier Bay over the course of 7 hours, receiving a one-day tour of the glaciers, wildlife, and scenery within the park. Visitors remain on the day boat for the duration of the trip and return to the dock at Bartlett Cove. The day boat is operated by a concessionaire, Glacier Bay Lodge and Tours. A graduate student was stationed on the day boat for 20 days during the summer sampling period ( 6 days in June, 8 days in July, and 6 days in August). A survey was given to one person per group onboard the day boat, with 21 participants expected per sampling day (targeted sample was 240). Based on last season's research where we had a response rate of $98 \%$ for day boat passengers, we anticipated making 245 contacts in order to reach our targeted sample of 240 (Table B3). Individuals sampled within each group were randomized by next birthday, with no more than one person per group being sampled, in order to minimize group bias. If the group declined to 
participate, the group member originally contacted was asked to complete several quick non-response bias questions.

\section{Expedition Guided Tour Survey}

Commercial "tour boat" vessels are chartered vessels that may arrive at GBNP from Skagway or other ports. Roughly 20 of these vessels enter the park each season, carrying an average of 100 visitors to up bay areas of the park (roughly 2,000 visitors). Visitors using these vessels often remain on the vessel for multiple days and may or may not exit the boat during their tour. The time these vessels spend in Glacier Bay is typically a fraction of the overall trip. A total of 12 sampling periods were randomly scheduled based on willingness to participate from 5 tour vessel companies, availability in Bartlett Cove (itinerary based) and estimated number of passengers on board (4 days in June, 5 days in July and 2 days in August). When possible, a graduate student was stationed onboard a tour vessel for the day (4 sampling events), but most often a graduate student was stationed at the dock to intercept visitors as they returned to the vessel after their time in Bartlett Cove. A census of all visitor groups on the vessel was conducted for each sampling event, with 21 participants expected per sampling day (targeted sample of 216). We assumed a 98\% response rate similar to the 2017 day boat survey. As such, we anticipated making 220 contacts in order to reach our sample of 216 (Table F3). Surveys specific to tour boat experiences were administered through direct contact by a USU student researcher. Surveys were administered to one individual within each group after visitors had completed their wilderness experience. Individuals sampled within each group were randomized by next birthday, with no more than one person per group being sampled, in order to minimize group bias. If the group declined to participate, the group member originally contacted was asked to complete several quick non-response bias questions.

\section{On-site survey at Gustavus Airport}

With a total of 9,242 people departing the airport each year, the Gustavus Airport is the primary resource for visitors leaving the area (US Department of Transportation, n.d.). Based on the 84 flights arriving and departing in 2017, there was an average of 220 people per flight. There is one flight departing Gustavus Airport via Alaska Airlines daily, which is the only commercial carrier out of this airport. A graduate student was stationed at the Gustavus Airport from 3pm to 5:30pm (open-close) and visitors were approached after they had cleared the ticketing line. This was an effort to intercept Charter Boat visitors and other visitors who did not take the day boat or obtain an overnight permit (targeted sample of 186). A census of all groups was conducted, first asking them if they had just finished a visit to GBNP. If the answer was "yes", the student asked if they were willing to participate in our study, following the same script used with other populations. Visitors willing to participate were asked if they rode the day boat, a chartered boat, or completed an independent kayak trip during their visit in order to determine which survey version to administer. Visitors were administered the survey instrument appropriate to their response. If the group declined to participate, the group member originally contacted was asked to complete several quick non-response bias questions. Assuming a response rate similar to the VIS at 91\%, we planned to contact at least 204 visitors in an effort to obtain our targeted sample size of 186. A total of 15 sampling events were scheduled (5 days per month June, July, and August). 


\section{Methodological Protocols}

Table B5 presents the sampling plan and protocols for each population by year.

Table B5. Detailed methodological protocols for data collection in 2017 and 2018.

\begin{tabular}{|c|c|c|}
\hline Sample Population & 2017 Pre-Experience Survey & 2018 Post-Experience Survey \\
\hline Residents & $\begin{array}{l}\text { - Gustavus, AK residents received a postcard with an online } \\
\text { link and unique access code. } \\
\text { - Hard copies available at the VIS for those without computer } \\
\text { access. } \\
\text { - Follow-up postcards were sent two weeks after initial } \\
\text { contact, including mail-back non-response bias questions. }\end{array}$ & Not included in 2018 sample \\
\hline Independent Backcountry & $\begin{array}{l}\text { - Censused all groups (target } \mathrm{n}=100 \text { ). } \\
\text { - Intercepted at the VIS after each backcountry orientation } \\
\text { (10am, 3pm, } 6 \mathrm{pm} \text { ) or after receiving their permit. } \\
\text { - One member of each group, randomized by next upcoming } \\
\text { birthday, was asked to complete the pre-experience survey } \\
\text { before departure and carry a GPS unit. } \\
\text { - Instructions were provided for GPS unit placement within } \\
\text { their kayak or on their pack. } \\
\text { - Returned GPS unit to VIS staff or researcher along Bartlett } \\
\text { Cove dock. Mail-back instructions were attached in case any } \\
\text { were forgotten. } \\
\text { - Non-response bias questions were asked for those that } \\
\text { declined participation when possible. }\end{array}$ & $\begin{array}{l}\text { - Censused all groups (target } n=100 \text { ). } \\
\text { - Intercepted at the VIS after each backcountry orientation } \\
\text { (10am, 3pm, 6pm), after receiving their permit or on the day } \\
\text { boat before daily departure (7am). } \\
\text { One member of each group, randomized by next upcoming } \\
\text { birthday, was asked to carry a GPS unit and complete the } \\
\text { post-experience survey upon return. } \\
\text { - Instructions were provided for GPS unit placement within } \\
\text { their kayak or on their pack. } \\
\text { - Projected return date and time was recorded for efficient } \\
\text { post-experience survey administration. } \\
\text { - Survey was administered at the VIS, the dock in Bartlett } \\
\text { Cove, or on their return trip via day boat. } \\
\text { - Survey specific to an independent, non-motorized } \\
\text { experience, including visual simulation questions. } \\
\text { - Non-response bias questions were asked for those that } \\
\text { declined participation when possible. }\end{array}$ \\
\hline
\end{tabular}


Table B5 (continued). Detailed methodological protocols for data collection in 2017 and 2018.

\begin{tabular}{|c|c|c|}
\hline Sample Population & 2017 Pre-Experience Survey & 2018 Post-Experience Survey \\
\hline Independent Boaters ${ }^{1}$ & $\begin{array}{l}\text { - Censused all groups (no target } n \text { ). } \\
\text { - Intercepted at the VIS after each backcountry orientation or } \\
\text { after receiving their permit. } \\
\text { - One member of each group, randomized by next upcoming } \\
\text { birthday, was asked to complete the pre-experience survey } \\
\text { before departure. } \\
\text { - Non-response bias questions were asked for those that } \\
\text { declined participation when possible. } \\
\text { - Ceased sampling - outside of scope of the study. }\end{array}$ & Not included in 2018 sample \\
\hline Day Boat & $\begin{array}{l}\text { - Censused all groups on board (target } n=300 \text { ) daily (June, } \\
\text { July, August). } \\
\text { - Surveys were administered between } 0700-0720 \text { on-board } \\
\text { the day boat. When possible, completed surveys were } \\
\text { collected before day boat departure }(0730) \text {; all others were } \\
\text { collected upon return ( } 1530) \text {. } \\
\text { - One member of each group was asked to complete the } \\
\text { survey, randomized by next upcoming birthday. } \\
\text { - Non-response bias questions were asked for those that } \\
\text { declined participation when possible. }\end{array}$ & $\begin{array}{l}\text { - Censused all groups on board (target } \mathrm{n}=300 \text { ), } 5 \text { days each } \\
\text { month (June, July, August). } \\
\text { - Administered surveys after } 2 \mathrm{pm} \text { on the return to Bartlett } \\
\text { Cove. } \\
\text { - One member of each group was asked to complete the } \\
\text { survey, randomized by next upcoming birthday. } \\
\text { - Survey specific to a guided, motorized experience. } \\
\text { - Non-response bias questions were asked for those that } \\
\text { declined participation when possible. }\end{array}$ \\
\hline
\end{tabular}

\footnotetext{
${ }^{1}$ Independent boaters and charter vessels were not originally part of our sampling protocol, which resulted in a limited number of complete surveys before additional survey administration ceased. Completed surveys were used in the final analysis.
} 
Table B5 (continued). Detailed methodological protocols for data collection in 2017 and 2018.

\begin{tabular}{|c|c|c|}
\hline Sample Population & 2017 Pre-Experience Survey & 2018 Post-Experience Survey \\
\hline Tour Vessel Visitors & $\begin{array}{l}\text { Park interpreters administered surveys on board vessels, } \\
\text { totaling } 9 \text { sampling events in August. Each interpreter was } \\
\text { trained in survey protocol. } \\
\text { Censused all groups on board. A total of } 5-10 \text { visitors } \\
\text { participated in the study per vessel (targeted } n=100 \text { ). } \\
\text { - Surveys were distributed after the vessel left the dock and } \\
\text { all safety announcements were given. } \\
\text { - Non-response bias questions were asked for those that } \\
\text { declined participation when possible. }\end{array}$ & $\begin{array}{l}\text { - Censused all groups (target } n=100 \text { ), with a total of } 12 \\
\text { random sampling events ( } 4 \text { in June, July, and August). } \\
\text { - One member of each group was asked to complete the } \\
\text { survey, randomized by next upcoming birthday. } \\
\text { - Sampling dates were randomized based on dates provided } \\
\text { by tour vessel companies. } \\
\text { - When possible, a researcher boarded the vessel at 6am } \\
\text { from the Bartlett Cove dock, administering surveys on the } \\
\text { return to Bartlett Cove. } \\
\text { - When boarding was not possible, surveys were } \\
\text { administered to passengers as they returned to their tour } \\
\text { vessel at the Bartlett Cove dock. } \\
\text { - Survey specific to a guided, motorized experience. } \\
\text { - Non-response bias questions were asked for those that } \\
\text { declined participation when possible. }\end{array}$ \\
\hline Charter Vessel Visitors $^{1}$ & $\begin{array}{l}\text { - Surveys were provided to the Sea Wolf charter vessel staff } \\
\text { for distribution while charter vessels were docked in Bartlett } \\
\text { Cove before departure. } \\
\text { - Non-response bias questions were asked for those that } \\
\text { declined participation when possible. } \\
\text { - Ceased sampling - outside of scope of the study. }\end{array}$ & Not included in 2018 sample \\
\hline
\end{tabular}

\footnotetext{
${ }^{1}$ Independent boaters and charter vessels were not originally part of our sampling protocol, which resulted in a limited number of complete surveys before additional survey administration ceased. Completed surveys were used in the final analysis.
} 
Table B5 (continued). Detailed methodological protocols for data collection in 2017 and 2018.

\begin{tabular}{|c|c|c|}
\hline Sample Population & 2017 Pre-Experience Survey & 2018 Post-Experience Survey \\
\hline Gustavus Airport & Not included in 2017 Sample & $\begin{array}{l}\text { - Censused all groups who were at the airport, had visited } \\
\text { GBNP, and had not previously completed the survey (target } \\
\mathrm{n}=100 \text { ). } \\
\text { - A total of } 15 \text { random sampling days, } 5 \text { days per month } \\
\text { (June, July, and August). } \\
\text { - Administered survey specific to the visitor's experience (i.e., } \\
\text { guided, motorized or independent, non-motorized survey). } \\
\text { - One member of each group was asked to complete the } \\
\text { survey, randomized by next upcoming birthday. } \\
\text { - Non-response bias questions were asked for those that } \\
\text { declined participation when possible. }\end{array}$ \\
\hline
\end{tabular}

\footnotetext{
${ }^{1}$ Independent boaters and charter vessels were not originally part of our sampling protocol, which resulted in a limited number of complete surveys before additional survey administration ceased. Completed surveys were used in the final analysis.
} 


\section{Appendix C. Code Book for Open-Ended Questions}

Table C1. Code book for open-ended questions.

\begin{tabular}{|c|c|c|}
\hline Qualitative Code & Responses referring to... & Data example \\
\hline Accessibility of park/wilderness & $\begin{array}{l}\text { cost; difficulty of getting to a place; challenges of travel } \\
\text { coordination; travel limitations. Different than remoteness - } \\
\text { refers to travel constructs specifically. }\end{array}$ & $\begin{array}{l}\text { "It was hard to get to (cancel flight) but maybe that's part } \\
\text { of the allure." }\end{array}$ \\
\hline Adventure (i.e., have an adventure) & $\begin{array}{l}\text { adventure, excitement, sense of a challenge, risk, } \\
\text { expedition, experiencing the unknown }\end{array}$ & $\begin{array}{l}\text { "See wildlife, see incredible views of scenery, physical } \\
\text { challenge, learning about geography, plants, wildlife." }\end{array}$ \\
\hline Anthropogenic sounds & $\begin{array}{l}\text { hearing sounds that were anthropogenically caused: } \\
\text { aircraft, motor boats, cruise ships, PA systems, other } \\
\text { visitors or kayakers }\end{array}$ & $\begin{array}{l}\text { "The narration noise coming from the cruise boats was } \\
\text { very annoying and seems unnecessary." } \\
\text { "One plane flew circles for about } 30 \text { minutes - I like quiet } \\
\text { here; passing planes are not so bothersome." }\end{array}$ \\
\hline Boat tour & $\begin{array}{l}\text { a guided-motorized experience (i.e., day boat, tour vessel, } \\
\text { charter vessel); staff specific to boat tour; amenities on- } \\
\text { board (i.e., food availability, binoculars, naturalists that } \\
\text { were not NPS interpreters); ability to get to sites }\end{array}$ & $\begin{array}{l}\text { "The boat - allowed me to just focus on the scenery } \\
\text { around me and fully immerse myself in nature/glacier Bay } \\
\text { national Park." } \\
\text { "The dayboat was fabulous, great boat, food." }\end{array}$ \\
\hline Camping & $\begin{array}{l}\text { camping, sleeping outside or in nature, overnight } \\
\text { processes. Most often reported by independent } \\
\text { backcountry visitors, but not exclusively }\end{array}$ & $\begin{array}{l}\text { "Absolutely! I slept great on a bed of moss, watch a } \\
\text { gorgeous sunset, and felt a wonderful connection to } \\
\text { nature." } \\
\text { "Kayaking and tenting. Feeling part of nature." }\end{array}$ \\
\hline Connection to nature & $\begin{array}{l}\text { feelings associated with nature; close to, emotional } \\
\text { response to, commune with nature; spiritual experience, } \\
\text { inspiring }\end{array}$ & $\begin{array}{l}\text { "We hope to feel close to nature and continue to learn } \\
\text { and help others appreciate the gift it offers." }\end{array}$ \\
\hline Cruise ships & $\begin{array}{l}\text { basic presence or visually observing cruise ships; feeling } \\
\text { the wake; ships blocking views at glaciers. All references } \\
\text { to sounds associated with cruise ships were included in } \\
\text { anthropogenic sound code }\end{array}$ & $\begin{array}{l}\text { "Large cruise ships in front of glacier." } \\
\text { "Seeing the cruise ships in the otherwise pristine } \\
\text { landscape." }\end{array}$ \\
\hline
\end{tabular}


Table C1 (continued). Code book for open-ended questions.

\begin{tabular}{|c|c|c|}
\hline Qualitative Code & Responses referring to... & Data example \\
\hline Did not experience adventure & $\begin{array}{l}\text { negative responses to the question by saying they did not } \\
\text { experience adventure; would not classify experience as } \\
\text { adventure; N/A; not applicable }\end{array}$ & $\begin{array}{l}\text { "I'm not sure that the day boat experience constitutes an } \\
\text { 'adventure.' We picked up and dropped off kayakers, who } \\
\text { were in for, or had just experienced, an adventure." } \\
\text { "No so adventurous." }\end{array}$ \\
\hline Environmental adaptability & $\begin{array}{l}\text { personal adaptability to environmental conditions including } \\
\text { weather, wildlife, and broadly }\end{array}$ & $\begin{array}{l}\text { "Rugged conditions, reworking the plan to account for } \\
\text { weather conditions and injury, navigation, animal } \\
\text { sightings, having to use resources at our disposal." }\end{array}$ \\
\hline Escape & $\begin{array}{l}\text { relaxation; unplugging from technology, Wi-Fi, cell service; } \\
\text { experience something different than home; leave stressors } \\
\text { of cities, civilization, work, distractions, etc. }\end{array}$ & $\begin{array}{l}\text { "By breaking my daily routine, and getting lots of } \\
\text { exercise. Getting physically stronger." } \\
\text { "Get to see natural state of the landscape, geologic, } \\
\text { animal, plant, be away from civilization." }\end{array}$ \\
\hline Experience nature & $\begin{array}{l}\text { general nature; observing plants, water, tide pools, } \\
\text { geology; studying or enjoying edible plants; ecosystems or } \\
\text { ecology }\end{array}$ & $\begin{array}{l}\text { "An opportunity to enjoy a pristine backcountry } \\
\text { wilderness with natural beauty, flowers, and animals. An } \\
\text { opportunity as well to be away from normal life and } \\
\text { reconnect with a personal tradition." } \\
\text { "Getting close and personal with nature." }\end{array}$ \\
\hline Experience wilderness & $\begin{array}{l}\text { wilderness; unspoiled, untouched, preserved, protected, } \\
\text { pristine nature; wild areas, wildness; protected area; health } \\
\text { of ecosystems; natural habitats. "Vastness" was often } \\
\text { incorporated into this code. }\end{array}$ & $\begin{array}{l}\text { "That this is a pristine, intact wilderness, which is well } \\
\text { managed." } \\
\text { "I'm here to look at one of the few remaining places on } \\
\text { this earth where nature is in its untouched from (for the } \\
\text { most part)." }\end{array}$ \\
\hline Experiencing glaciers & $\begin{array}{l}\text { specific glaciers by name; viewing or hearing glaciers; } \\
\text { calving; glaciation events }\end{array}$ & $\begin{array}{l}\text { "The views of the glaciers looking at their paths for } \\
\text { through the mountains." }\end{array}$ \\
\hline Explore & $\begin{array}{l}\text { exploration; experience something that not many others } \\
\text { have; experience something new, excursions }\end{array}$ & $\begin{array}{l}\text { "When kayaking in Glacier Bay, we're looking for quiet } \\
\text { and solitude and the thrill of exploring new places we } \\
\text { haven't been before." }\end{array}$ \\
\hline Facilities & $\begin{array}{l}\text { physical facilities including the camp ground or the lodge in } \\
\text { GBNP, or lodging onboard tour or charter vessels }\end{array}$ & $\begin{array}{l}\text { "Having the lodge in the park." } \\
\text { "Lodge rooms were too hot. Bus from airport to lodge was } \\
\text { hot. Airport was hot; no good sitting areas." }\end{array}$ \\
\hline
\end{tabular}


Table C1 (continued). Code book for open-ended questions.

\begin{tabular}{|c|c|c|}
\hline Qualitative Code & Responses referring to... & Data example \\
\hline Fishing & fishing; crabbing & $\begin{array}{l}\text { "Enjoying the wildlife and catching fish for personal use. } \\
\text { Halibut, Salmon, shrimp. Providing our guests an } \\
\text { opportunity to do some of the things we have grown } \\
\text { accustom to." }\end{array}$ \\
\hline Hiking/Walking & $\begin{array}{l}\text { hiking or walking outdoors; nature walks; when trails were } \\
\text { referred to in terms of hiking, but not the general presence } \\
\text { of trails (see trails code below) }\end{array}$ & $\begin{array}{l}\text { "The atmosphere was one of beauty and nature at her } \\
\text { best, there were times walking on the trails where I felt } \\
\text { completely alone and serene." } \\
\text { "A leisurely walk in the woods and along the beach, } \\
\text { seeing beautiful scenery and wildlife during the cruise." }\end{array}$ \\
\hline Insects & bugs; mosquitoes; biting gnats & "The gnats and mosquitoes." \\
\hline Interacting with wildlife & $\begin{array}{l}\text { reports of actual encounters with wildlife, opposed to } \\
\text { viewing from a distance; breaching whales nearby; brown } \\
\text { bears in camp; moose being nearby. Mainly referenced by } \\
\text { independent backcountry visitors. }\end{array}$ & $\begin{array}{l}\text { "Charged by a grizzly bear. Breaching whale." } \\
\text { "Paddling with whales." }\end{array}$ \\
\hline Kayak equipment rentals & kayak rental equipment & $\begin{array}{l}\text { "Ease of kayak rentals and coordination between Glacier } \\
\text { Bay Sea kayaks and national park service permits." }\end{array}$ \\
\hline Kayaker (or day boat) pick up/drop off & $\begin{array}{l}\text { day boat pick-up and drop-off service; both referenced in a } \\
\text { positive and negative way }\end{array}$ & $\begin{array}{l}\text { Positive Ex: "The ability to access the backcountry with } \\
\text { the day boat." } \\
\text { Negative Ex: "We were on the Glacier Cruise excursion } \\
\text { [i.e., day boat] when we stopped and picked up about } 20 \\
\text { kayakers. We lost our seats as well as couldn't stay in the } \\
\text { same place with them because of the smell." }\end{array}$ \\
\hline Kayaking & kayaking; paddling; self-powered travel & $\begin{array}{l}\text { "Being in a kayak makes the adventure feel much more } \\
\text { intimate and personal." }\end{array}$ \\
\hline Learning & $\begin{array}{l}\text { general learning; knowledge; distribution of information; } \\
\text { putting yourself in the position of others; interpretive } \\
\text { presentations, guidance, materials; guides in general. } \\
\text { Learning was often separated by topic specifically } \\
\text { interpretation vs. general learning }\end{array}$ & $\begin{array}{l}\text { "Reference books on the boat allowed us to read more } \\
\text { about the landscapes and deepen our appreciation for } \\
\text { them." } \\
\text { "Developing an understanding of the lands succession." }\end{array}$ \\
\hline
\end{tabular}


Table C1 (continued). Code book for open-ended questions.

\begin{tabular}{|c|c|c|}
\hline Qualitative Code & Responses referring to... & Data example \\
\hline Learning: specifically interpretation & $\begin{array}{l}\text { learning based off of an interpretive experience: materials, } \\
\text { signage, presentations at the lodge or nature walks, but } \\
\text { mainly on-board boat tours; cultural }\end{array}$ & $\begin{array}{l}\text { "Also having a ranger on the boat is really beneficial in } \\
\text { learning more about the history of the ecosystem." }\end{array}$ \\
\hline Limited other visitors & $\begin{array}{l}\text { the limited or lack of other visitors; based on crowding and } \\
\text { is different than solitude }\end{array}$ & $\begin{array}{l}\text { "Sense of remote tranquility and beauty, not many people } \\
\text { and overrun like many other parks" }\end{array}$ \\
\hline Minimal interaction with wilderness & $\begin{array}{l}\text { little to no interaction with wilderness typically due to being } \\
\text { confined to a boat, often saying they observed nature but } \\
\text { did not interact }\end{array}$ & $\begin{array}{l}\text { Minimal Interaction: "It's hard to fully experience nature } \\
\text { on the boat this size (also, the unfortunate rain keeping } \\
\text { us indoors - no one's fault obviously)." } \\
\text { No Interaction: "Landscape just viewed - not interactive." }\end{array}$ \\
\hline Motorized boats & $\begin{array}{l}\text { observing the day boat, private, charter or tour vessels; } \\
\text { feeling wake from boats; larger ships but not specifically } \\
\text { cruise ships. Cruise ships were analyzed as their own } \\
\text { category. }\end{array}$ & $\begin{array}{l}\text { "Motor boat between strawberry island and Beardslee } \\
\text { scared all the mammals away." }\end{array}$ \\
\hline National park visit & $\begin{array}{l}\text { visiting GBNP because it is part of the national park } \\
\text { system or on a bucket list }\end{array}$ & "Visiting all of the national parks." \\
\hline Natural quiet & $\begin{array}{l}\text { quiet; limited anthropogenic sounds; silence. Different from } \\
\text { natural soundscape, referring to specific natural sounds } \\
\text { opposed to quiet. }\end{array}$ & $\begin{array}{l}\text { "I'm looking to experience wilderness, quiet, and time with } \\
\text { family. Viewing wildlife is also important. I am particularly } \\
\text { interested in birding." } \\
\text { "The moment of total silence on the boat as we looked at } \\
\text { Marjorie glacier and my hike on the Bartlett lake trail." }\end{array}$ \\
\hline Natural soundscape & $\begin{array}{l}\text { natural sounds: wildlife sounds (i.e., bird calls, sea lion } \\
\text { grunts); glaciers calving or ice cracking; water on the } \\
\text { beach }\end{array}$ & $\begin{array}{l}\text { "Everything! The soundscapes of this park are incredible. } \\
\text { Listening to glaciers calve, birds galore, and the lapping } \\
\text { of the water makes an incredible experience." }\end{array}$ \\
\hline Nature immersion & $\begin{array}{l}\text { being in, spending time in, or immersing yourself in nature } \\
\text { or the outdoors. Immersion may include explaining multiple } \\
\text { aspects of a nature experience. }\end{array}$ & $\begin{array}{l}\text { "We are hoping for a safe quiet trip including wildlife from } \\
\text { a safe distance, glaciers from a safe distance, and } \\
\text { general peace and quiet. We rejuvenate and rest in the } \\
\text { beauty of mother nature. Find COM in the temples of } \\
\text { John Muir." }\end{array}$ \\
\hline
\end{tabular}


Table C1 (continued). Code book for open-ended questions.

\begin{tabular}{|c|c|c|}
\hline Qualitative Code & Responses referring to... & Data example \\
\hline Non-motorized areas & $\begin{array}{l}\text { areas where motorized use is not present; non-motorized } \\
\text { specific areas (i.e., Beardslee Islands); motor free zones }\end{array}$ & $\begin{array}{l}\text { "...(being alone in nature, especially the non-motorized } \\
\text { areas)." }\end{array}$ \\
\hline Nothing detracted & nothing; N/A; none; not really & $\begin{array}{l}\text { "None; came expecting, open to new experiences and } \\
\text { challenges." } \\
\text { "Nothing really, you just have to be diligent (bears, tides, } \\
\text { etc.)." }\end{array}$ \\
\hline Observations & $\begin{array}{l}\text { stating or alluding to viewing, smelling, feeling general } \\
\text { aspects of the experience. Specific observations (e.g., } \\
\text { wildlife, nature, scenic beauty, glaciers) were coded } \\
\text { separately and reported respectively. For general } \\
\text { observations, the majority of responses referred to } \\
\text { viewing, while responses surrounding hearing were coded } \\
\text { as anthropogenic sounds, natural quiet, or natural } \\
\text { soundscapes appropriately. }\end{array}$ & $\begin{array}{l}\text { "Seeing so much l've never seen before." } \\
\text { "Being able to be outside and use all my senses." } \\
\text { "Observed with pictures, sight, sound, smell." }\end{array}$ \\
\hline Other & $\begin{array}{l}\text { extremely specific content that was not related to other } \\
\text { responses; too broad of content that did not have an } \\
\text { interpretable direction for coding purposes; difficult to } \\
\text { interpret in general. Comments were often coded into } \\
\text { "other," later to be moved to a more specific code when } \\
\text { more than two similar enough responses were found within } \\
\text { a theme (e.g., fishing, camping, overall experience). }\end{array}$ & $\begin{array}{l}\text { "This is my } 407 \text { th national Park service unit l've visited so } \\
\text { only } 10 \text { parks are remaining now." } \\
\text { "The cruise was in the direction of Tarr inlet, but our boat } \\
\text { did not go to target Tarr inlet." }\end{array}$ \\
\hline Other visitors & $\begin{array}{l}\text { negative interactions with other visitors; positive } \\
\text { interactions with others (less often than negative); visitor } \\
\text { behavior; elements associated with other visitors (e.g., } \\
\text { large yacht with helicopter) }\end{array}$ & $\begin{array}{l}\text { Positive Ex: "Like-minded people on the tour." } \\
\text { Negative Ex: "People constantly taking photos of } \\
\text { themselves/talking over guides." }\end{array}$ \\
\hline Overall experience & $\begin{array}{l}\text { being in a place or a moment, but not necessarily specific } \\
\text { to Alaska; not referring to a single element but the } \\
\text { experience as a whole }\end{array}$ & $\begin{array}{l}\text { "Enjoy the moment, over and over." } \\
\text { "There is no one single thing. It is the environment itself. } \\
\text { It's always great." "Just being here." }\end{array}$ \\
\hline Part of larger tour & $\begin{array}{l}\text { visiting GBNP as part of a tour vessel experience, only } \\
\text { reported from } 2017 \text { tour vessel groups }\end{array}$ & "Part of the tour itinerary." \\
\hline
\end{tabular}


Table C1 (continued). Code book for open-ended questions.

\begin{tabular}{|c|c|c|}
\hline Qualitative Code & Responses referring to... & Data example \\
\hline Personal challenges & issues that arose from personal feelings or challenges & "Weather, anxiety, animal encounters." \\
\hline Photography & taking photos; photo shoots; photography & $\begin{array}{l}\text { "Up close view of glaciers and maybe some whales, } \\
\text { ability to get good pictures and comfortable window seat." }\end{array}$ \\
\hline Recreational limitations & $\begin{array}{l}\text { not having the opportunity for recreational activity (i.e., not } \\
\text { being able to leave the ship; not having enough time) }\end{array}$ & $\begin{array}{l}\text { "I also would have liked to get closer to the shore in a } \\
\text { zodiac or a small motor-less boat." } \\
\text { "Not being able to go ashore." }\end{array}$ \\
\hline Relaxation & $\begin{array}{l}\text { relaxation; feelings of calm or peacefulness. Often } \\
\text { included in the larger theme "Escape." }\end{array}$ & $\begin{array}{l}\text { "Scenery, wildlife mountain and maritime vistas relaxing } \\
\text { boat trip." }\end{array}$ \\
\hline Remoteness & $\begin{array}{l}\text { remote; remoteness; distance from development (i.e., } \\
\text { towns, cities); limited/exclusive access }\end{array}$ & $\begin{array}{l}\text { "A wilderness, remote experience with quiet solitude. } \\
\text { Wildlife sightings are complementary, though not a } \\
\text { necessary part of the experience." }\end{array}$ \\
\hline Scenic beauty & beauty of landscapes, nature, or scenery/scenic views & $\begin{array}{l}\text { "Just experiencing the beauty of this magnificent land." } \\
\text { "The ability to witness at a very slow pace, all of the } \\
\text { scenic surroundings." }\end{array}$ \\
\hline Self-sufficiency & $\begin{array}{l}\text { sense of freedom, abilities, independence, self-sufficiency, } \\
\text { and overall confidence }\end{array}$ & $\begin{array}{l}\text { "Being out there alone and being totally self-reliant. We } \\
\text { now have greater confidence in our ability to go on an } \\
\text { extended backcountry kayak trip." }\end{array}$ \\
\hline Services & $\begin{array}{l}\text { services provided including the day boat service, staff, gift } \\
\text { shops, food availability/quality, amenities onboard tour and } \\
\text { charter vessels; park staff (non-interpretation role) }\end{array}$ & "Lack of kayak rental availability." \\
\hline Solitude & $\begin{array}{l}\text { solitude; isolation; feeling alone or like the first person to } \\
\text { be in a place; the act or feeling of being away from others; } \\
\text { secluded }\end{array}$ & $\begin{array}{l}\text { "The serenity of solitude, punctuated by walking sea lions } \\
\text { and courting otters, takes me to a simpler time and } \\
\text { place." }\end{array}$ \\
\hline Time with family/friends & $\begin{array}{l}\text { time with family or friends; companionship; kids, partners, } \\
\text { parents; togetherness }\end{array}$ & $\begin{array}{l}\text { "Seeing beautiful areas again and keeping up on the } \\
\text { rapid changes there. Spending time with my grandson } \\
\text { and friends in these places. Getting the exercise of kayak } \\
\text { paddling." }\end{array}$ \\
\hline
\end{tabular}


Table C1 (continued). Code book for open-ended questions.

\begin{tabular}{|c|c|c|}
\hline Qualitative Code & Responses referring to... & Data example \\
\hline Tranquility & $\begin{array}{l}\text { tranquility, peacefulness, calming, serenity. Specific to } \\
\text { question "Connection to Nature." }\end{array}$ & $\begin{array}{l}\text { "Getting to experience the glaciers/wildlife and hear the } \\
\text { sounds of the sea/animals, birds etc. It's very serene and } \\
\text { a powerful experience." }\end{array}$ \\
\hline Unconfined recreation & $\begin{array}{l}\text { freedom to make decisions; independence without } \\
\text { restrictions. Referenced by independent backcountry } \\
\text { visitors only. }\end{array}$ & "Ability to just explore without too much direction." \\
\hline Unique AK experience & $\begin{array}{l}\text { being in a place or a moment specific to Alaska or that } \\
\text { different from where they live/know; not referring to a } \\
\text { single element but the experience as a whole }\end{array}$ & $\begin{array}{l}\text { "I want to experience a park the majority of people will } \\
\text { never visit. I want to see glaciers and learn more about } \\
\text { our changing climate. I want to grow my understanding of } \\
\text { why our public lands are so important to preserve for } \\
\text { future generations." }\end{array}$ \\
\hline Viewing wildlife & $\begin{array}{l}\text { viewing general wildlife or specific species; actions of } \\
\text { wildlife }\end{array}$ & $\begin{array}{l}\text { "Wildlife - whales, seals, and dolphins were amazing and } \\
\text { distracting while we worked on our campsite." }\end{array}$ \\
\hline Weather & $\begin{array}{l}\text { weather events or descriptions (e.g., cold, hot, wet, rainy, } \\
\text { etc.); elements due to weather (i.e., waves); both negative } \\
\text { and positive reactions reported }\end{array}$ & $\begin{array}{l}\text { "Weather, anxiety, animal encounters." "Beautiful weather } \\
\text { - no wind, sunny, and clear." }\end{array}$ \\
\hline
\end{tabular}


The Department of the Interior protects and manages the nation's natural resources and cultural heritage; provides scientific and other information about those resources; and honors its special responsibilities to American Indians, Alaska Natives, and affiliated Island Communities.

NPS 132/177232, August 2021 
Thional Park Service

U.S. Department of the Interior

Natural Resource Stewardship and Science

1201 Oakridge Drive, Suite 150

Fort Collins, CO 80525 